\title{
ADAPTAÇÃO DO ENSAIO SPT PARA DETERMINAÇÃO DE PARÂMETROS ADICIONAIS PARA O DIMENSIONAMENTO DE FUNDAÇÕES
}

\begin{abstract}
Dissertação apresentada à Escola de Engenharia de São Carlos da Universidade de São Paulo, como parte dos requisitos para obtenção do Título de Mestre em Ciências, Programa de PósGraduação em Geotecnia.
\end{abstract}

Orientador: Prof. Dra. Cristina de Hollanda Cavalcanti Tsuha

Versão corrigida

Original se encontra disponível na Unidade que aloja o Programa

SÃO CARLOS - SP 
AUTORIZO A REPRODUÇÃO TOTAL OU PARCIAL DESTE TRABALHO, POR QUALQUER MEIO CONVENCIONAL OU ELETRONNICO, PARA FINS DE ESTUDO E PESQUISA, DESDE QUE CITADA A FONTE.

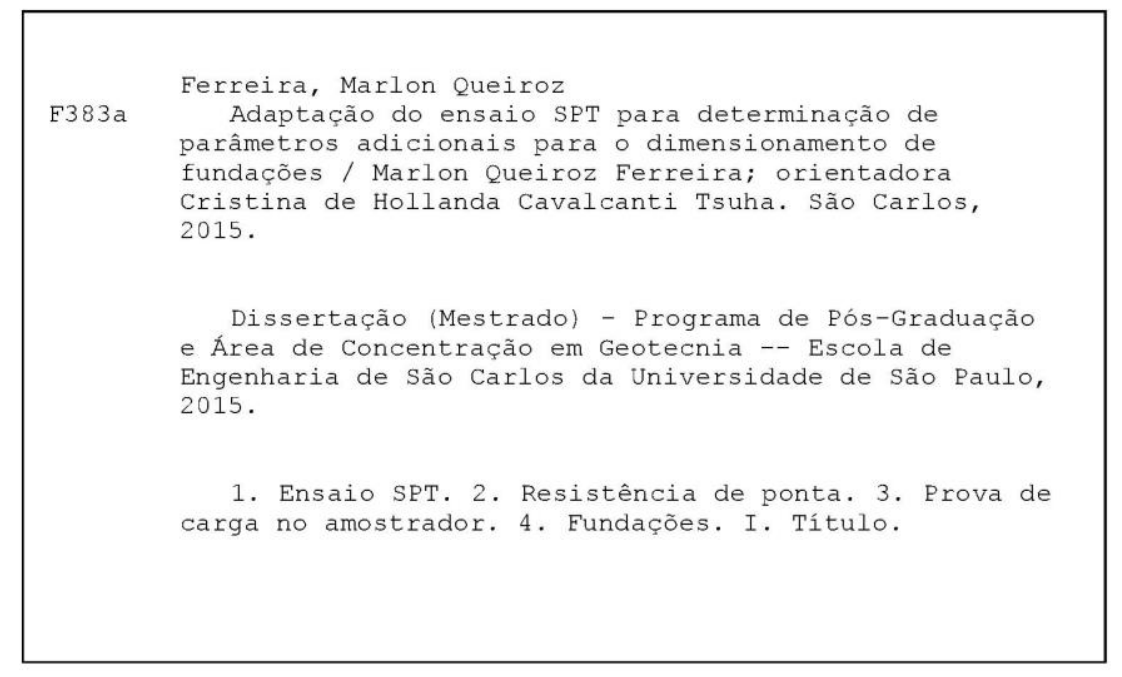




\section{FOLHA DE JULGAMENTO}

Candidato: Engenheiro MARLON QUEIROZ FERREIRA.

Título da dissertação: "Adaptação do ensaio SPT para determinação de parâmetros adicionais para o dimensionamento de fundações".

Data da defesa: 22/02/2016

\section{Comissão Julgadora:}

Profa. Dra. Cristina de Hollanda Cavalcante Tsuha (Orientadora)

(Escola de Engenharia de São Carlos/EESC)

Prof. Dr. Nelson Aoki

(Escola de Engenharia de São Carlos/EESC)

Profa. Dra. Anna Silvia Palcheco Peixoto

(Universidade Estadual Paulista "Júlio de Mesquita Filho"/UNESP Bauru)

\section{Resultado:}

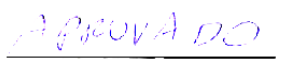

ATPCNAX

Coordenador do Programa de Pós-Graduação em Geotecnia:

Prof. Dr. Edmundo Rogério Esquivel

Presidente da Comissão de Pós-Graduação:

Prof. Associado Paulo César Lima Segantine 
À minha família pelo apoio $e$ incentivo direcionado a mim. A Deus pela motivação e proteção em todas as minhas viagens... Sou eternamente grato por tudo, pois sem eles nada disso seria possível. 


\section{AGRADECIMENTOS}

Agradeço a minha família que me deu total apoio até a conclusão desta tese. Ao meu pai Jarbas, que me incentivou e esteve ao meu lado desde quando iniciei minha carreira na área de engenharia civil. Obrigado por seu forte exemplo e por me conduzir todos os dias o valor de uma boa educação. À minha querida mãe Eucarice pela preocupação e amor, e por ser um dos grandes pilares em minha vida. Ao meu irmão Glauco que durante todos meus dias de vida mostrou solidariedade e amor incondicional. A todos referenciados acima, desejo minha eterna gratidão e direciono todo o meu amor.

A madrinha Jussara, ao meu tio Odair e aos meus primos Gustavo e Cinthia, que me acolheram inúmeras vezes em Ribeirão Preto, e me deram a oportunidade e imenso prazer de viver cada minuto ao lado desta minha segunda família.

Agradeço a empresa Geometa Engenharia de Fundações que forneceu local e equipamento para realização dos ensaios de campo e garantiram o desenvolvimento desta pesquisa. A Engenheira Daiane e ao Engenheiro Fernando que sempre disponibilizaram datas e perfeito funcionamento do equipamento de sondagem. Ao Engenheiro Célio por me substituir na empresa em alguns momentos que estive ausente. Ao Engenheiro José Ribeiro pela contribuição inestimável do meu crescimento profissional. Em especial, agradeço ao Eng. Gildásio que foi o incentivador principal para meu ingresso no mestrado e durante dois anos demonstrou total entusiasmo de ser meu professor particular de fundações.

A todos professores, funcionários e colegas do Departamento de Geotecnia da Escola de Engenharia de São Carlos, que me receberam muito bem e foram decisivos para minha formação. Em especial a minha orientadora Professora Dra. Cristina de Hollanda Cavalcanti Tsuha que acreditou no meu potencial e me concedeu a oportunidade de trabalhar ao seu lado e adentrar no meio geotécnico. Sem dúvida deve proporcionar uma felicidade incontestável a todos que a conhecem devido as suas inúmeras qualidades e a pessoa que é. 
Por fim agradeço a Deus, que sem dúvida é o principal motivo que permitiu minha chegada até aqui, e sei que ELE recompensará todos os sacrifícios, trabalhos e cuidados que aqueles citados acima tiveram por mim e retribuirá todo o bem que me fizeram no corpo e na alma, pois eu por mim não sou capaz de pagar-lhes tudo isto. 


\section{RESUMO}

FERREIRA, M.Q. (2015). Adaptação do ensaio SPT para determinação de parâmetros adicionais para o dimensionamento de fundações. Dissertação (Mestrado) - Escola de Engenharia de São Carlos, Universidade de São Paulo, São Carlos, 2015.

A presente pesquisa foi desenvolvida com o intuito de agregar alguns procedimentos ao Ensaio SPT, para se obter um maior número de parâmetros para o dimensionamento de fundações, visto que este ensaio é o tipo de investigação de subsolo mais utilizado no Brasil para este fim. Os procedimentos adicionados foram: medida de eficiência do equipamento e ensaio de arrancamento do amostrador em cada camada distinta de solo atravessado. Foram realizados nove ensaios de arrancamento do amostrador, em três furos de sondagem, nas profundidades de dois, cinco e dez metros (três camadas de solos distintas). Em um quarto furo foram realizadas duas provas de carga à compressão no amostrador (nas profundidades de dois e cinco metros) para determinação da eficiência do equipamento. Por meio destes ensaios foi possível obter: a resistência de ponta do ensaio SPT, a resistência por atrito lateral na face externa do amostrador, e a razão de atrito do ensaio SPT, que pode ser usada para a classificação de solo de modo similar ao utilizado para o ensaio de cone. Além destes resultados, neste trabalho foi também analisada a relação entre a resistência por atrito interna e externa no amostrador durante o ensaio, conhecida por $a$. Esta relação mostrou-se maior para a camada de solo com grande porcentagem de pedregulho e menor para a camada que apresentava maior porcentagem de argila. Foi observado também que o valor de $a$ cresce linearmente com a razão entre o valor de $N_{S P T}$ e a tensão vertical efetiva na profundidade do ensaio. Os resultados deste trabalho também mostraram que o valor da razão entre a resistência de ponta do ensaio SPT $\left(q_{S P T}\right)$ e o valor de $N_{S P T}$ é único para o mesmo tipo de solo. Além disso, os valores encontrados nesta pesquisa da razão $q_{S P T} / N_{S P T}$ são próximos aos valores da razão entre a resistência de ponta do ensaio de cone e o $N_{S P T}$ encontrados na literatura.

Palavras-chave: ensaio SPT; resistência de ponta; prova de carga no amostrador; eficiência; fundações 


\begin{abstract}
FERREIRA, M.Q. (2015). Adaptation of the SPT test for the determination of additional parameters for the design of foundations. Dissertation (Master) - Escola de Engenharia de São Carlos, Universidade de São Paulo, São Carlos, 2015.

This research was developed in order to add some procedures to the SPT test, to obtain new parameters for the design of foundations, since this test is the most used in Brazil for this purpose. The additional measurements are: the energy delivered to the rod during a hammer impact, and the sampler's shaft resistance known from static uplift. For this investigation, nine uplift tests were conducted on the SPT sampler, in three boreholes, at three different depths (two, five and ten meters) to the determination of the SPT side friction resistance. Additionally, two compressive static load tests were carried out on the sampler in a fourth borehole to the determination of the efficiency of the SPT equipment. The results showed that the SPT test could provide measurements of end bearing and side friction resistances. Also, a SPT normalized friction ratio was determined for the classification of soil in a similar way used based on CPT data. In addition, the ratio between the internal and the external skin friction in the sampler during the test, known as " $a$ " was analyzed. The values of this ratio were higher for the soil with higher percentage of gravel, and smaller for the soil with higher percentage of fines. Additionally, the " $a$ " value increases linearly with the ratio between the $\mathrm{N}_{\mathrm{SPT}}$ value and the effective vertical stress at the tested depth. The results of the ratio between the SPT end bearing resistance and the $\mathrm{N}_{\mathrm{SPT}}$ found in this research are of similar magnitude to the ratios between CPT end bearing resistance and the $\mathrm{N}_{\mathrm{SPT}}$ found in the literature.
\end{abstract}

Keywords: SPT test; tip resistance; load test on SPT sampler; efficiency; foundations 


\section{LISTA DE FIGURAS}

Figura 1- Amostrador do tipo Raymond bipartido (Belincanta et al, 2010)

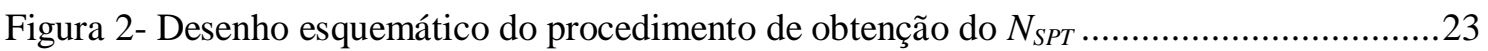

Figura 3- Amostrador padrão 24

Figura 4- Energia potencial do sistema considerando o acréscimo da energia potencial do martelo e das hastes (Odebrecht, 2003).

Figura 5- Relação entre o comprimento da haste e a eficiência (Schmertmann e Palácios, 1979)

Figura 6- Relação entre o comprimento da haste e a eficiência $\eta$ (Aoki e Cintra, 2000) ............28

Figura 7- Esquema de propagação de ondas de tensão no SPT (Lukiantchuki, 2012) ................30

Figura 8- Evolução de energia potencial, energia cinética e trabalho durante o evento golpe do martelo (Neves, 2004).

Figura 9- Trabalho calculado através de uma prova de carga estática para a penetração obtido no último golpe dinâmico do martelo SPT (Neves, 2004) .....

Figura 10- Equilíbrio das forças atuantes no amostrador durante o golpe no ensaio SPT

(modificado de Cintra et al. (2013))

Figura 11- Equilíbrio das forças atuantes na ponta aberta do amostrador (Cintra et al. (2013)) .40

Figura 12- Equilíbrio de forças no amostrador do ensaio SPT considerado nesta pesquisa........44

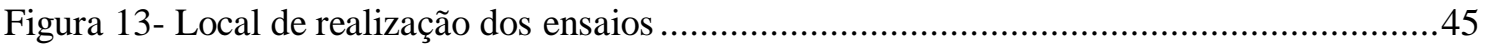

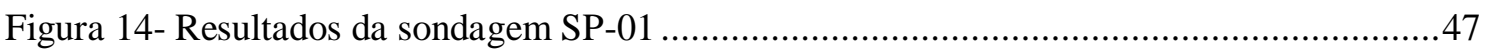

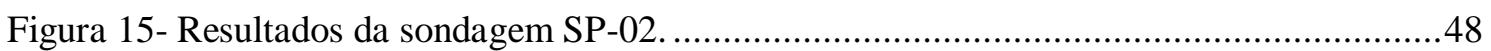

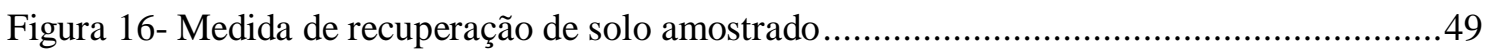

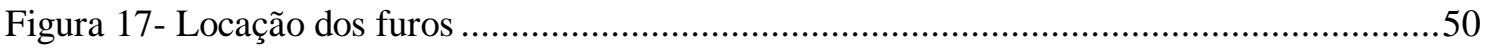

Figura 18- Equipamento de sondagem a ser utilizado na realização dos ensaios: (a) vista geral e

(b) detalhe do martelo

Figura 19- Equipamentos para ensaios de arrancamento: (a) desenho esquemático e (b) montagem do ensaio

Figura 20- Calibração da célula de carga

Figura 21- Equipamento para monitoramento do carregamento: (a) segmento de tubo semelhante ao das hastes e (b) célula de carga

Figura 22- Sistema de prova de carga com relógio magnético + medidor LVDT+ equipamento com célula de carga + sistema de aquisição de dados .55

Figura 23- Prova de carga estática na haste do amostrador ......................................................55

Figura 24- Curva carga x deslocamento dos ensaios realizados no amostrador a $2 \mathrm{~m}$ de profundidade. 
Figura 25- Curva carga $\mathrm{x}$ deslocamento dos ensaios realizados no amostrador a $5 \mathrm{~m}$ de profundidade.

Figura 26- Curva carga $\mathrm{x}$ deslocamento dos ensaios realizados no amostrador a 10m de profundidade.

Figura 27- Curva carga x recalque da prova de carga a compressão a 2,0 $\mathrm{m}$ de profundidade ...58

Figura 28- Curva carga x recalque da prova de carga a compressão a 5,0 $\mathrm{m}$ de profundidade ...58

Figura 29- Curva Granulométrica para amostra obtida a 2,0 $\mathrm{m}$ de profundidade. .63

Figura 30- Curva Granulométrica para amostra obtida a 5,0 $\mathrm{m}$ de profundidade. 63

Figura 31- Curva Granulométrica para amostra obtida a $10,0 \mathrm{~m}$ de profundidade. .64

Figura 32- Curvas Granulométricas obtidas das amostras a 2, 5 e $10 \mathrm{~m}$ de profundidade. .64

Figura 33- Resultados de $q_{s p t} \times N_{S P T}$ para as profundidades de $2,0 \mathrm{~m}, 5,0 \mathrm{~m}$ e $10 \mathrm{~m}$. .66

Figura 34- Comparação entre as componentes de resistência à penetração do ensaio SPT e CPT (modificado por Schmertmann (1979)) .68

Figura 35- Valores da razão $q_{c} / N_{S P T}$ x D50 (Robertson et. al. 1983) . .69

Figura 36- Valores da razão $q_{s p t} / N_{S P T}$ x D50 e $q_{s p t} / N_{S P T}$ x D20 obtidos nesta pesquisa para os solos a 2,5 e $10 \mathrm{~m}$ de profundidade .69

Figura 37- Resultados de $q_{s p t} \times \mathrm{R}_{\mathrm{f}}$ plotados no ábaco de classificação de solo por Robertson et al. (1986) 71

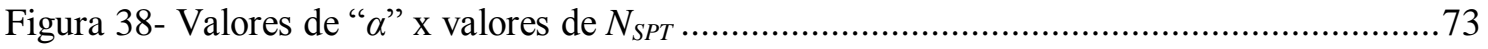

Figura 39- $\alpha \times N_{S P T} / \sigma_{v}$ para todas as profundidades 74 


\section{LISTA DE TABELAS}

Tabela 1- Resultados de comprimento da recuperação ...............................................................

Tabela 2- Resultados dos ensaios de arrancamento do amostrador ............................................57

Tabela 3- Resultados das provas de carga a compressão no Furo 4 ...........................................58

Tabela 4- Deslocamento correspondente a um golpe do ensaio SPT ......................................59

Tabela 5- Encurtamento elástico da haste nos ensaios relativos a um golpe de martelo..............59

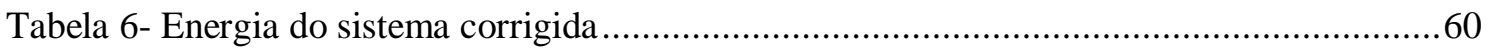

Tabela 7- Eficiência do equipamento de sondagem empregado.............................................61

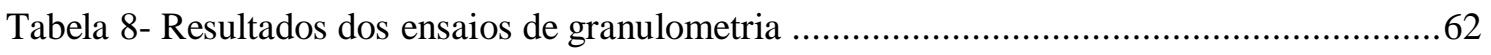

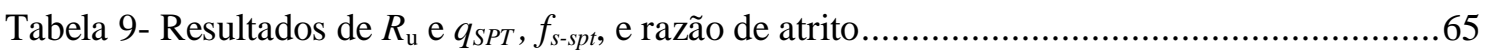

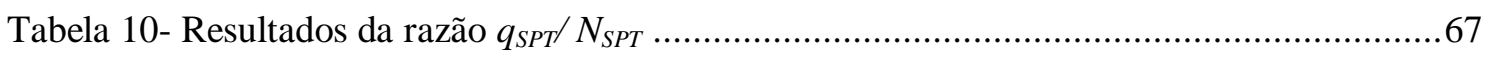

Tabela 11- Valores de $q_{d} / N_{S P T}$ proposto por Schmertmann (1970 apud Danziger 1982) ............68

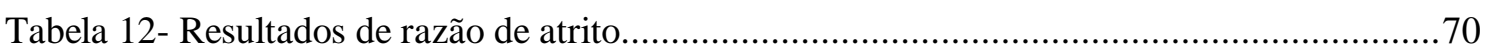

Tabela 13- Classificação pelo ensaio de granulometria e através do ábaco de Robertson et

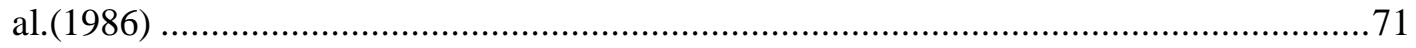

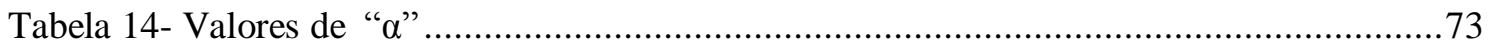

Tabela 15- Valores de $N_{S P T} / \sigma_{v}$ para todas as profundidades ..................................................... 74 


\section{LISTA DE SÍMBOLOS}

A: Área

c: Velocidade de propagação de impulsos de tensão por Lukiantchuki (2012)

$D_{b}$ : Diâmetro externo do anel na ponta do amostrador

$D_{\text {int }}$ : Diâmetro interno

$D_{\text {ext }}$ : Diâmetro externo

$D_{p}$ : Diâmetro da ponta do amostrador

$E$ : Módulo de Elasticidade

$E_{\text {amostrador }}$ : Energia mobilizada para efetivamente cravar o amostrador no solo

$E h$ : Energia transferida ao topo da composição de hastes

EPsistema: Energia potencial imposta durante o evento

$f_{s-s p t}:$ Atrito lateral do ensaio SPT

$g$ : Aceleração da gravidade

$h_{q}:$ Altura de queda padrão do martelo

l: Comprimento da composição de hastes por Lukiantchuki (2012)

$L$ : Comprimento externo do anel

$L_{\text {int }}$ : Comprimento de recuperação do solo embuchado no amostrador

$L_{h:}$ Comprimento total de haste utilizado não considerando o amostrador

$L_{p}:$ Comprimento da ponta do amostrador

$L_{\text {ext }}$ : Comprimento correspondente ao total penetrado para obter o $N_{S P T}$

$M_{h}$ : Massa das hastes

$M_{m}$ : Massa do martelo

$N_{S P T}:$ Número de golpes do Ensaio SPT

$Q_{u}$ : Carga de ruptura

$q_{c}$ : Resistência de ponta do cone

$q_{S P T}$ : Resistência de ponta do ensaio SPT

$R$ : Produto de resistência 
$R_{b}$ : Resistência de ponta do amostrador

$R_{f}:$ Razão de atrito

$r_{L}$ : Atrito na lateral em unidades de tensão

$r_{l i}$ : Atrito na lateral interna em unidades de tensão

$r_{p}$ : Resistência de ponta em unidades de tensão

$R_{s}$ : Resistência do sistema amostrador-solo dependente do movimento relativo

entre as partes no golpe do ensaio SPT, ou força elástica

$R_{s e}$ : Resistência externa por atrito lateral do amostrador

$R s, s$ : Resistência do sistema amostrador-solo para uma nega $\mathrm{s}$

$R_{u}$ : Resistência do solo à penetração estática do amostrador

$R_{I}$ : Força de atrito na parede vertical externa do amostrador

$R_{2}$ : Força de atrito na parrede vertical interna do amostrador

$R_{3}$ : Força de reação vertical na seção anelar da ponta do amostrador

$R_{4}$ : Componente vertical da força de atrito ao longo da superfície biselada troncocônica do amostrador

$S$ : Deslocamento permanente

$s_{m}$ : Deslocamento resultante do último golpe do ensaio SPT

$S_{L}$ : Área externa do anel cortante

$T$ : Energia cinética

$T_{A}$ : Energia transferida ao sistema amostrador-solo

$U$ : Energia potencial teórica do sistema ou energia nominal do SPT

$V$ : Energia potencial

$V_{e}:$ Energia potencial elástica

$V_{e h}$ : Energia potencial elástica armazenada no conjunto de hastes

$V_{e s}:$ Energia potencial elástica armazenada no solo que envolve o amostrador

W: Trabalho por Neves (2004)

$W$ : Peso das hastes + amostrador + cabeça de bater

$W_{h}$ : Peso da haste + cabeça de bater 
$W_{n c}$ : Trabalho efetuado por forças não-conservativas

$W_{p}$ : Trabalho gerado pelas forças resistentes não conservativas mobilizadas ao longo do amostrador durante sua penetração

$W_{p, s}:$ Trabalho gerado pelas forças resistentes não conservativas mobilizadas ao longo do amostrador durante sua penetração em um ensaio estático

$W_{q}$ : Trabalho gerado durante o evento golpe do martelo antes da cravação do amostrador padrão no solo

$a$ : Razão entre o atrito na lateral interna e externa do amostrador padrão

$\delta$ : Variação em um intervalo de tempo

$\eta$ : Eficiência do Ensaio SPT

$\eta^{*}$ : Eficiência do Ensaio SPT definida por Aoki e Cintra (2000) através da máxima energia transferida ao sistema amostrador-solo

$\eta_{s}$ : Eficiência do Ensaio SPT definida por Aoki e Cintra (2000) através do trabalho realizado para penetrar o amostrador no solo

$\eta_{1}$ : Eficiência do martelo (ODEBRECHT, 2003)

$\eta_{2}$ : Eficiência da composição de hastes (ODEBRECHT, 2003)

$\eta_{3}$ : Eficiência do sistema (ODEBRECHT, 2003)

$\rho$ : Penetração permanente do amostrador devido a aplicação de um golpe

$\rho_{e}$ : Encurtamento elástico

$s:$ Nega de um ensaio dinâmico 


\section{LISTA DE SIGLAS}

ABEF: Associação Brasileira de Engenharia de Fundações e Geotecnia

ABNT: Associação Brasileira de Normas Técnicas

CPT: Cone Penetration Test (Ensaio de cone)

LVDT: Linear Variable Differential Transformer (medidor de deslocamento)

NBR: Norma Brasileira

SPT: Standart Penetration Test (Ensaio de simples reconhecimentos de solo)

USP: Universidade de São Paulo 



\section{SUMÁRIO}

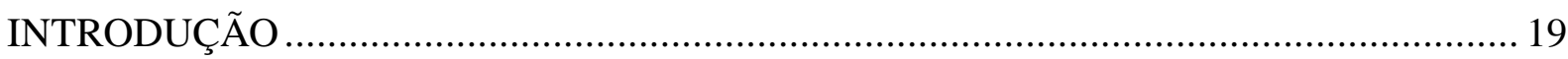

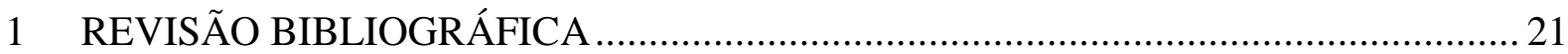

1.1 PROSPECÇÃO GEOTÉCNICA DO SUBSOLO ................................................. 21

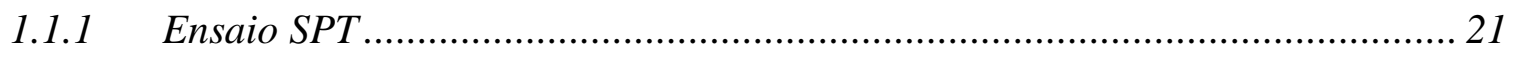

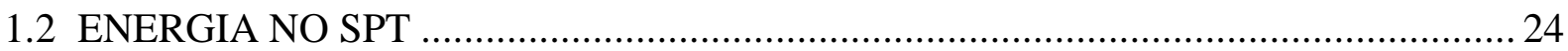

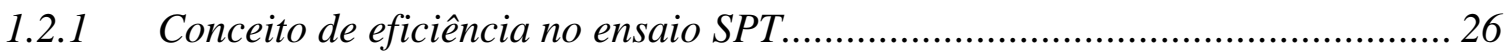

1.2.2 Mecanismos de transferência de energia no ensaio SPT ............................... 28

1.2.3 Princípio da Conservação de energia de Hamilton .......................................... 30

1.2.4 Determinação da eficiência do ensaio SPT mediante prova de carga estática sobre o amostrador padrão ..................................................................... 34

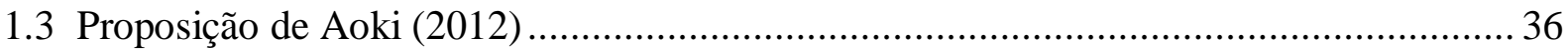

2 MATERIAIS E MÉTODOS _............................................................................ 43

2.1 Procedimento para a determinação da resistência de ponta e por atrito lateral do ensaio

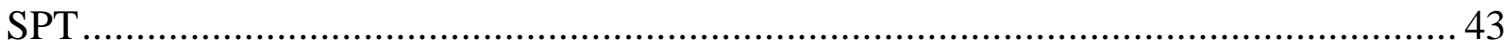

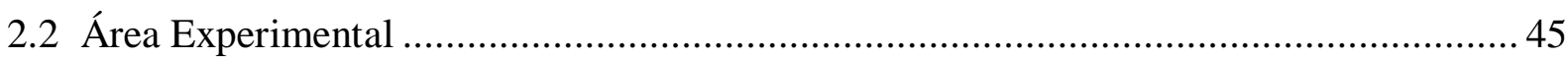

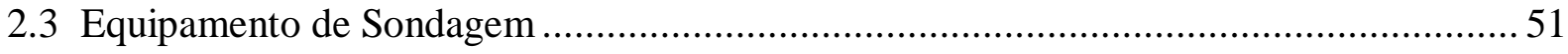

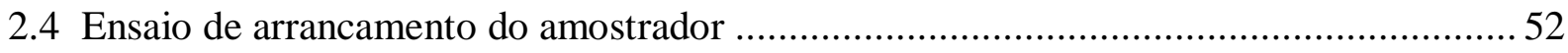

2.5 Prova de carga à compressão no amostrador para determinação da eficiência do sistema

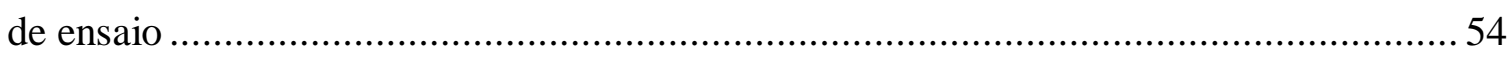

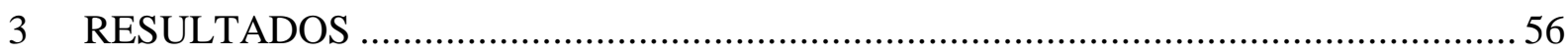

3.1 Resultados dos ensaios de arrancamento no conjunto haste + amostrador .....................56

3.2 Resultado dos ensaios de compressão para determinação da eficiência .......................... 57

3.3 Resultados dos ensaios de caracterização granulométrica dos solos nas profundidades

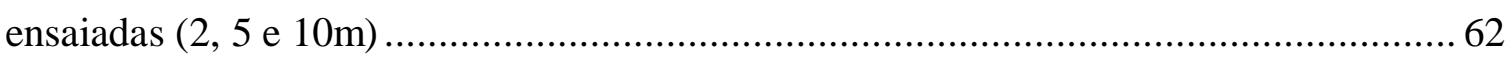

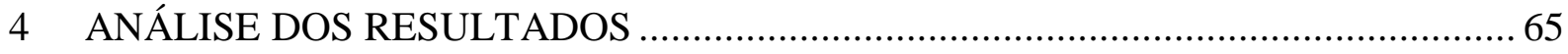

4.1 Comparação da resistência de ponta do ensaio SPT, $q_{s p t}$, com valores de $N_{s p t} \ldots \ldots \ldots \ldots \ldots . . . .66$ 
4.2 Comparação das resistências de ponta do ensaio de cone $q_{c}$ e do ensaio SPT $q_{s p t} \ldots \ldots \ldots . . . .67$

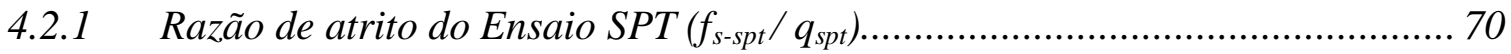

4.3 Análise da relação entre atrito interno e externo no amostrador " $\boldsymbol{a}$ " proposta em Aoki

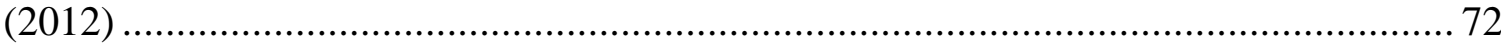

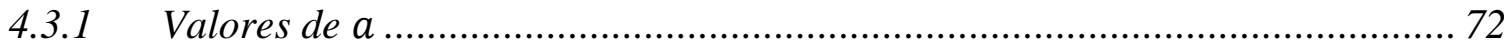

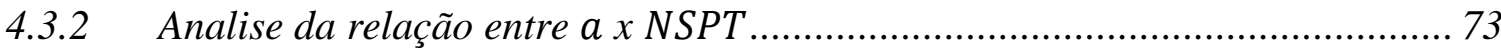

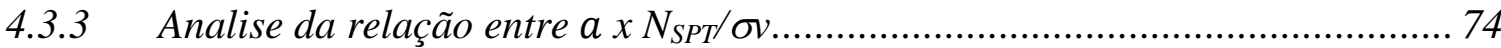

5 CONCLUSÃO

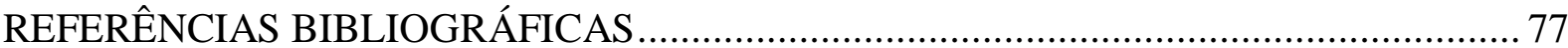




\section{INTRODUÇÃO}

Devido à complexidade de determinar teoricamente a capacidade de carga de fundações por estacas e sapatas, correlações empíricas que estabelecem relações entre os resultados do ensaio SPT com o comportamento do elemento de fundação são comumente utilizadas na prática brasileira.

Inicialmente, antes de qualquer interpretação dos dados do ensaio SPT, é importante saber que existem variações no processo executivo e no equipamento que interferem nos resultados do ensaio. Portanto, para que os resultados de resistência a penetração deste ensaio $\left(N_{S P T}\right)$ sejam adequadamente interpretados e utilizados, é necessário que se conheça a eficiência do equipamento de sondagem, pois o valor de $N_{S P T}$ é dependente da energia que chega no amostrador no momento do golpe. A energia transmitida ao sistema amostrador-solo é um dos principais fatores que influenciam o valor do índice de resistência à penetração $N_{S P T}$.

Inúmeros trabalhos publicados já trataram sobre a eficiência do ensaio SPT, destacando-se Schmertmann \& Palacios (1979), Kovacs \& Salamone (1982), Belincanta (1985, 1998) e Cavalcante (2002). Para determinação da eficiência do ensaio SPT, Neves (2004) propôs executar uma prova de carga estática no amostrador realizada logo após o ensaio. Conhecer a eficiência do sistema de ensaio é fundamental na interpretação do ensaio SPT para posterior aplicação nos métodos de previsão de capacidade de carga de fundações, e também em outras aplicações em obras geotécnicas.

Aoki (2012), fundamentado no princípio da conservação de energia de Hamilton, obteve a relação entre a resistência lateral e de ponta do ensaio SPT a partir do equilíbrio de forças no amostrador, com o intuito de melhorar a previsão de capacidade de carga de fundações por estacas. Para obter esta relação, foi utilizada a medida do comprimento de recuperação de solo no amostrador padrão após a determinação do índice $N_{S P T}$ juntamente com eficiência do equipamento. 
Com base no cenário mencionado acima, e com o intuito de melhorar o dimensionamento de fundações, o presente trabalho apresenta algumas adaptações no ensaio SPT, para a determinação de parâmetros como resistência de ponta e razão de atrito deste ensaio, com base na medida de eficiência do equipamento e no equilíbrio de forças no amostrador.

A ideia principal desta pesquisa foi verificar se a partir do ensaio SPT seria possível obter valores de resistência de ponta de modo equivalente ao ensaio de cone para o dimensionamento de fundações, e também valores de razão de atrito para a classificação do solo quanto ao seu comportamento. Para este fim, foi verificado um novo procedimento para o ensaio SPT, onde foram acrescentados ao ensaio padrão:

1. Provas de carga à compressão para a determinação da eficiência do equipamento de ensaio (que pode ser substituída por outro procedimento para medir a eficiência);

2. Provas de carga à tração (ensaios de arrancamento), após a medida do índice $N_{S P T}$, para medir a resistência por atrito lateral externo no amostrador. 


\section{REVISÃO BIBLIOGRÁFICA}

\subsection{PROSPECÇÃO GEOTÉCNICA DO SUBSOLO}

$\mathrm{Na}$ medida em que o solo é o meio que suporta as cargas provenientes da estrutura, sua identificação e a caracterização de seu comportamento são essenciais para solução de qualquer problema.

A determinação das propriedades do subsolo de instalação das fundações de uma estrutura pode ser feita por meio de ensaios de laboratório ou por ensaios de campo. No entanto, na prática das construções, os ensaios de campo são mais empregados, ficando a investigação laboratorial restrita a uma minoria de casos especiais.

Dentre os principais processos de investigação do subsolo para fins de projeto de fundações, se destacam os ensaios CPT e o SPT. O presente trabalho irá abordar apenas o segundo ensaio, que é o método de prospecção geotécnica mais utilizado no Brasil.

\subsubsection{Ensaio SPT}

A relação de equipamentos utilizados no ensaio SPT pode ser encontrada em diversos manuais e trabalhos, assim como em sua norma vigente NBR 6484 (2001). Uma lista detalhada pode ser encontrada no Manual de Execução de Fundações e Geotecnia da Associação Brasileira de Empresas de Engenharia de Fundações e Geotecnia (ABEF).

Fernando Schnaid (2000) afirma que “ $O$ ensaio de SPT constitui a investigação mais utilizada na prática corrente da Geotecnia, especialmente em fundações, e a tendência observada deve ser mantida no futuro próximo, devido à simplicidade, economia e experiência acumulada". 
A grande vantagem deste tipo de ensaio sobre os outros que se destinam ao mesmo fim é a de reunir em uma só operação a coleta de amostras, profundidade do lençol freático e a medição da resistência do solo através do índice de resistência a penetração $N_{S P T}$. Aliada a esta grande vantagem, este método de sondagem é de baixo custo e não demanda mão de obra altamente especializada.

O ensaio SPT (normalizado pela NBR 6484 - Execução de sondagem de simples reconhecimento dos solos) é realizado a cada metro de profundidade e consiste na cravação de um amostrador de dimensões normalizadas, chamado originalmente de Raymond-Terzaghi (Figura 1), por meio de golpes de um peso de $65 \mathrm{kgf}$ caindo em queda livre de uma altura igual a $75 \mathrm{~cm}$ de altura.

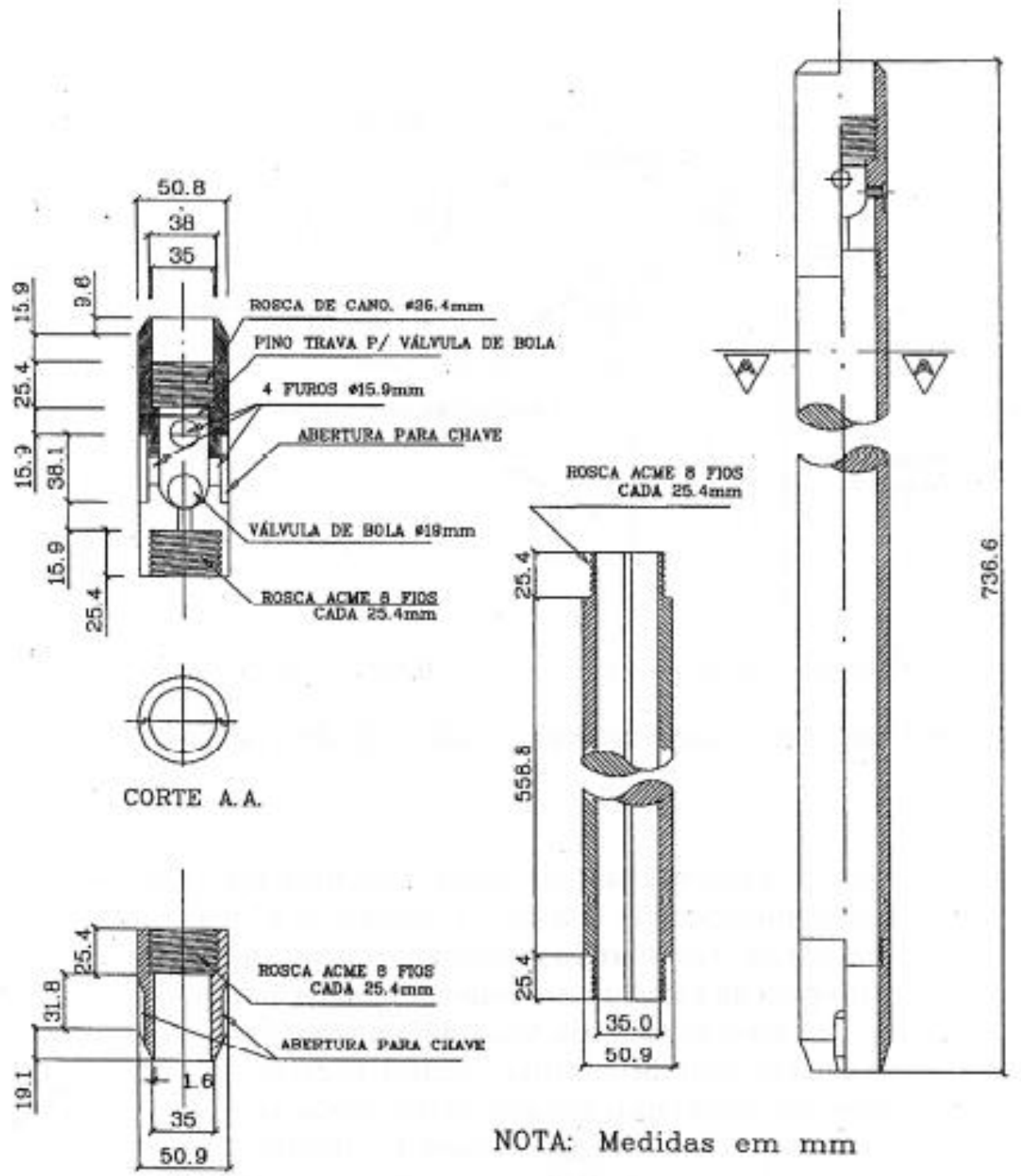

Figura 1- Amostrador do tipo Raymond bipartido (Belincanta et al, 2010). 
No ensaio SPT é obtido o índice de resistência é penetração $N_{s p t}$, definido como o número de golpes necessários para fazer com que o amostrador penetre $30 \mathrm{~cm}$ no solo, após uma cravação inicial de $15 \mathrm{~cm}$. Este procedimento é esquematizado na Figura 2.

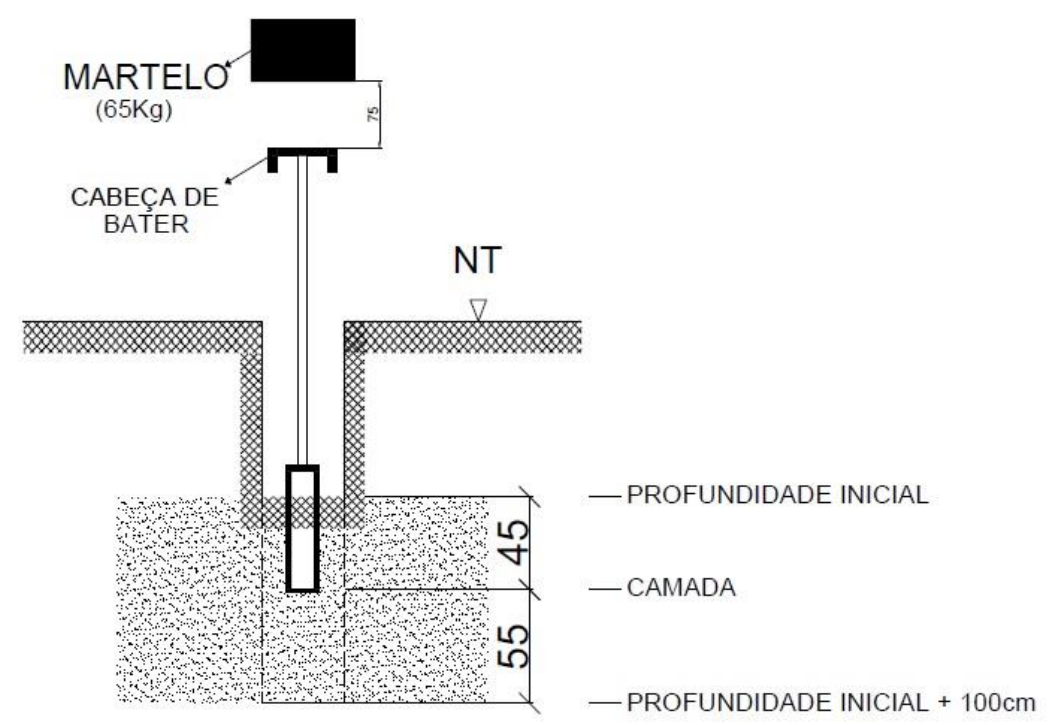

Figura 2 - Desenho esquemático do procedimento de obtenção do $N_{s p t}$.

O número de golpes necessários à penetração dos primeiros $15 \mathrm{~cm}$ não é considerado para o calculo do $N_{s p t}$. Após a obtenção do $N_{s p t}$, é utilizado um trado helicoidal para a escavação de um metro, onde será repetido o ensaio. O avanço com trado é feito até atingir o nível de água ou caso ocorra um aumento da resistência do solo. Daí em diante, a perfuração continua com o uso de trépano e circulação de água, processo denominado de "lavagem". O trépano é uma ferramenta da largura do furo e com terminação em bisel cortante, utilizado para desagregar o material que se encontra no fundo do furo, e dotada de duas saídas laterais para a água. Caso o lençol freático seja encontrado, deverá ser anotada a profundidade do nível d'água e a sua posição final após decorrer, no mínimo, 12 horas do fim da sondagem.

Após o término de cada ensaio SPT, o amostrador é retirado do furo e a amostra deformada é coletada para posterior identificação tátil-visual da Norma ABNT NBR 6484 (2001) - identificação e classificação de amostras obtidas em sondagem de simples reconhecimento dos solos, e uma parte delas que se encontra em melhor estado deverá ser guardada em um frasco que mantenha a umidade da mesma, e posteriormente enviada ao laboratório para confirmação do resultado de campo e se necessário algum ensaio de classificação. 
A paralização do ensaio é definida pela Norma ABNT NBR 6484 (2001). A Figura 3 apresenta um modelo do amostrador padrão utilizado no ensaio SPT.

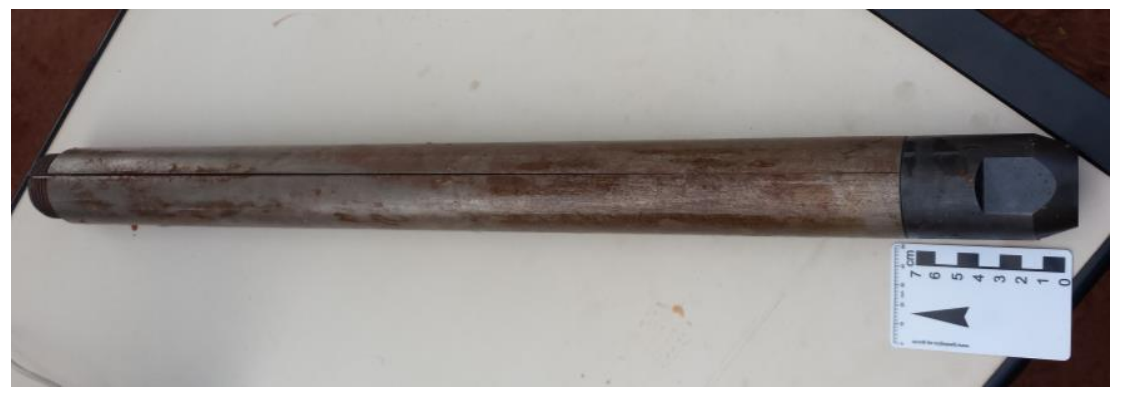

Figura 3 - Amostrador padrão.

\subsection{ENERGIA NO SPT}

Segundo Belicanta \& Ferraz (2000), no instante do impacto do martelo durante o ensaio SPT, a energia cinética é transferida para o conjunto de hastes por meio da propagação de uma onda de tensão, sendo que, a configuração do martelo, das hastes, da cabeça de bater e dos materiais que constituem os equipamentos influenciam na magnitude e na duração desses impulsos.

A energia disponibilizada ao sistema quando o martelo é levantado encontrase na forma de energia potencial, sendo assim, de acordo com a NBR 6484 (2001) podese representar a energia nominal do SPT pela equação abaixo:

$$
U=M_{m} \times g \times h_{q}=65 \times 9,81 \times 0,75 \cong 478,2 J
$$

Onde:

$M_{m}$ - massa do martelo (kg);

$g$ - aceleração da gravidade $\left(\mathrm{m} / \mathrm{s}^{2}\right)$

$h_{q}-$ altura de queda padrão do martelo (m). 
Considerando tal evento, foi proposto por Odebrecht (2003) uma correção da energia potencial, tal qual, considera um aumento de energia em consequência à penetração do amostrador no solo. Segundo o autor a energia potencial imposta durante o evento, quando se considera um referencial fixo e externo, pode ser representada por:

$$
E P_{\text {sistema }}=M_{m} \times g \times\left(h_{q}+\rho\right)+M_{h} \times g \times \rho
$$

Sendo:

$\rho$ - penetração permanente do amostrador devido à aplicação de um golpe $M_{h}-$ massa das hastes

O processo de cravação do amostrador no solo é demonstrado em três etapas conforme a Figura 4. A primeira $\left(t_{1}=0\right)$ representa o momento que antecede a liberação do martelo, já a segunda etapa $\left(\mathrm{t}_{2}=\mathrm{t}\right)$ indica o instante antes do martelo atingir a cabeça de bater, e a última etapa $\left(\mathrm{t}_{3}=\infty\right)$ corresponde ao instante após à cravação do amostrador no solo, ou seja, quando a energia potencial gravitacional do martelo e das hastes já foi consumida na cravação do amostrador, devolvidas elasticamente e amortecidas dinamicamente no interior do martelo e das hastes.

A variação da energia potencial gravitacional do martelo e das hastes é similar ao valor da energia potencial gravitacional teórica do martelo, em situações de solos resistentes $\left(N_{S P T} \geq 15\right)$ associados a comprimentos de composição de hastes maiores que 20 metros, sendo assim, é tolerável assumir valores iguais para essas condições (ODEBRECHT, 2003). Para solos de menor resistência, onde a penetração do amostrador do solo é maior, esta diferença de valores é mais intensa. 


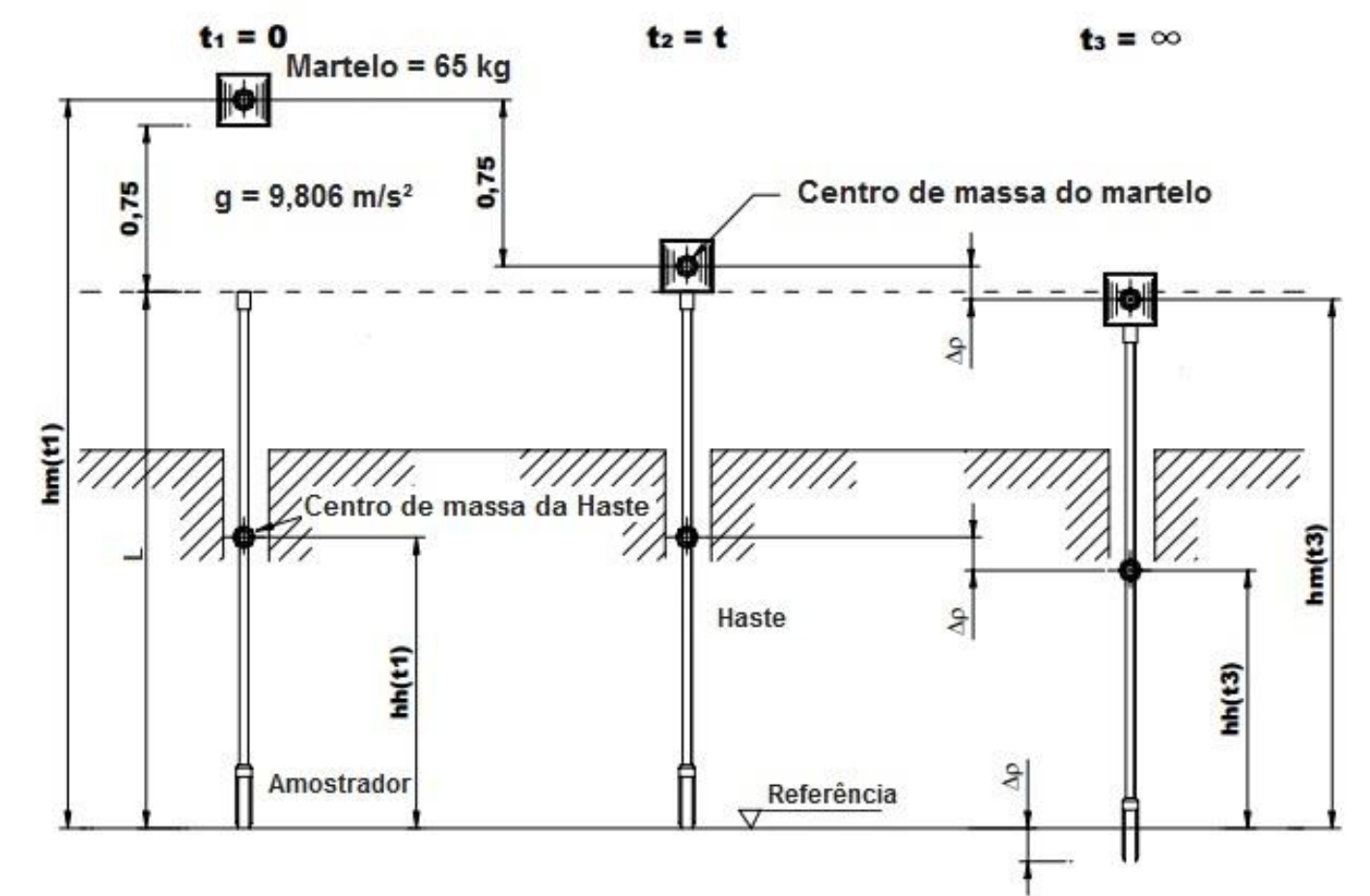

Figura 4 - Energia potencial do sistema considerando o acréscimo da energia potencial do martelo e das hastes (Odebrecht, 2003).

\subsubsection{Conceito de eficiência no ensaio SPT}

De acordo com Lukiantchuki (2012) a relação entre a quantidade de energia transferida ao topo da composição de hastes $\left(E_{h}\right)$, no instante do primeiro impacto do martelo, e a energia potencial nominal do ensaio SPT (478,2 J), define a eficiência do ensaio SPT ( $\eta$ ) que é representada pela seguinte equação:

$$
\eta=E_{h} / 478.2 \times 100(\%)
$$

A Figura 5, apresenta uma relação por Schmertmann e Palácios (1979), entre o comprimento da haste e a eficiência através de alguns ensaios, na qual os autores atestaram que hastes com comprimentos curtos fazem a eficiência $\eta$ tender a zero e quando o comprimento da haste excede $15 \mathrm{~m}$ a eficiência tende a um valor máximo. No entanto, esta suposição parece contradizer o bom senso em que hastes mais longas apresentam perdas maiores do que hastes mais curtas . 


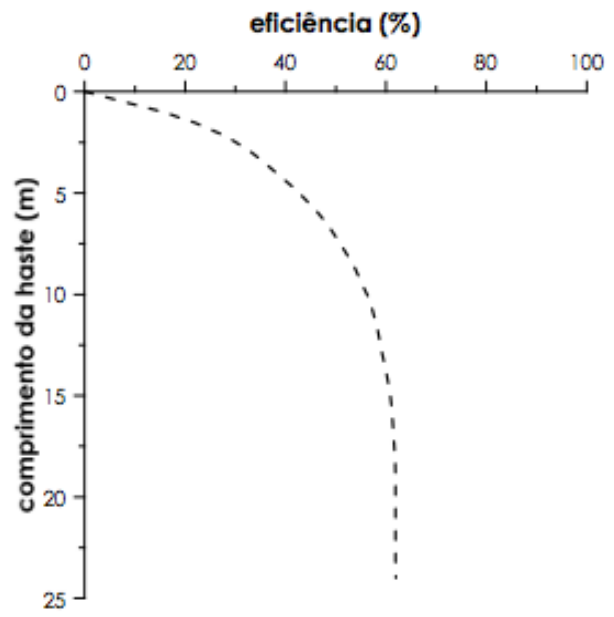

Figura 5 - Relação entre o comprimento da haste e a eficiência (Schmertmann e Palácios, 1979).

Uma nova proposta, por Aoki e Cintra (2000), definiu a eficiência no ensaio SPT $\eta^{*}$ como sendo a relação entre a máxima energia transferida ao sistema amostrador-solo $\left(T_{A}\right)$, e a energia potencial normalizada do SPT. Para isto, a instrumentação deve estar localizada próxima do topo do amostrador, resultando assim, no valor da energia que realmente chega ao amostrador.

$$
\eta^{*}=T_{A} / 478,2 \times 100(\%)
$$

Aoki e Cintra (2000) também determinaram uma relação entre o comprimento da haste e a eficiência na qual é apresentada pela Figura 5. Além disso, caracterizaram que a variável independente mais importante, se tratando da eficiência, é a rigidez/resistência do solo sob a ponta do amostrador.

A eficiência do ensaio SPT, de acordo com Odebrecht (2003), pode ser discriminada pelas seguintes eficiências: do martelo $\left(\eta_{1}\right)$, da composição de hastes $\left(\eta_{2}\right)$ e do sistema $\left(\eta_{3}\right)$. Estas eficiências quantificam as perdas de energia que surgem durante a cravação do amostrador no solo, permitindo assim, calcular a energia mobilizada para efetivamente cravar o amostrador no solo.

$$
\mathrm{E}_{\text {amostrador }}=\eta_{3}\left[\eta_{1}(0.75+\rho) \times M_{m} \times g \times \eta_{2}\left(M_{h} \times g \times \rho\right)\right]
$$




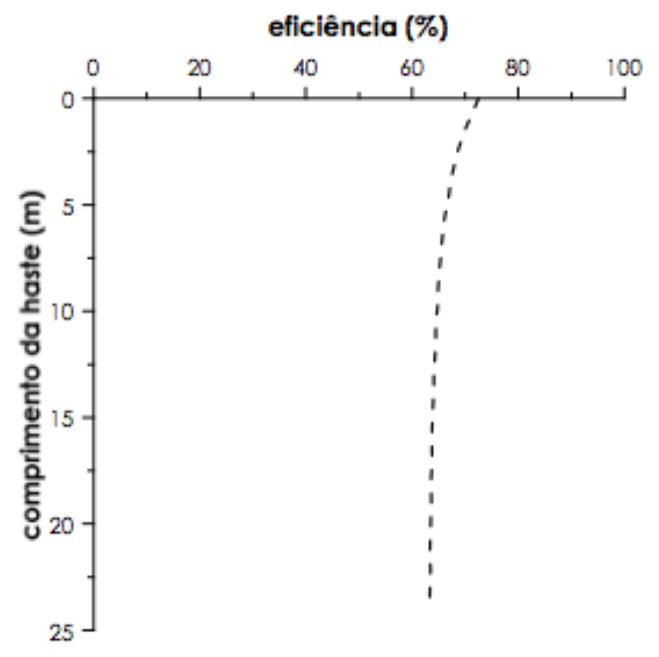

Figura 6 - Relação entre o comprimento da haste e a eficiência $\eta$ (Aoki e Cintra, 2000).

\subsubsection{Mecanismos de transferência de energia no ensaio SPT}

O mecanismo de transferência de energia no ensaio SPT foi detalhado por Belincanta e Ferraz (2000). Durante o impacto do martelo na cabeça de bater, uma onda de tensão é propagada no sentido descendente da composição de hastes, composta de impulsos de tensão sucessivos e decrescentes na intensidade, em um intervalo de tempo aproximado de $2 l / c$, sendo 1 o comprimento da composição de hastes e c a velocidade de propagação destes impulsos de tensão.

Até o tempo de $2 l / c$, enquanto o martelo e as hastes permanecem em contato, ocorre o início de chegada dos impulsos de tração refletidos junto ao amostrador. Em seguida, o martelo e a cabeça de bater se separam ocasionando uma paralisação da transferência de energia, esta que se mantém até o momento que o martelo atinge uma força resultante maior do que aquela proveniente dos impulsos de tração, resultando em um novo contato entre o martelo e a cabeça de bater e consequentemente um novo impacto que transfere a energia remanescente no martelo.

Segundo Lukiantchuki et al. (2011), solos com baixa resistência apresentam intervalo de tempo maiores, entre o primeiro e segundo impacto, quando comparado com solos mais resistentes. Em ensaios SPT realizados em solos de baixa resistência com composições de hastes curtas, notou-se que a cravação do amostrador no solo tem contribuição relevante da energia transferida pelos impactos subsequentes.

Lukiantchuki (2012) apresenta um esquema do mecanismo de transferência de energia e detalha os seus respectivos fenômenos: 
- A princípio, a energia no sistema se mantém em forma de energia potencial. Neste momento o martelo se mantém imóvel a uma altura $(h q)$, ou seja, não iniciou o movimento de queda livre;

- Após a liberação do martelo a energia potencial se transforma em energia cinética. Esta última será transferida ao conjunto de hastes, apos o impacto do martelo na cabeça de bater, na forma de impulsos de compressão em sentido descendente da composição de hastes até o instante $2 l / c$;

- Os impulsos de compressão chegam ao amostrador no instante $l / c$ e parte de sua energia é transformada em trabalho para cravação do amostrador no solo, a outra parte da energia é refletida na forma de impulsos de tração em direção ao topo da composição de hastes;

- Os impulsos de tração que chegam ao topo da composição de hastes irão voltar no sentido descendente como impulsos de compressão até atingirem novamente o amostrador, no instante $3 l / c$, podendo continuar a sua cravação no solo dependendo da magnitude dos impulsos de tensão e da resistência do solo.

O fim da primeira onda de compressão incidente se dá no momento em que o martelo não toca mais a cabeça de bater. Neste momento o topo da composição de hastes é atingido pelos impulsos refletidos do amostrador. Quando acontece o impacto subjacente do martelo na cabeça de bater, novos impulsos de compressão serão gerados e propagados pelo conjunto de hastes, transferindo assim a energia remanescente do martelo. Os impulsos ascendentes que se encontram refletidos no sistema amostrador e hastes se juntam as ondas de tensão geradas com o novo impacto, se propagando até se dissiparem totalmente em perdas ou se acabarem em conseqüência do trabalho de penetração do amostrador no solo. O evento do golpe do martelo se dá por encerrado no momento em que o solo apresenta uma resistência considerável para que os impulsos de tensão não continuem a penetração do amostrador. Todo este mecanismo de transferência de energia é apresentado na Figura 7. 

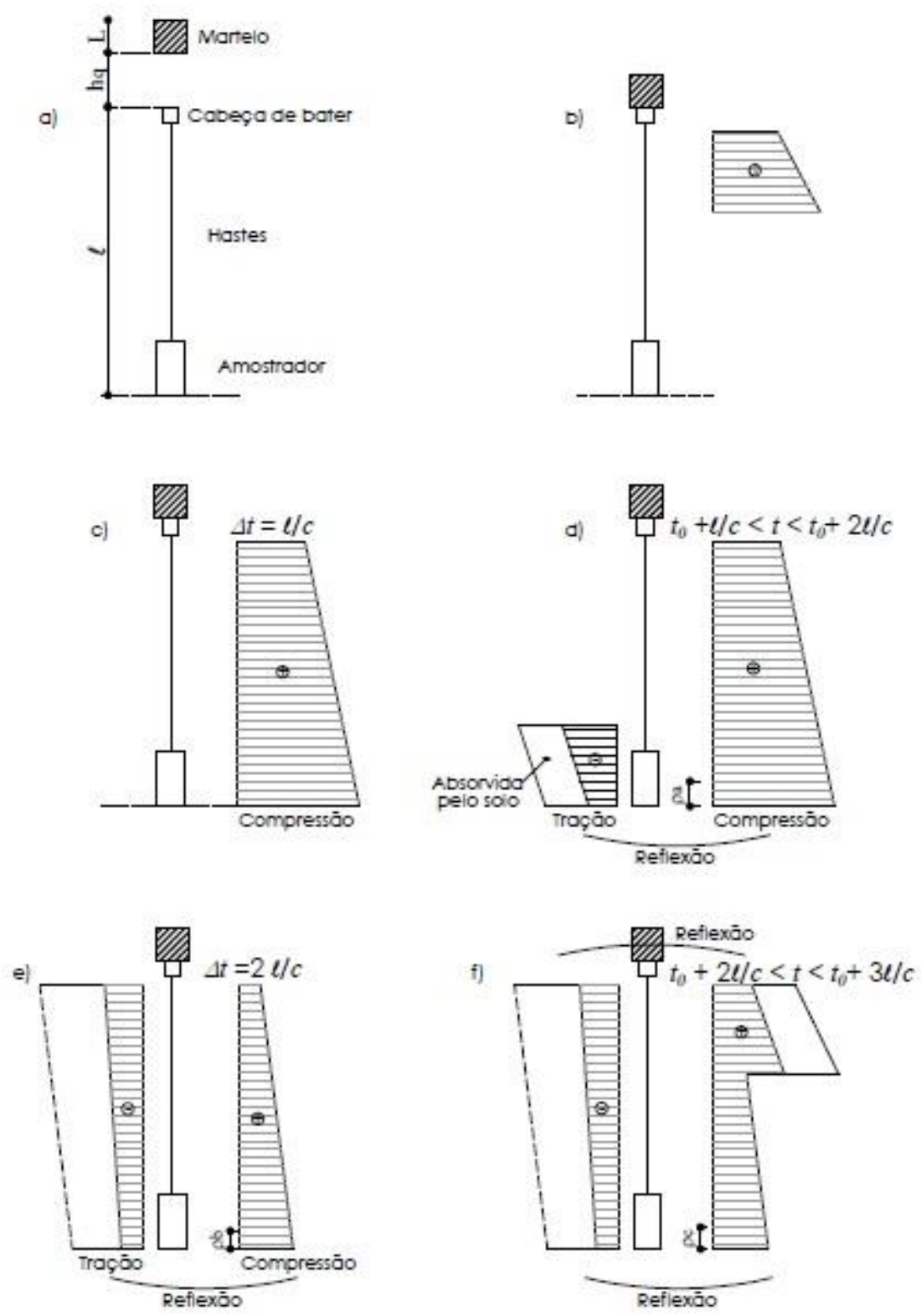

Figura 7 - Esquema de propagação de ondas de tensão no SPT (Lukiantchuki, 2012).

\subsubsection{Princípio da Conservação de energia de Hamilton}

O princípio de Hamilton é mostrado em Cintra et. al (2013) para avaliação da conservação de energia entre dois instantes no ensaio SPT, sendo sua expressão variacional dada por:

$$
\int_{t_{1}}^{t_{2}} \delta(T-V) d t+\int_{t_{1}}^{t_{2}} \delta\left(W_{n c}\right) d t=0
$$


Temos que: $\delta$ é a variação ocorrida no intervalo de tempo $\left(t_{2}-t_{1}\right) ; T$ é a energia cinética no sistema; $V$ corresponde a energia potencial; $W_{n c}$ é o trabalho realizado por forças não conservativas (incluindo amortecimento).

A energia cinética pode ser compreendida como a energia do sistema quando este se encontra em movimento e a energia potencial pode ser interpretada como a energia do sistema que só depende da localização ou características das massas que atuam no sistema.

Entende-se por forças conservativas as forças que não dissipam energia do sistema no decorrer do evento, e por forças não conservativas, aquelas que durante o evento dissipam energia do sistema com conversão em calor, amortecimento e energia sonora. A Figura 8 representa um esquema da aplicação do princípio Hamilton, no ensaio SPT, exibindo as parcelas de energia e suas transformações durante o percurso da onda de impacto na haste até alcançar o amostrador. Para uma análise correta das transformações de energia no ensaio SPT é necessário acrescentar a parcela da energia potencial resultante da penetração do amostrador no solo. 


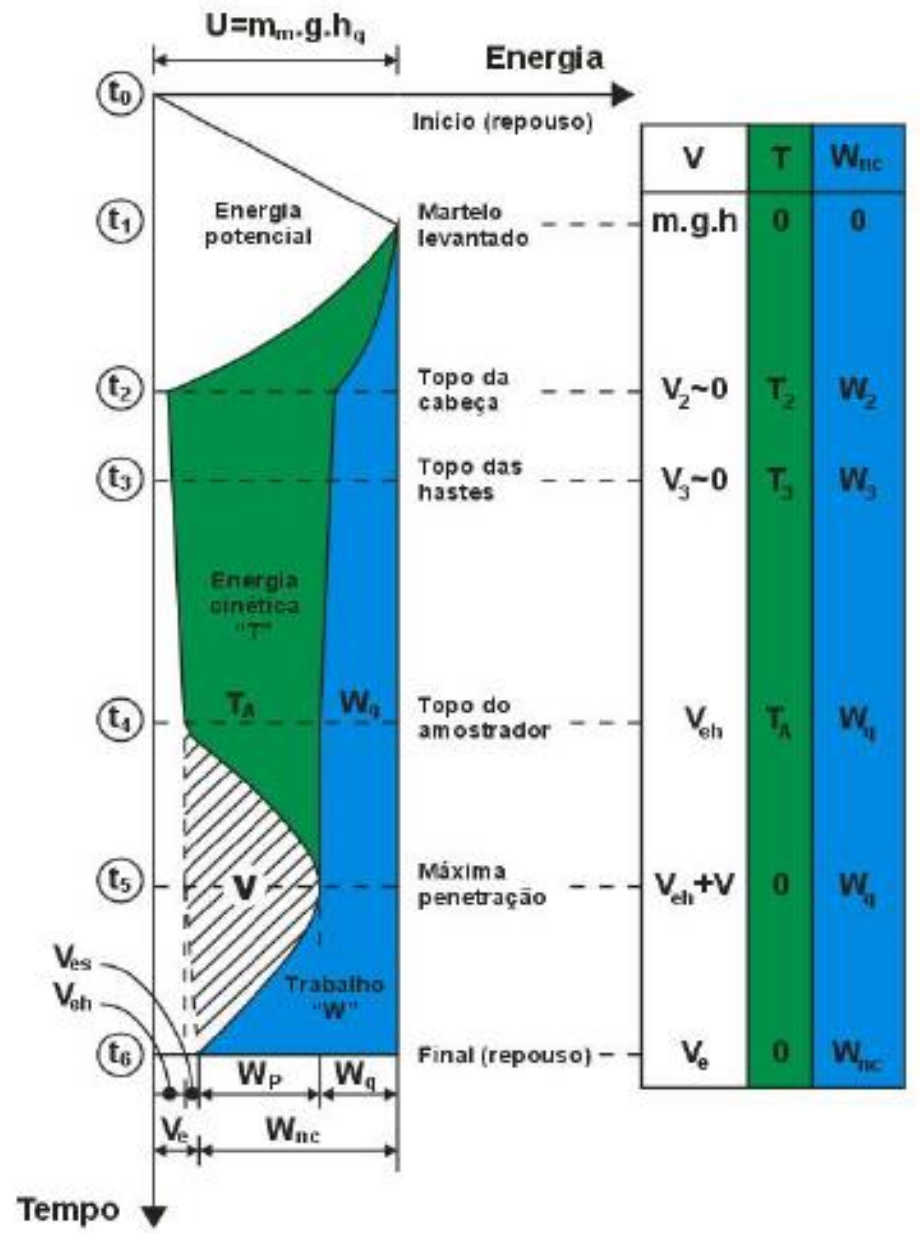

Figura 8 - Evolução de energia potencial, energia cinética e trabalho durante o evento golpe do martelo (Neves, 2004).

De acordo com Neves (2004):

1. No instante $t_{0}$, o sistema encontra-se em repouso e sua energia potencial nominal é o resultado do produto do peso do martelo vezes a sua altura de queda;

2. No instante $t_{1}$, a energia nominal do SPT $(U)$ equivale a 478,3 J, momento este em que o martelo é suspenso a uma altura de $750 \mathrm{~mm}$;

3. No instante $t_{2}$, o martelo é liberado e em queda livre atinge a cabeça de bater. No intervalo de tempo $\left(t_{2}-t_{1}\right)$ a energia potencial inicial $U$ se transforma em energia cinética $T_{2}$, energia de deformação elástica $\left(V_{2}\right)$, proveniente das deformações da corda utilizada no ensaio com utilização do tripé, e trabalho realizado por forças não conservativas $\left(W_{2}\right)$. Esse trabalho é gerado por vários fatores, tais como o atrito no sistema corda-roldana, guia mal centralizada e utilização de coxins de madeira; 
4. No intervalo de tempo $\left(t_{3}-t_{2}\right)$ a onda percorre a cabeça-de-bater até atingir o topo das hastes. Neste momento as variações de trabalho, energia potencial e energia cinética podem ser desconsideradas;

5. No intervalo de tempo $\left(t_{4}-t_{3}\right)$, momento em que a onda percorre o conjunto de hastes, a energia cinética $\left(T_{3}\right)$ é reduzida para $T_{A}$. Todo o resto da energia é transformado em energia potencial $V_{e h}$ e em trabalho realizado por forças não conservativas no sistema, se modificando posteriormente no trabalho gerado durante o evento golpe do martelo antes da cravação do amostrador padrão no solo $\left(W_{q}\right)$, isso tudo devido ao tipo de haste, a flambagem que pode ocorrer em todo o conjunto e as deformações entre os encaixes das hastes. Cintra e Aoki (2000) recomendam a utilização da energia cinética $T_{A}$ no instante $t_{4}$, máxima energia que atinge o amostrador, para o cálculo da eficiência do ensaio SPT $\left(\eta^{*}\right)$. Nota-se que quanto maior o comprimento das hastes, menor é o valor de $T_{A}$;

6. No intervalo de tempo $\left(t_{5}-t_{4}\right)$ o amostrador penetra no solo, sendo o instante $t_{5} \mathrm{o}$ momento ocorre a máxima penetração e gera a transformação da energia cinética $\left(T_{A}\right)$ em energia potencial de deformação $(V)$;

7. Durante o intervalo $\left(t_{6}-t_{5}\right)$ uma pequena parcela da energia potencial de deformação $\left(V_{A}\right)$ se transforma em energia potencial elástica $\left(V_{e s}\right)$, por causa da deformação elástica do solo e do amostrador, e em trabalho realizado pelas forças resistentes não conservativas $\left(W_{p}\right)$ devido a penetração do amostrador no solo.

8. O final do evento, representado pelo instante $t_{6}$, é o momento em que toda a energia potencial elástica $\left(\mathrm{V}_{\mathrm{e}}\right)$ acumulada no conjunto de hastes $\left(V_{e h}\right)$ e no solo que envolve o amostrador $\left(V_{e s}\right)$ é liberada. Deste modo, o sistema entra em repouso e o trabalho das forças não conservativas $\left(W_{n c}\right)$ é composto pela parcela $W_{q}$ e $W_{p}$, que representam o trabalho final, gerado pelas forças não conservativas, mobilizadas ao longo do amostrador durante sua penetração no solo.

A partir das informações anteriores é possível escrever as seguintes equações:

$$
V_{e}=V_{e s}+V_{e h}
$$




$$
U=V_{e}+W_{n c}
$$

$$
T_{A}=V=V_{e s}+W_{p}
$$

Através da utilização do Principio de Hamilton no ensaio SPT, tem-se que entre o instante inicial $t_{1}$ e o instante final $t_{6}$, a energia potencial no sistema é transformada em energia potencial elástica e em trabalho das forças não conservativas. Sendo assim, Aoki e Cinta (2000) propõem a determinação da eficiência do ensaio SPT por meio do trabalho realizado para a penetração do amostrador no solo.

$$
\eta_{s}=W_{p} / U \times 100
$$

No qual $\eta_{s}$ representa a eficiência calculada através do trabalho realizado para penetrar o amostrador no solo.

\subsubsection{Determinação da eficiência do ensaio SPT mediante prova de carga estática sobre o amostrador padrão}

De acordo com os experimentos de Neves (2004), verificou-se que para o caso de areias e siltes arenosos, a eficiência do ensaio SPT pode ser calculada através de $W_{p, s}$ (trabalho gerado pelas forças resistentes não conservativas mobilizadas ao longo do amostrador durante sua penetração em um ensaio estático).

$$
W_{p, s}=\frac{n_{s} \cdot U}{100}(\%)
$$


Para tanto, $W_{p, s}$ corresponde ao trabalho inferido na prova de carga estática, $n_{s}$ é a eficiência calculada através deste trabalho e $U$ é a energia potencial normalizada do SPT que vale 478,3 J. O autor admite que para conhecer $W_{p, s}$, basta realizar uma prova de carga estática sobre o sistema, logo após a medição exata da penetração de um golpe do martelo do SPT, até atingir a penetração similar obtida no golpe dinâmico. A área sob a curva do ensaio estático, relativa a um deslocamento igual à penetração do último golpe do martelo, equivale ao valor de $W_{p, s}$ (Figura 9).

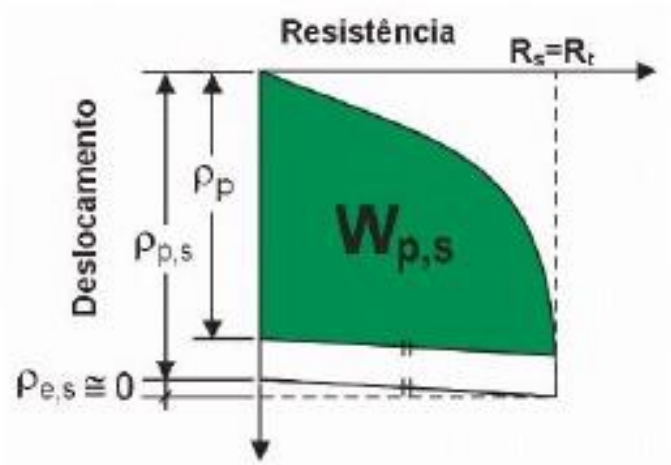

Figura 9 - Trabalho calculado através de uma prova de carga estática para a penetração obtido no último golpe dinâmico do martelo SPT (Neves, 2004).

Como mostrado em Neves (2004), sabendo-se que trabalho $(W)$ corresponde ao produto da resistência $(R)$ pelo deslocamento permanente $(s)$, pode-se considerar que:

$$
R=W / s
$$

Considerando-se que o deslocamento relativo a um golpe $s=30 \mathrm{~cm} / N_{s p t}$ :

$$
R_{s} \approx \frac{W_{p, s} \cdot\left[N_{s p t}\right]}{30}
$$

Por conseguinte, a equação abaixo pode chegar a um valor aproximado da resistência estática mobilizada $R_{S}$ do sistema amostrador-solo: 


$$
R_{s, s} \approx \frac{\eta_{s} \cdot U \cdot\left[N_{s p t}\right]}{30}
$$

Em que $R_{s, s}(N)$ simboliza aproximadamente à resistência estática mobilizada no sistema amostrador-solo para uma nega $s$, a eficiência do sistema é representada por $\eta_{s}$ $(\%)$ e a energia potencial normalizada do SPT corresponde a $U(J)$.

\subsection{Proposição de Aoki (2012)}

Aoki (2012) sugeriu um novo procedimento para o cálculo de capacidade de carga de estacas, baseado em novos parâmetros retirados de um ensaio SPT. Para este método é considerada a eficiência do sistema de ensaio e o equilíbrio de forças no amostrador durante o ensaio. Este autor mostra que para a realização deste equilíbrio de forças é necessário conhecer a medida do comprimento de solo recuperado dentro do amostrador ao final do ensaio $\left(\mathrm{L}_{\text {int }}\right)$

Como mostrado pela Equação 15, em razão da natureza não conservativa das forças atuantes (Aoki et al., 2007), a reação $R_{u}$ que o solo apresenta à penetração do amostrador vale:

$$
R_{u}=\left(\eta \times 467 \times N_{S P T}\right) / 0,3 \mathrm{~m}
$$

Onde, $\eta$ corresponde à eficiência do impacto sob o amostrador, que depende das condições do sistema de aplicação do impacto, do comprimento das hastes e do valor $N_{S P T}$.

Fundamentado no Princípio de Hamilton, e com o objetivo de interpretar a resistência de ponta $r_{p}$ e de atrito lateral $r_{l}$ do ensaio SPT, Cintra et al. (2013) apresentam uma interpretação do equilíbrio de forças no amostrador durante o impacto do martelo de peso $65 \mathrm{~kg}$ caindo de uma altura $0,75 \mathrm{~m}$, como mostra a Figura 10. 


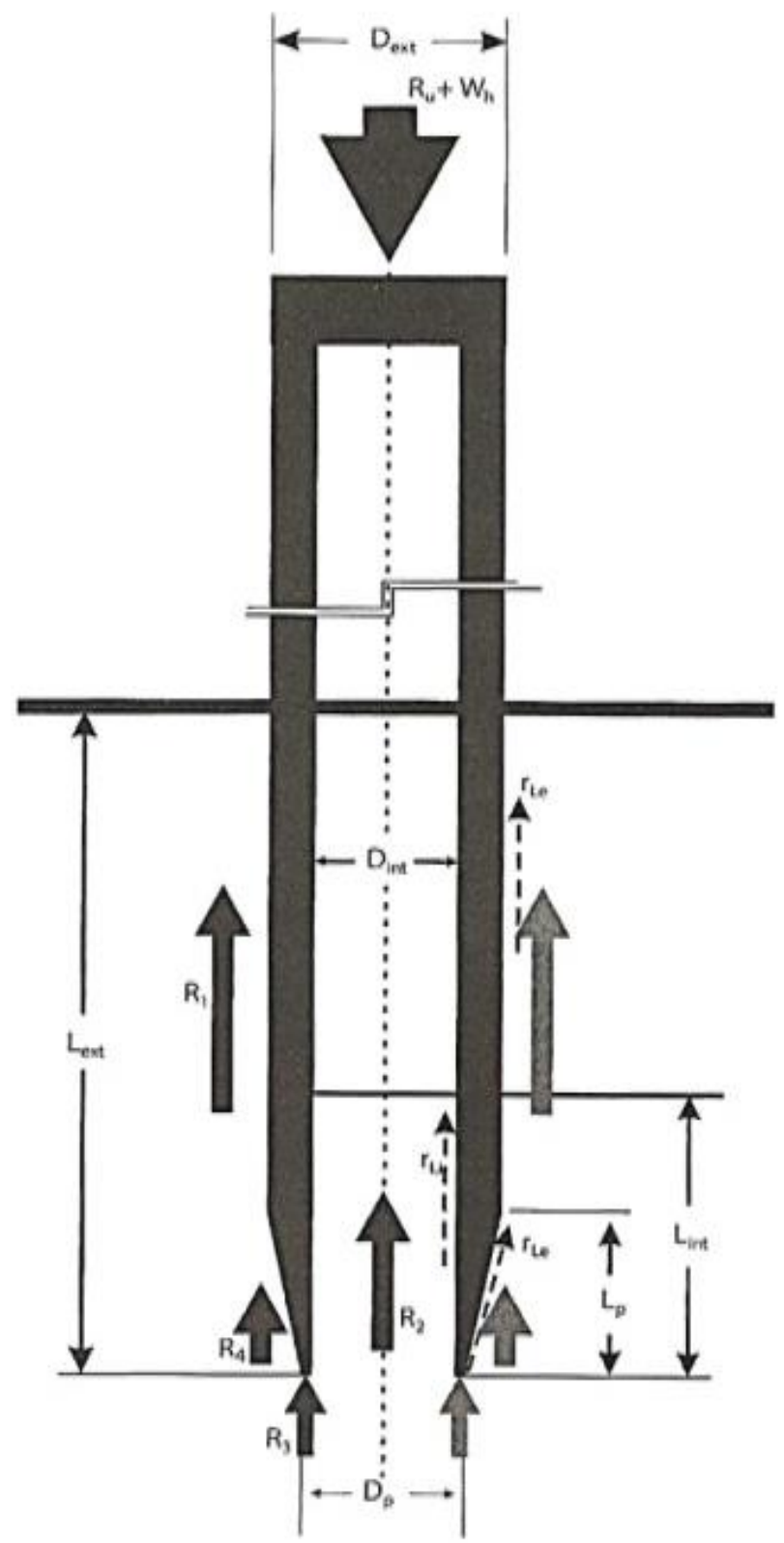

Figura 10- Equilíbrio das forças atuantes no amostrador durante o golpe no ensaio SPT (modificado de Cintra et al., (2013)).

Para o amostrador padrão no Brasil, temos as seguintes medidas (indicadas na Figura 12) padronizadas:

$D_{\text {ext }}=5,08 \mathrm{~cm}$;

$D_{\text {int }}=3,49 \mathrm{~cm} ;$

$D_{p}=3,81 \mathrm{~cm} ;$

$L_{p}=2,00 \mathrm{~cm}$ 
$L_{e x t}=45,00 \mathrm{~cm}$;

Na Figura 10, é indicado o parâmetro $L_{\text {int }}$ que representa o comprimento da recuperação do solo no amostrador ao final do ensaio. Como mostrado na Figura 11, o $L_{\text {ext }}$ é correspondente ao total penetrado pelo amostrador para obter o valor de $N_{S P T}$ (aproximadamente $45 \mathrm{~cm}$ ).

As tensões cisalhantes resistentes atuantes na interface solo-amostrador são:

$r_{L}=$ resistência por atrito na parede externa e no chanfro do amostrador

$r_{L i}=$ resistência por atrito na parede interna do amostrador

As forças resultantes no golpe são:

$R_{1}$ - força de atrito na parede vertical externa do amostrador;

$R_{2}$ - força de atrito na parede vertical interna do amostrador;

$R_{3}$ - força de reação vertical na seção anelar da ponta do amostrador;

$R_{4}$ - componente vertical da força de atrito ao longo da superfície biselada troncocônica do amostrador;

De acordo com Cintra et al. (2013), o equilíbrio estático das forças atuantes no amostrador permite escrever:

$$
R_{u}+W_{h}=R_{1}+R_{2}+R_{3}+R_{4}
$$

Em que:

$W_{h}$ - peso das hastes e cabeça de bater

$$
R_{u}=\eta x 6 \times 75 \times\left[\frac{\left(\frac{30}{N_{s p t}}+75\right)}{75}\right] \times \frac{N_{s p t}}{30}(\mathrm{kgf})
$$


As expressões das forças resistentes são:

$$
R_{1}=\pi x D_{\text {ext }} x\left(L_{\text {ext }}-L_{p}\right) \times r_{L}
$$

$\mathrm{Na}$ parede vertical interna do amostrador se desenvolve uma força correspondente a:

$$
R_{2}=\pi \times D_{\text {int }} \times r_{L i} \times L_{\text {int }}
$$

Considerando o atrito externo " $a$ " vezes menor que o atrito interno, temos:

$$
a=\frac{r_{L i}}{r_{L}}
$$

Pode-se escrever:

$$
R_{2}=\pi \times D_{\text {int }} \times \text { a } x r_{L} \times L_{\text {int }}
$$

O equilíbrio das forças atuantes na ponta do amostrador é interpretado pela Figura 11, sendo possível admitir que a força $R_{2}$ (atrito interno na parede do amostrador) é equivalente à resistência da ponta aberta do amostrador SPT, ou seja:

$$
R_{2}=\pi x \frac{D_{i n t^{2}}}{4} \times r_{p}
$$




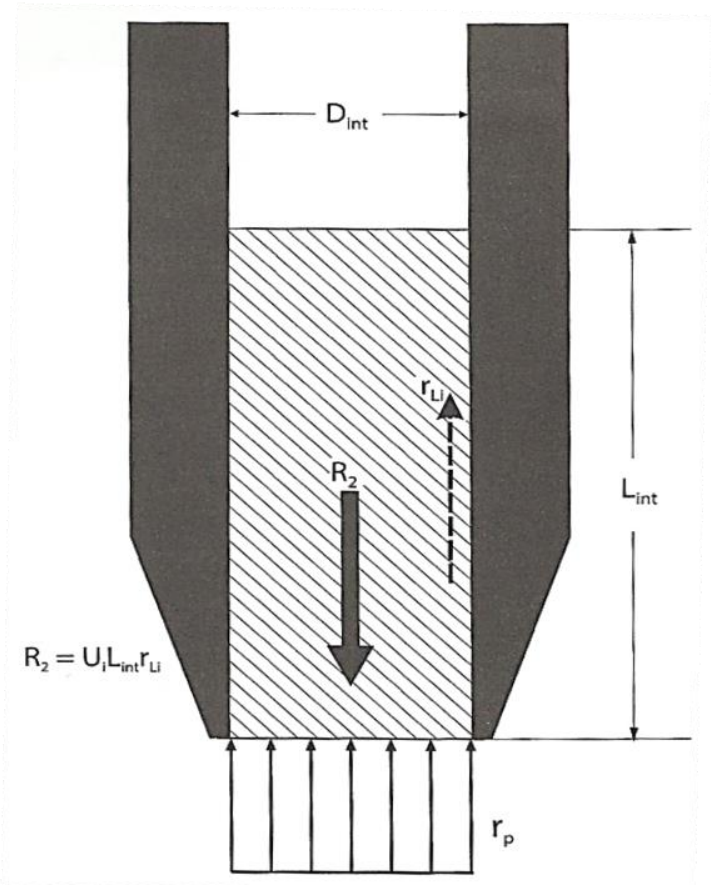

Figura 11 - Equilíbrio das forças atuantes na ponta aberta do amostrador (Cintra et al. (2013)).

Similarmente ao ensaio de cone CPT denomina-se razão de atrito $R_{f}$ ao número que relaciona o atrito lateral unitário (externo) e a resistência de ponta unitária do amostrador do ensaio de simples reconhecimento $N_{S P T}$ :

$$
R_{f}=\frac{r_{L}}{r_{p}}=\frac{r_{L i}}{a \times r_{p}}
$$

Logo, a razão de atrito pode ser determinada pela equação:

$$
R_{f}=\frac{D_{\text {int }}}{4 \times a \times L_{\text {int }}}
$$

As seguintes expressões podem ser utilizadas para determinação do restante das forças: 


$$
R_{3}=\frac{\pi}{4} x\left(D_{p}^{2}-D_{\text {int }}^{2}\right) x\left(r_{L} / R_{f}\right)
$$

$$
R_{4}=\left(S_{L} \times \frac{L_{p}}{L}\right) \times r_{L}
$$

Em que:

$$
\begin{gathered}
L=\left\{L_{p}^{2}+\left[\left(D_{\text {ext }}-D_{p)} / 2\right]^{2}\right\}^{0,5}\right. \\
S_{L}=\pi \times L \frac{\left(D_{\text {ext }}-D_{p}\right)}{2}
\end{gathered}
$$

Pelas considerações referenciadas, pode-se admitir que o atrito lateral entre o amostrador do ensaio SPT e o solo adjacente seja determinado pela expressão abaixo:

$$
r_{L}=\frac{R_{u}+W_{h}}{\pi x D_{\text {ext }}\left(L_{\text {ext }}-L_{p}\right)+\pi x D_{\text {int }} \times a \times L_{\text {int }}+\frac{\pi}{4} \times \frac{\left(D_{p}^{2}-D_{\text {int }}^{2}\right)}{R_{f}}+S_{L} \times \frac{L_{p}}{L}}
$$

Portanto, a resistência de ponta é deduzida pela seguinte equação:

$$
r_{p}=\frac{r_{L}}{R_{f}}
$$

Segundo Aoki (2012), conhecendo-se o valor da eficiência $\eta$, o valor $N_{S P T}$, o valor do comprimento de recuperação de solo no amostrador, e adotando-se um valor para $a$, é possível obter valores de resistência de ponta e de atrito lateral pelo ensaio SPT, utilizados em dimensionamento de resistência das estacas. 
A eficiência $\eta$ do ensaio não é considerada no método Aoki e Velloso (1975). Portanto, a determinação da medida do comprimento de recuperação da amostra juntamente com a eficiência possibilitam que o ensaio SPT proporcione valores de razão de atrito similares aos fornecidos pelo ensaio de cone, podendo assim, ser aplicado em métodos semi-empíricos como o de Aoki-Velloso (1975). 


\section{MATERIAIS E MÉTODOS}

Esta seção apresenta os materiais e métodos que foram utilizados para o desenvolvimento desta pesquisa, que é baseada em experimentos de campo e laboratório (caracterização da granulometria do solo amostrado).

\subsection{Procedimento para a determinação da resistência de ponta e por atrito lateral do ensaio SPT}

A nova proposta de SPT descrita e avaliada neste trabalho, baseada na proposta de Aoki (2012), é dividida em seis etapas:

1. Determinação da eficiência $\eta$ (taxa de energia fornecida) do equipamento de ensaio SPT. Neste trabalho a eficiência foi estimada pelo procedimento apresentado em Neves (2004), por meio de provas de carga à compressão no amostrador.

2. Estimativa da resistência à penetração estática $R_{u}$ mobilizada no amostrador durante um golpe (ilustrada na Figura 12) utilizando-se os resultados de eficiência do sistema $(\eta)$ e a Equação 17.

3. Determinação da resistência externa por atrito lateral do amostrador $R_{s e}$ a partir do ensaio de arrancamento estático realizado no amostrador logo após o ensaio dinâmico (descontar o peso das hastes + amostrador da carga de ruptura à tração obtida no ensaio).

4. Determinação da resistência de ponta do amostrador $R_{b}$ calculada pela diferença entre a resistência estática $R_{u}$ (adicionado ao peso $W$ da haste + cabeça de bater + amostrador, conforme descrito na Figura 12) e a resistência por atrito lateral obtida pelo ensaio de arrancamento $R_{s e}$. 
5. Determinação da resistência de ponta (em tensão) do ensaio SPT, denominada nesta pesquisa por " $q_{s p t}$ ", dividindo-se $R_{b}$ pela área da ponta, como descrito na Figura 12. Por simplificação, neste trabalho assume-se que o valor $q_{s p t}$ é uma combinação das tensões que atuam na área do anel e na área do solo recuperado no amostrador. No entanto, como a área de anel na base amostrador é insignificante (espessura do anel de 1,6 mm) em comparação com a área do solo $\left(D_{i}=34,9 \mathrm{~mm}\right.$ na Figura 12), a fração mais significativa de $q_{s p t}$ é equivalente ao atrito na parede interna do amostrador $\tau_{i}$ (Figura 12b).

6. Determinação da razão de atrito do ensaio SPT (relação entre o atrito lateral $f_{s^{-} s p t}$ e o $q_{s p t}$ descritos na Figura 12) para a classificação do solo.

(a)

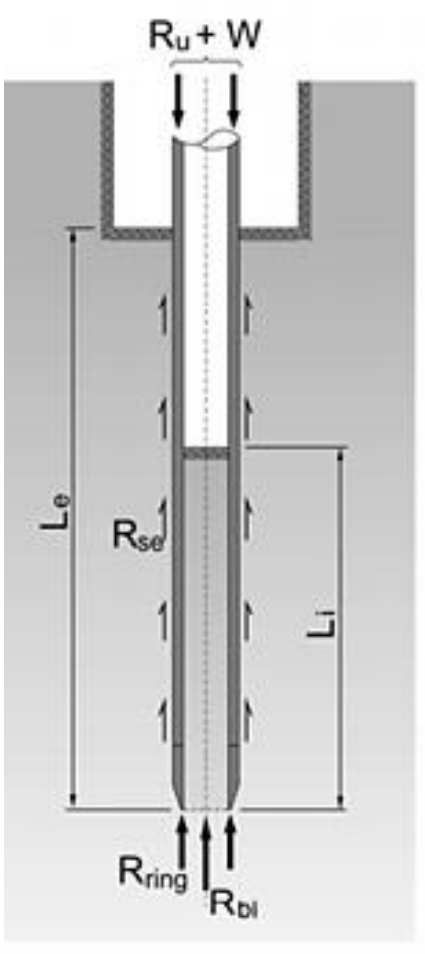

(b)

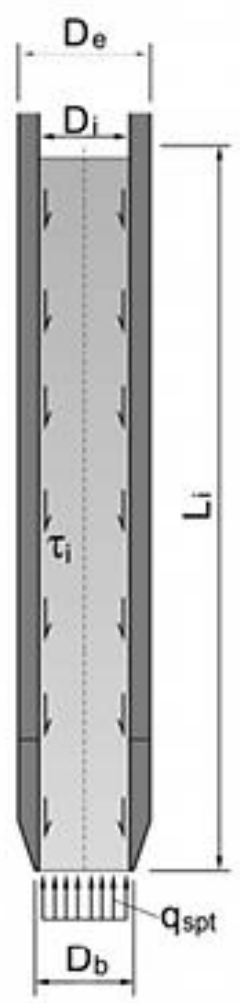

$D_{b}=$ diâmetro externo do anel na ponta do amostrador $(38,1 \mathrm{~mm})$

$\mathrm{D}_{\mathrm{e}}=$ diâmetro externo do amostrador $(50,8 \mathrm{~mm})$

$D_{i}=$ diâmetro interno do amostrador $(34,9 \mathrm{~mm})$

$\mathrm{L}_{0}=$ comprimento externo de penetração $(450 \mathrm{~mm})$

$L_{i}=$ comprimento de recuperação da amostra (variável)

$\mathrm{W}=$ peso das hastes+amostrador+cabeça de bater peso das hastes $=33 \mathrm{~N} / \mathrm{m}$ peso do amostrador $=58,9 \mathrm{~N}$ peso da cabeça de bater $=14,7 \mathrm{~N}$

$\mathrm{R}_{u}=$ resistência à penetração estática durante o ensaio

$R_{s e}=$ resistencia por atrito lateral (externo) no amostrador

$\mathrm{R}_{\mathrm{b}}=$ resistência de ponta da amostrador

Rring $=$ porção da resistencia de ponta atuante na área anelar do amostrador

$R_{b i}=$ porçăo da resistencia de ponta relativa à área do solo amostrado, devido ao atrito interno dentro do amostrador

$\tau_{\mathrm{i}}=$ atrito médio unitario médio na parede interna do amostrador

$\mathrm{fspt}_{\mathrm{sp}}=$ atrito lateral do ensaio SPT

$q_{s p t}=$ resistência de ponta do ensaio SPT

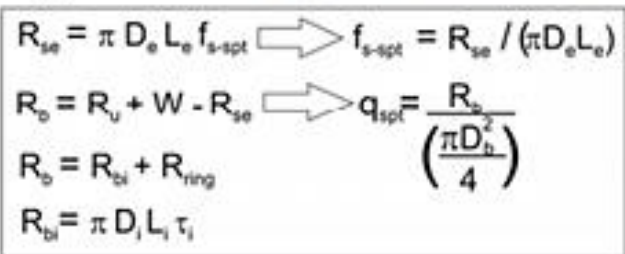

Figura 12 - Equilíbrio de forças no amostrador do ensaio SPT considerado nesta pesquisa. 
Para a determinação da resistência de ponta $q_{s p t}$ e o atrito lateral $f_{s p t}$ foram realizados nove ensaios de arrancamento (provas de carga à tração) em três furos de sondagem distintos (furos 1, 2 e 3), e em três profundidades distintas. O objetivo era realizar os ensaios três camadas distintas, portanto, para identificar estas camadas, antes de iniciar a pesquisa foram realizados dois furos prévios de sondagem com ensaio SPT (SP-01 e SP-02).

Nos três furos de ensaio, para avaliarmos o parâmetro " $a$ " descrito em Aoki (2012) e em Cintra et al. (2013), também foram feitas medidas do comprimento das amostras de solo no amostrador (recuperação) nas três profundidades ensaiadas.

Um quarto furo de sondagem (furo 4) foi realizado a fim de obter-se a eficiência do equipamento mecanizado utilizado nesta pesquisa, foram executadas duas provas de cargas estáticas a compressão no topo da haste do amostrador. A seguir são detalhados os equipamentos utilizados e os ensaios.

\section{2 Área Experimental}

Os ensaios foram realizados no pátio da Geometa Eng. de Fundações e Indústria Ltda., que fica localizado na Av. Bernardo Seibel 171, em Uberaba-MG. A Figura 13 indica a localização mencionada.

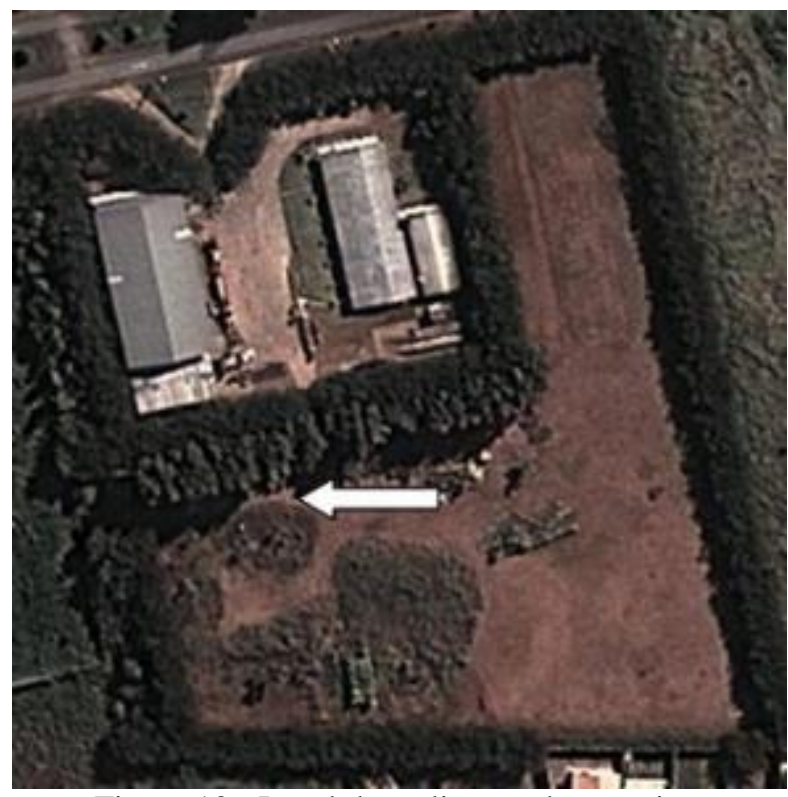

Figura 13 - Local de realização dos ensaios. 
A escolha do local para a realização dos ensaios deste trabalho foi devido à profundidade do perfil de solo, viabilidade financeira e ao apoio da empresa para a realização dos ensaios. Para conhecer o subsolo da área experimental, foram realizadas duas sondagens de simples reconhecimento com medida $N_{S P T}$, a fim se obter o provável perfil de solo. A Figura 14 e a Figura 15 apresentam os resultados obtidos.

A partir dos dados apresentados nas Figuras 14 e 15, é possível observar que a classificação tátil-visual do subsolo resultou em variações de camadas com argila arenosa e argila siltosa até a profundidade impenetrável. O nível freático foi encontrado em torno de 7,20 m de profundidade, os valores de $N_{S P T}$ variaram basicamente entre 5 a 20 golpes $/ 30 \mathrm{~cm}$ e o impenetrável foi encontrado a $16,30 \mathrm{~m}$. Juntamente com a sondagem SP-01, foi realizado o monitoramento do comprimento das amostras recuperadas. Os resultados preliminares são apresentados na Tabela 1:

Tabela 1- Resultados de comprimento da recuperação.

\begin{tabular}{ccc}
\hline Profundidade $(\mathrm{m})$ & $\begin{array}{c}\mathrm{N}_{\mathrm{SPT}} \\
\text { (golpes/cm) }\end{array}$ & $\begin{array}{c}\text { Comprimento da } \\
\text { amostra de solo }(\mathrm{m})\end{array}$ \\
\hline 1 & $6 / 30$ & 0,22 \\
2 & $6 / 31$ & 0,34 \\
3 & $8 / 30$ & 0,21 \\
4 & $7 / 30$ & 0,25 \\
5 & $8 / 30$ & 0,33 \\
6 & $8 / 30$ & 0,30 \\
7 & $7 / 32$ & 0,29 \\
8 & $14 / 30$ & 0,20 \\
9 & $8 / 30$ & 0,29 \\
10 & $19 / 30$ & 0,26 \\
11 & $15 / 30$ & 0,32 \\
12 & $10 / 30$ & 0,60 \\
13 & $13 / 30$ & 0,48 \\
14 & $14 / 30$ & 0,33 \\
15 & $19 / 30$ & 0,25 \\
16 & $60 / 16$ & 0,38 \\
\hline
\end{tabular}


geometa FUNDAÇŌES

SONDAGEM DE SIMPLES RECONHECIMENTO DO SOLO COM SPT NBR 6484/01

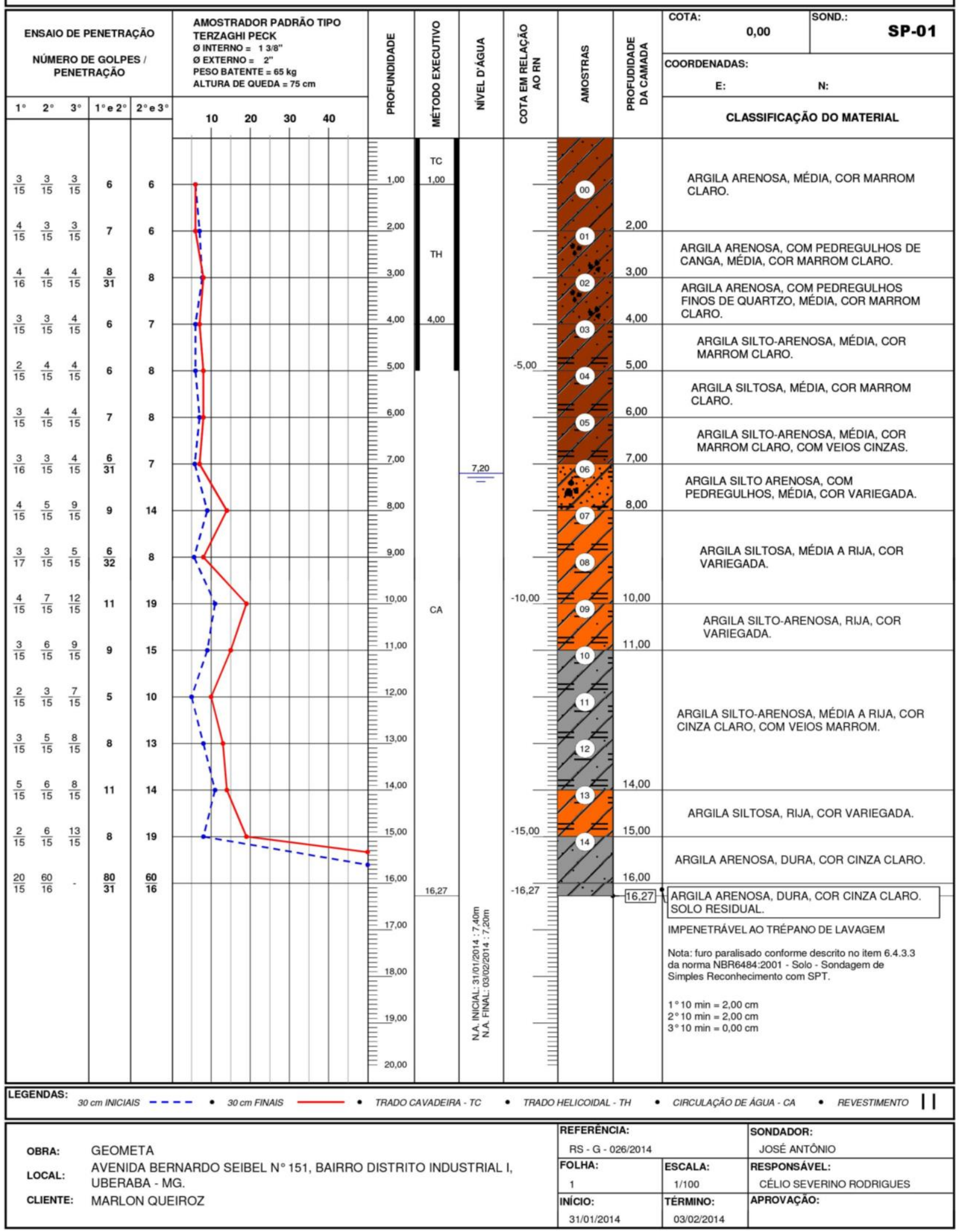

Figura 14 - Resultados da sondagem SP-01. 


\section{geometa FUNDACOES \\ SONDAGEM DE SIMPLES RECONHECIMENTO DO SOLO COM SPT NBR 6484/01}

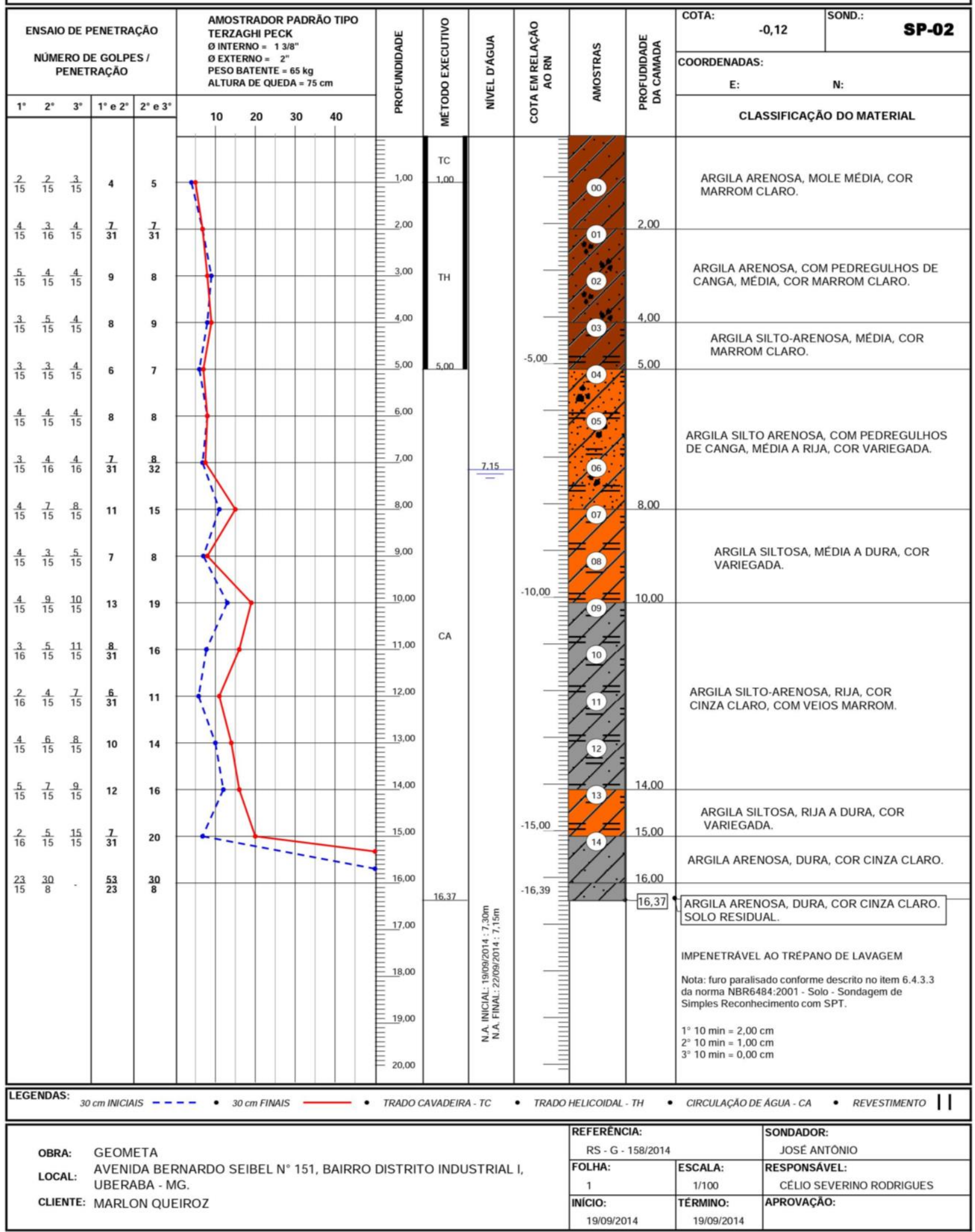

Figura 15 - Resultados da sondagem SP-02. 
A Figura 16 apresenta uma medida da recuperação do solo amostrado:

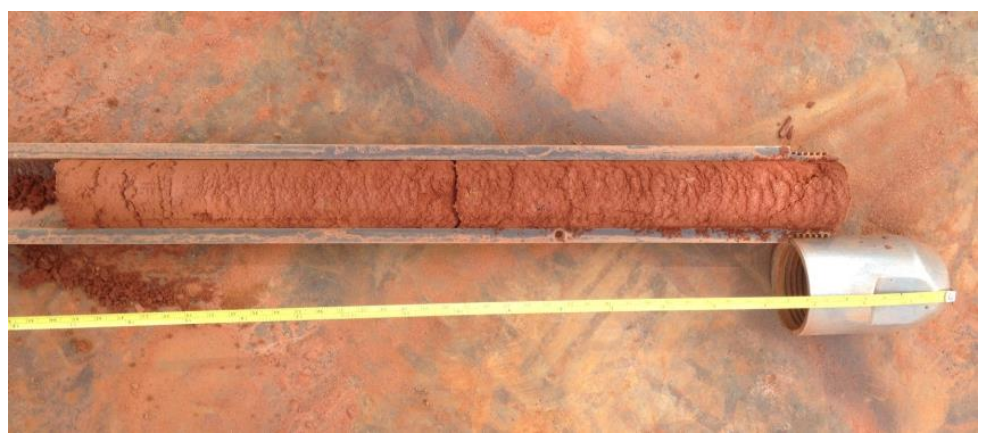

Figura 16 - Medida de recuperação de solo amostrado.

Como citado anteriormente, foram realizados quatro furos em pontos com aproximadamente cinco metros de distância entre eles. Em três destes furos (Furos 1, 2 e 3) foram realizados, ensaios de arrancamento do amostrador conduzidos em três profundidades distintas: 2, 5 e 10 metros respectivamente. Portanto, ao todo foram realizados nove ensaios de tração no amostrador.

Um quarto furo (Furo 4) foi necessário para realização de duas provas de carga estática a compressão no conjunto haste + amostrador SPT, nas profundidades de 2 e 5 metros, com objetivo de conhecer a eficiência do equipamento pelo procedimento sugerido em Neves (2004). A Figura 17 apresenta a locação em planta dos quatro furos realizados para os ensaios e também a locação das duas sondagens SPT executadas para prévia verificação do tipo de solo estudado. 


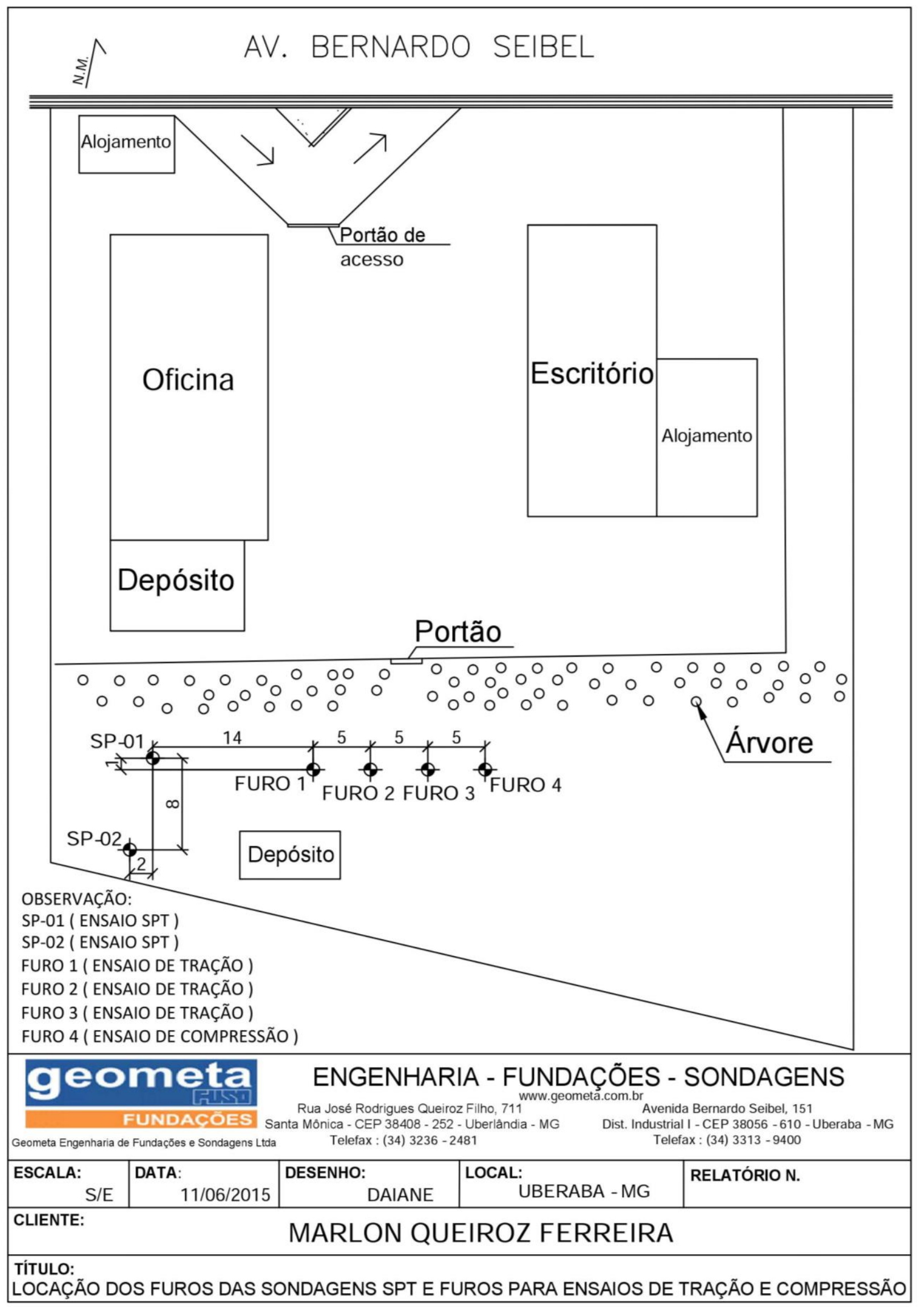

Figura 17 - Locação dos furos. 


\subsection{Equipamento de Sondagem}

Os furos de sondagem realizados neste trabalho foram executados utilizando-se os equipamentos recomendados pela norma NBR 6484 (2001), com exceção do martelo e da cabeça de bater. Esta norma especifica tanto os equipamentos como os procedimentos a serem seguidos para a execução da sondagem de simples reconhecimento com medida do SPT.

O equipamento de sondagem utilizado constitui-se de um conjunto torre + guincho + motor + bomba que reúne todos os equipamentos utilizados nas sondagens SPT em um único módulo. A Figura 18 (a) mostra uma fotografia do equipamento. $\mathrm{O}$ martelo utilizado é do tipo vazado com coxim de madeira e gatilho rápido de acionamento automático para a queda livre, que cai da altura constante de $0,75 \mathrm{~m}$ (Figura 18 (b)).

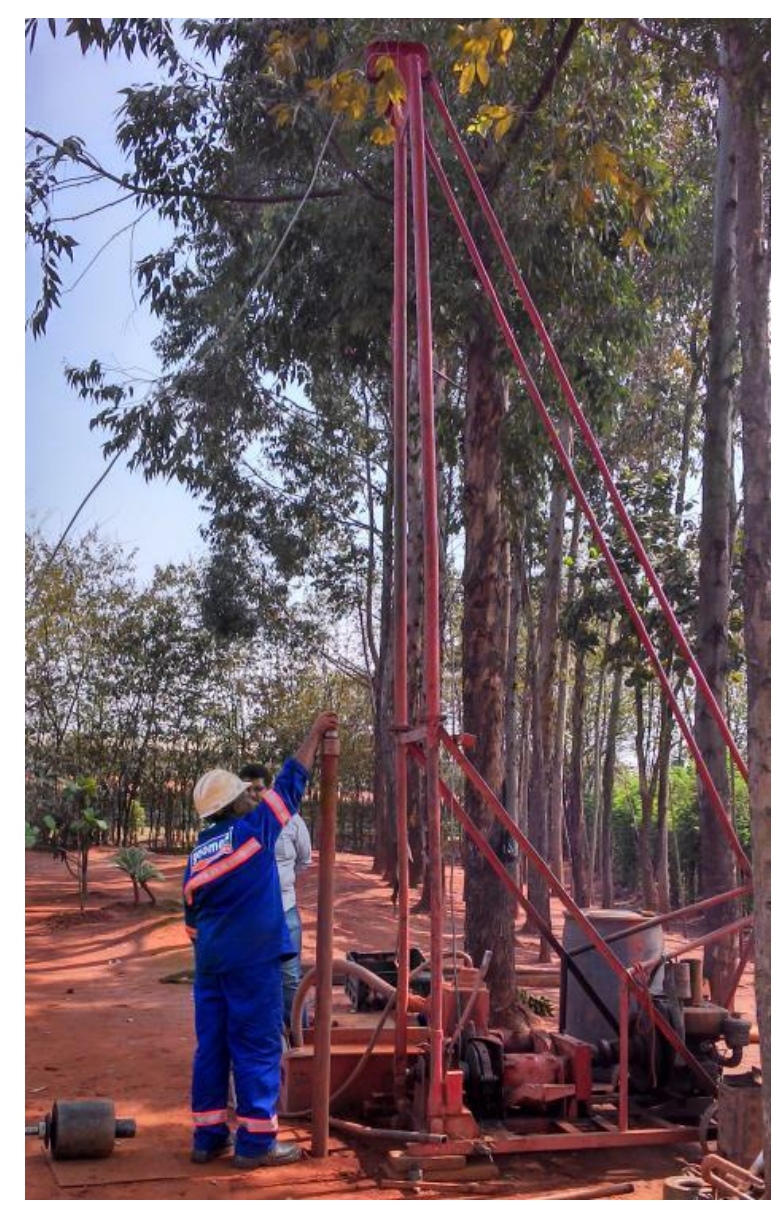

(a)

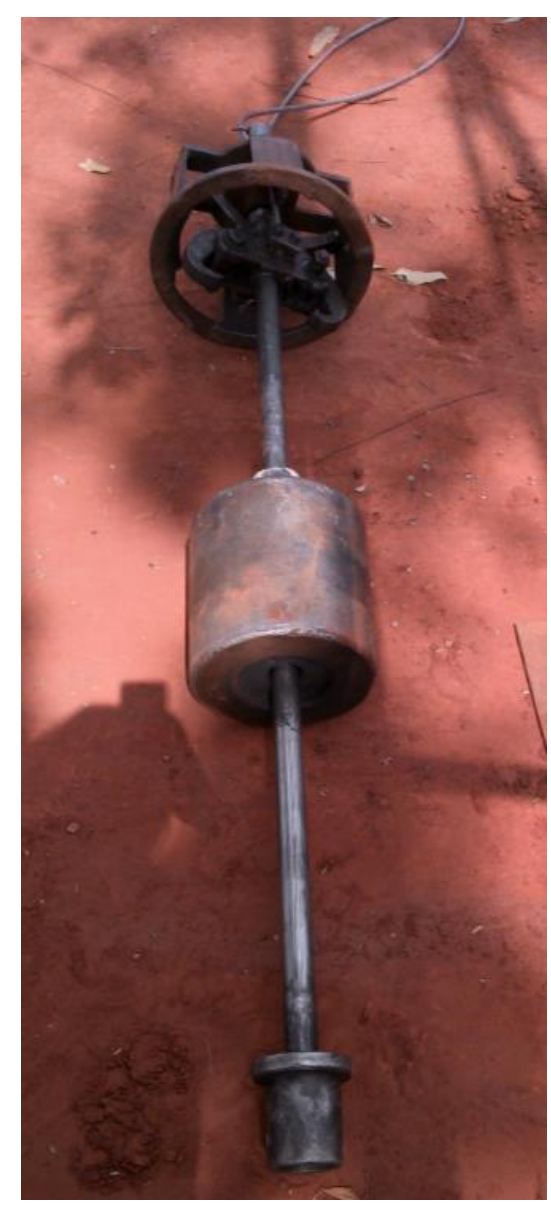

(b)

Figura 18 - Equipamento de sondagem a ser utilizado na realização dos ensaios: (a) vista geral e (b) detalhe do martelo. 
As especificações dos equipamentos utilizados neste trabalho são: conjunto de hastes com diâmetro externo de 33,34 mm, diâmetro interno de 23,94 mm e massa teórica de 3,60 kg/m; cabeça de bater com $53 \mathrm{~mm}$ de altura e diâmetro de $54 \mathrm{~mm}$; amostrador tipo Raymond bipartido, com comprimento de $610 \mathrm{~mm}$, diâmetro externo de $50,8 \mathrm{~mm}$ e interno de $34,9 \mathrm{~mm}$; martelo vazado de $65 \mathrm{~kg}$, com coxim de madeira e queda por acionamento via sistema de gatilho.

\subsection{Ensaio de arrancamento do amostrador}

Para realização dos ensaios de arrancamento do amostrador foi projetado e construído um sistema de reação, cujo esquema é apresentado na Figura 19:

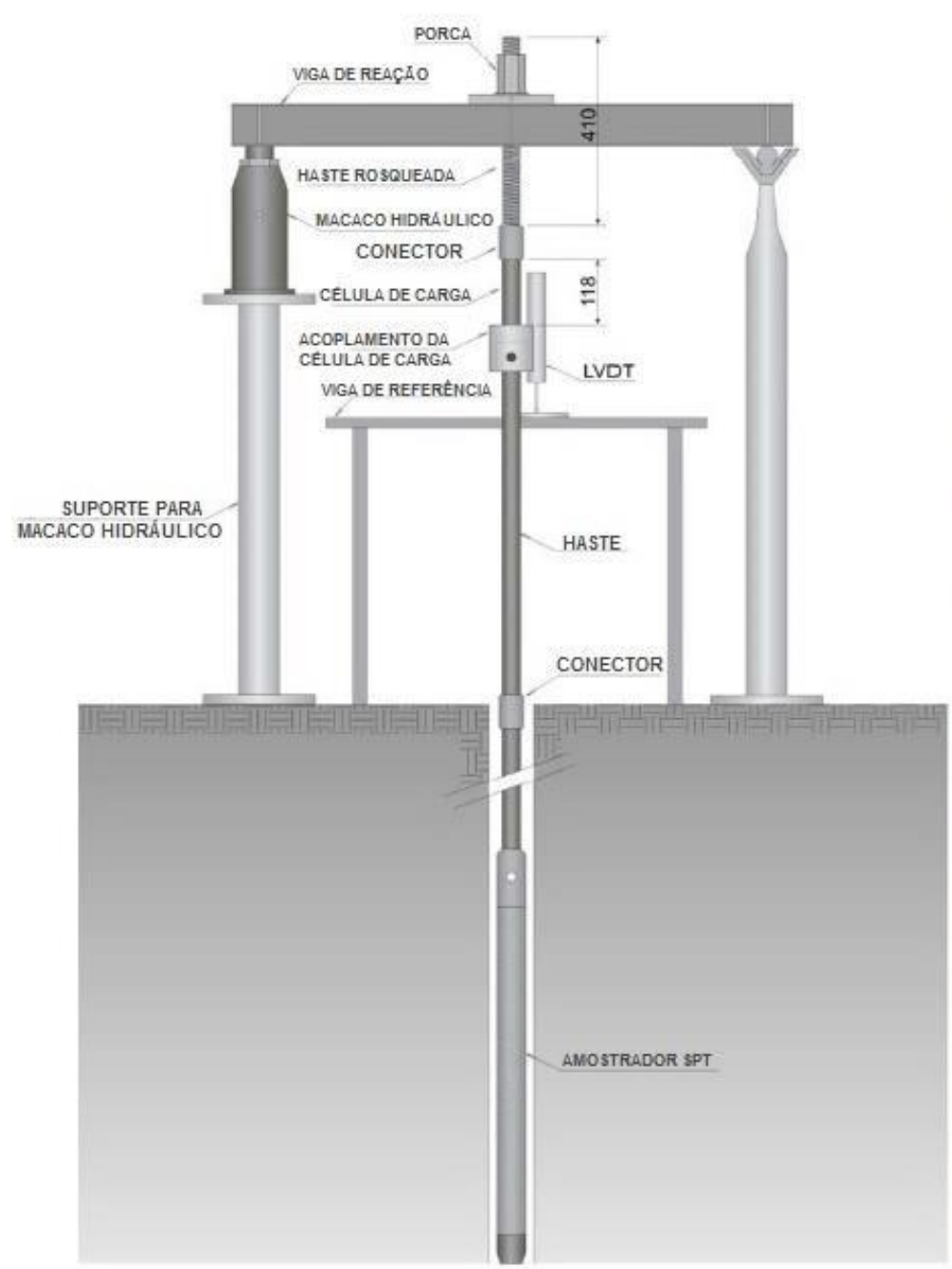

(a)

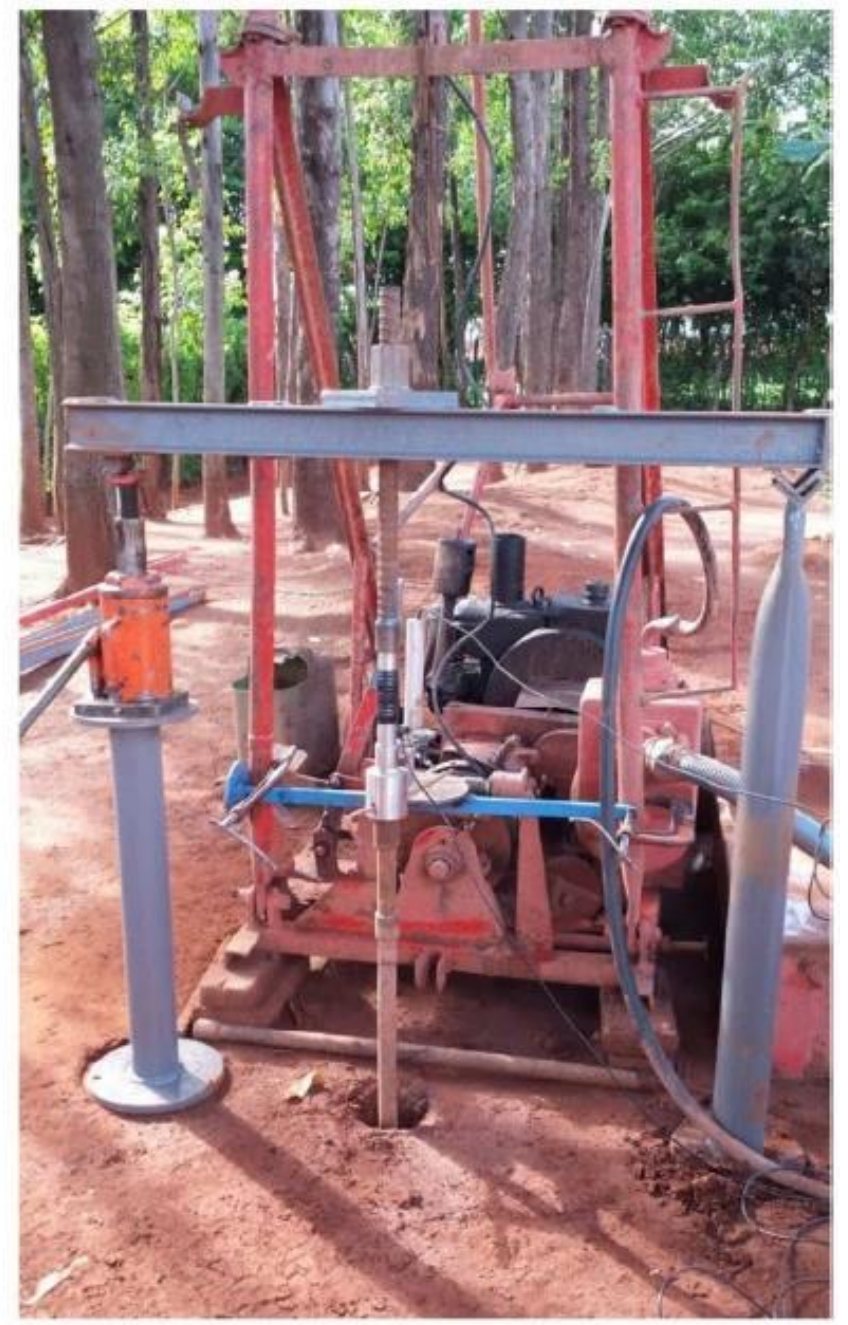

(b)

Figura 19 - Equipamentos para ensaios de arrancamento: (a) desenho esquemático e (b) montagem do ensaio. 
Cada ensaio de arrancamento foi realizado imediatamente após o ensaio SPT, para simular a mesma condição não drenada do ensaio SPT. Nos ensaios de arrancamento, a carga de tração foi aplicada manualmente por meio de um macaco hidráulico posicionado abaixo da viga de reação, pois não se dispunha de macaco vazado, que seria naturalmente indicado para este tipo de ensaio. O tempo para a realização de cada ensaio variou entre 1,2 e 2 minutos. A velocidade de carregamento variou entre 18 a $35 \mathrm{~mm} / \mathrm{s}$.

Durante o ensaio, os valores de carga de tração aplicada na haste foram obtidos por uma célula de carga com capacidade de $250 \mathrm{~N}$ e precisão de $5 \mathrm{~N}$, confeccionada a partir de um segmento de tubo igual ao das hastes da sondagem e extensômetros elétricos de resistência arranjados em ponte de Wheatstone. Antes de sua utilização, a célula de carga foi devidamente calibrada em uma prensa do departamento de Geotecnia da USP - São Carlos, conforme apresentado nas Figuras 20 e 21.

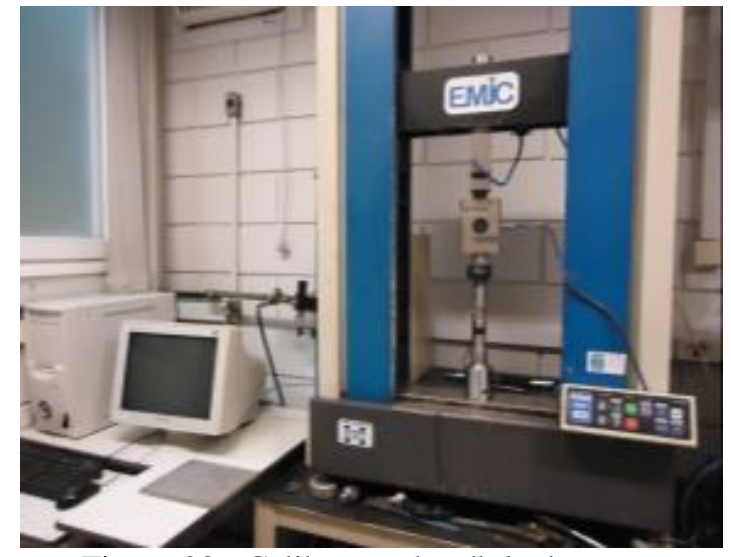

Figura 20 - Calibração da célula de carga.

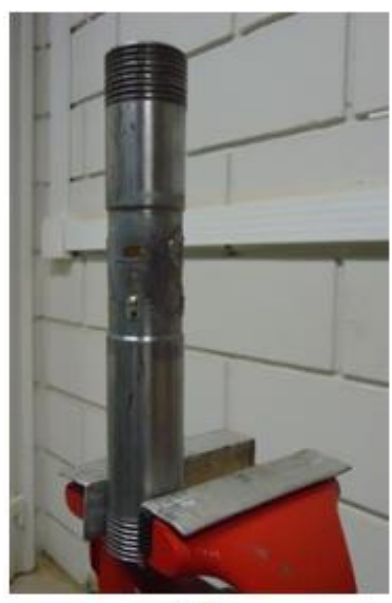

(a)

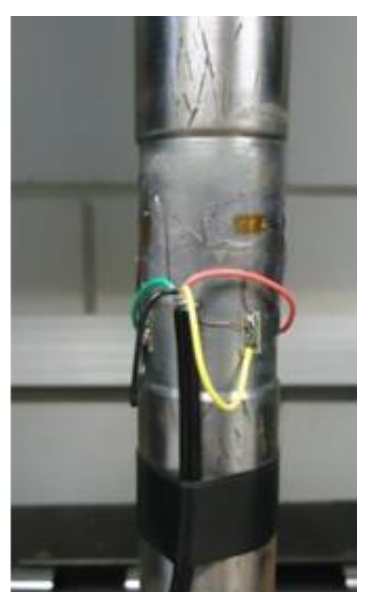

(b)

Figura 21 - Equipamento para monitoramento do carregamento: (a) Segmento de tubo semelhante ao das hastes e (b) célula de carga. 


\subsection{Prova de carga à compressão no amostrador para determinação da eficiência do sistema de ensaio}

Como comentado anteriormente, a medida da eficiência do equipamento do ensaio SPT é essencial para a interpretação dos resultados deste ensaio, e pode ser obtida por meio de prova de carga estática no sistema haste-amostrador como descrito em Neves (2004).

Do mesmo modo, conhecendo-se a eficiência e o valor do deslocamento do amostrador para um golpe, por meio da Equação 17 é possível estimar a resistência total $R_{u}$ mobilizada na penetração do amostrador no solo.

Portanto, para a determinação da eficiência do equipamento, foram realizados dois ensaios de prova de carga estática no sistema hastes + cilindro vazado do amostrador, logo após a medida do valor $N_{S P T}$, nas profundidades pré-determinadas de dois e cinco metros no furo 4 (Figura 17).

Todos os ensaios foram realizados com estágios de carregamentos mantidos constante. A leitura era realizada a cada minuto até o momento em que duas consecutivas acusassem diferenças inferiores a $0,5 \mathrm{~mm}$. Quando este parâmetro fosse

atingido, um novo incremento de carga era então colocado. $\mathrm{O}$ descarregamento era efetuado em quatro estágios de igual magnitude.

A eficiência do sistema no topo do amostrador foi obtida por meio do trabalho realizado pelas forças não conservativas nas provas de carga estática, então determinado com base na curva carga-recalque do ensaio.

Para aplicação da carga aplicada no ensaio foi utilizado o mesmo macaco hidráulico acionado manualmente empregado no ensaio de tração, e como reação foi usado um caminhão munck com $14.800 \mathrm{~kg}$ (vazio) disponibilizado pela empresa Geometa. Para as leituras de carga e deslocamento das provas de carga, foi utilizado um sistema de aquisição de dados. 
O sistema de leitura do deslocamento é composto por medidores de deslocamento do tipo LVDT (Linear Variable Differential Transformer) e relógio comparador, fixados em uma haste de referência, ligados a um sistema de aquisição de dados para leitura da instrumentação (no caso do LVDT). Para as leituras das cargas aplicadas, foi empregada uma célula de carga (a mesma dos ensaios de tração).

Os equipamentos e a execução do ensaio de compressão são apresentados nas Figuras 22 e 23.

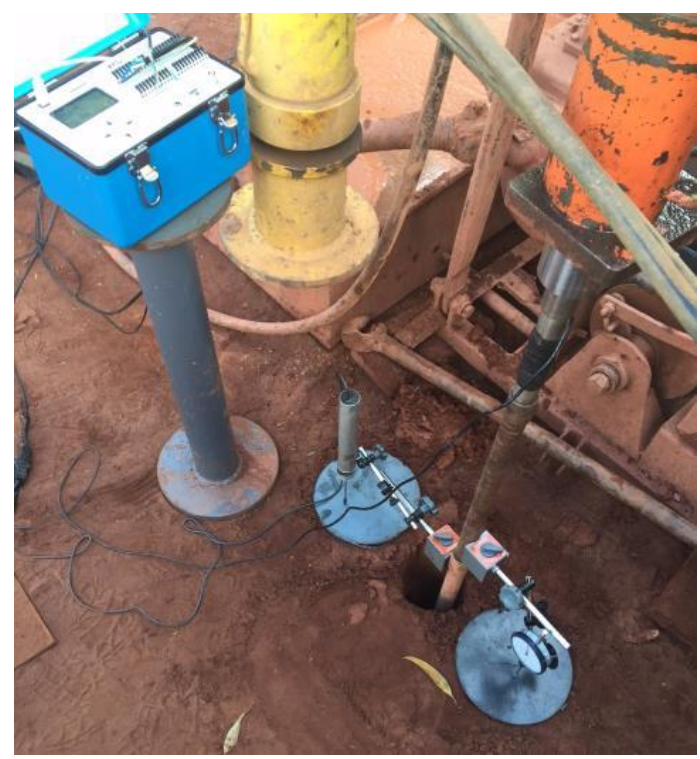

Figura 22 - Sistema de prova de carga com relógio magnético + medidor LVDT + equipamento com célula de carga + sistema de aquisição de dados.

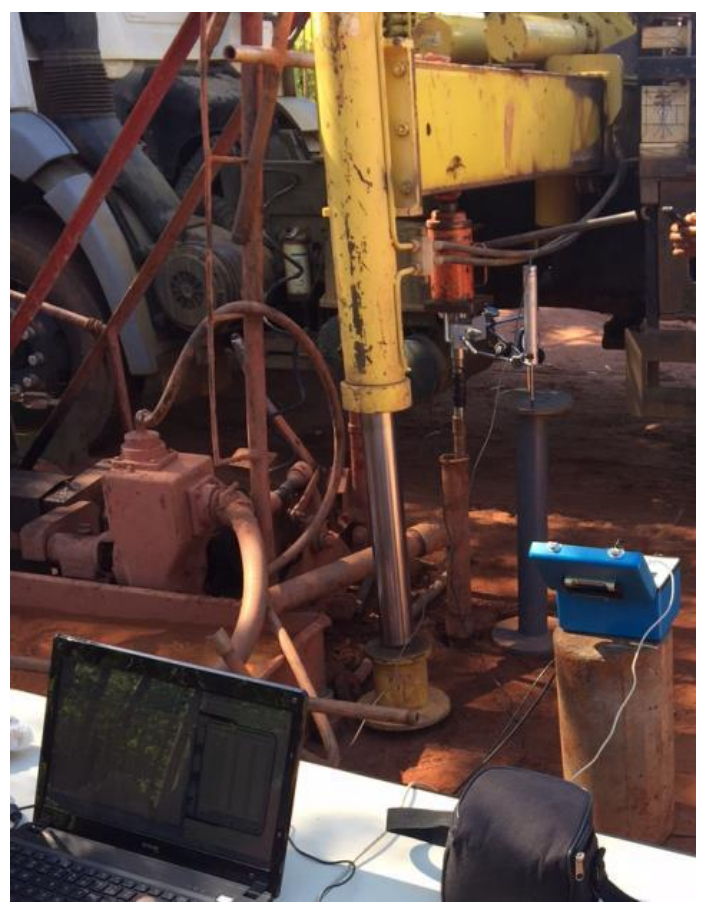

Figura 23 - Prova de carga estática na haste do amostrador. 


\section{RESULTADOS}

\subsection{Resultados dos ensaios de arrancamento no conjunto haste + amostrador}

Para cada uma das profundidades ensaiadas, são apresentadas as Figuras 24, 25 e 26 as curvas carga x deslocamento dos ensaios de arrancamento no amostrador, realizados imediatamente após um ensaio SPT padrão.

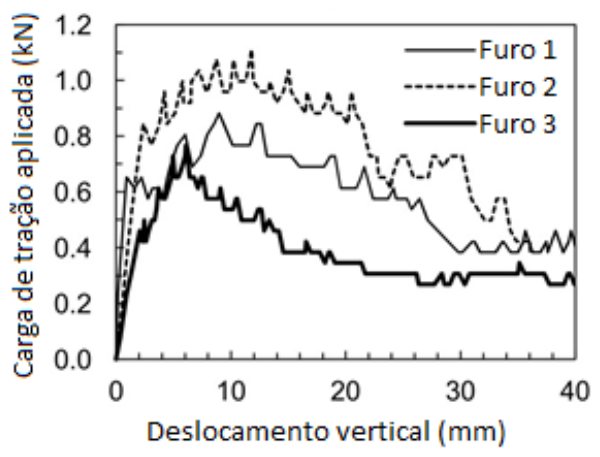

Figura 24- Curva carga $\mathrm{x}$ deslocamento dos ensaios realizados no amostrador a $2 \mathrm{~m}$ de profundidade.

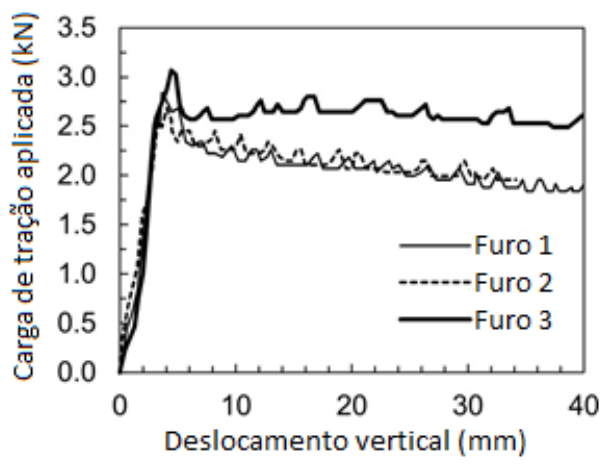

Figura 25- Curva carga $\mathrm{x}$ deslocamento dos ensaios realizados no amostrador a $5 \mathrm{~m}$ de profundidade.

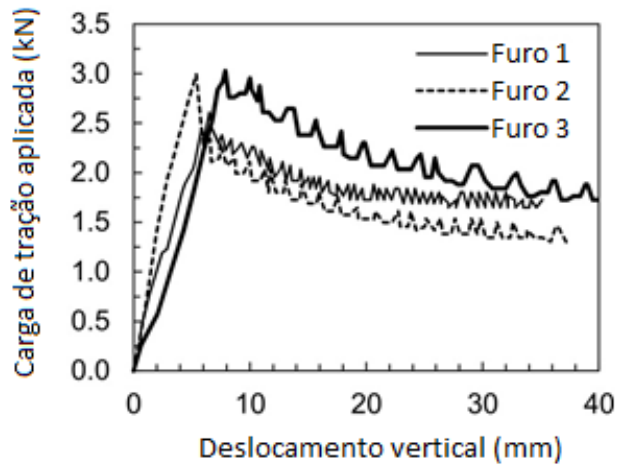

Figura 26- Curva carga x deslocamento dos ensaios realizados no amostrador a 10m de profundidade. 
A Tabela 2 apresenta-se os resultados de carga de ruptura $Q_{u}$ obtidos nos ensaios de arrancamento, juntamente com os valores de $N_{s p t}$, do comprimento de recuperação da amostra $L_{i}$ obtidos para cada ensaio, da resistência por atrito lateral externo no amostrador $R_{s e}$ (onde, $R_{s e}$ equivale a $Q_{u}$ subtraindo-se o peso de hastes e amostrador), e de $f_{s-s p t}$ (que é igual a $R_{s e}$ dividida pela área externa de contado solo-amostrador)

Nesta pesquisa, para estimar o valor da resistência por atrito lateral externo no amostrador durante o golpe de ensaio $R_{s e}$ (ver Figura 12a), assume-se por simplificação que a resistência por atrito lateral obtida à tração pelo ensaio de arrancamento é a mesma mobilizada no golpe do ensaio SPT (à compressão).

Tabela 2 - Resultados dos ensaios de arrancamento do amostrador.

\begin{tabular}{ccccccc}
\hline $\begin{array}{c}\text { Profundidade } \\
(\mathrm{m})\end{array}$ & Furo & $\begin{array}{c}L i \\
(\mathrm{~m})\end{array}$ & $\begin{array}{c}N_{s p t} \\
(\mathrm{golpes} / \\
30 \mathrm{~cm})\end{array}$ & $\begin{array}{c}\text { Carga de } \\
\text { ruptura } \\
Q_{u} \\
(\mathrm{kN})\end{array}$ & $\begin{array}{c}\text { Resistencia por } \\
\text { atrito lateral } \\
\text { externo } \\
R_{s e} \\
(\mathrm{kN})\end{array}$ & $\begin{array}{c}f_{s-s p t} \\
(\mathrm{kPa})\end{array}$ \\
\hline \multirow{2}{*}{2.0} & 1 & 0.25 & 6 & 0.88 & 0.72 & 10.0 \\
& 2 & 0.36 & 10 & 1.11 & 0.95 & 13.2 \\
& 3 & 0.38 & 17 & 0.77 & 0.61 & 8.5 \\
\hline \multirow{2}{*}{5.0} & 1 & 0.25 & 7 & 2.84 & 2.58 & 35.9 \\
& 2 & 0.21 & 7 & 2.68 & 2.42 & 33.7 \\
& 3 & 0.21 & 7 & 3.07 & 2.81 & 39.1 \\
\hline \multirow{2}{*}{10.0} & 1 & 0.21 & 14 & 2.61 & 2.18 & 30.4 \\
& 2 & 0.21 & 15 & 2.99 & 2.56 & 35.7 \\
& 3 & 0.21 & 22 & 3.03 & 2.60 & 36.3 \\
\hline
\end{tabular}

\subsection{Resultado dos ensaios de compressão para determinação da eficiência}

Como comentado anteriormente, foi realizado um quarto furo de sondagem (Furo 4) para a realização de provas de carga a compressão em duas profundidades distintas (2 e $5 \mathrm{~m}$ ), para a determinação da eficiência do equipamento no ensaio (de acordo com Neves 2004).

A Tabela 3 apresenta para as profundidades de 2,0 e 5,0 m do Furo 4: o valor de $N_{S P T}$ da camada, a medida do comprimento de recuperação do solo no amostrador, e a carga máxima aplicada no ensaio. As Figuras 27 e 28 apresentam as curvas carga x recalque das provas de carga à compressão realizadas a $2 \mathrm{~m}$ e a $5 \mathrm{~m}$ de profundidade. 


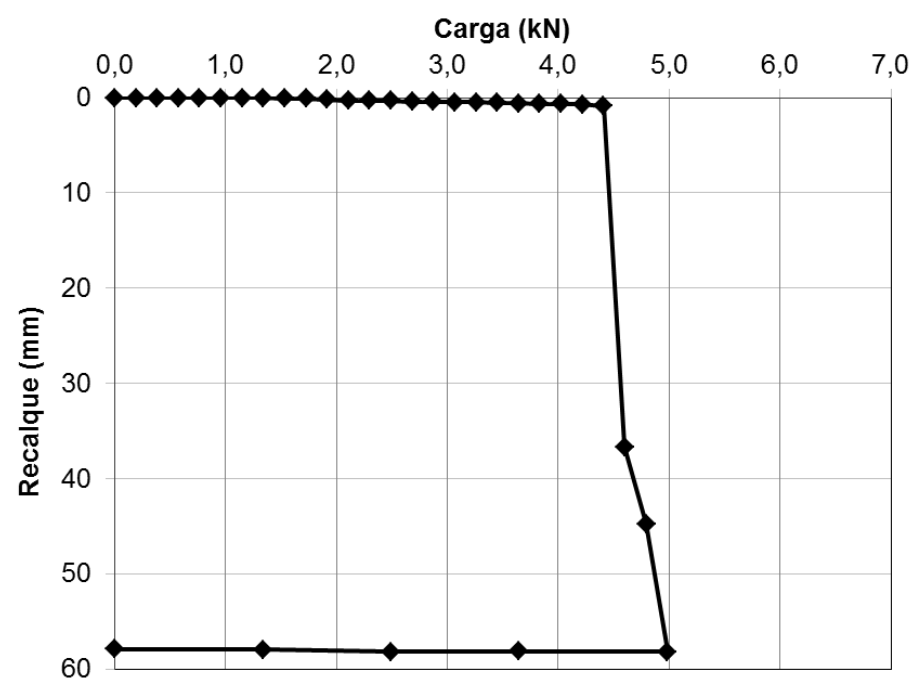

Figura 27 - Curva carga x recalque da prova de carga a compressão a 2,0 m de profundidade.

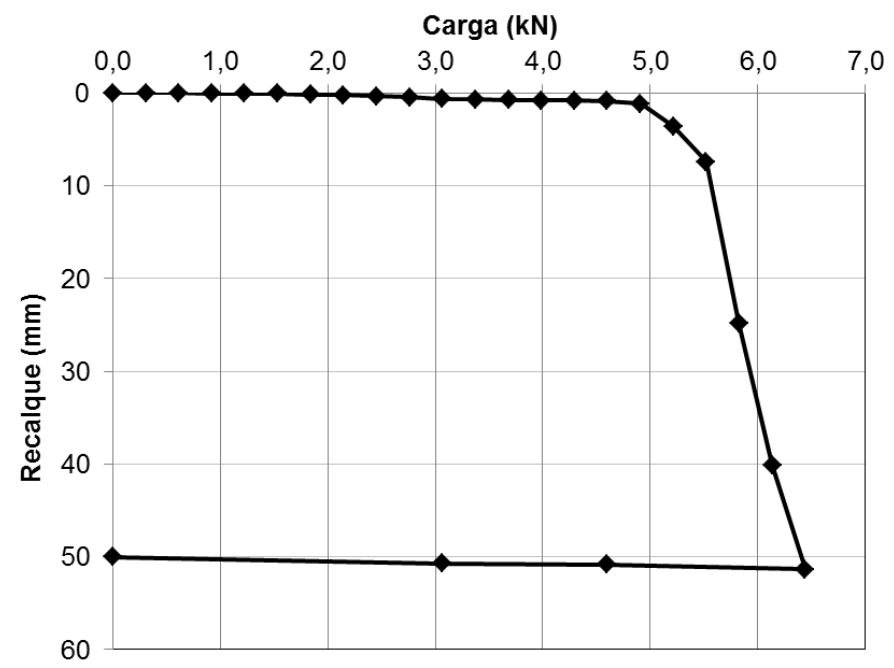

Figura 28 - Curva carga x recalque da prova de carga a compressão a 5,0 $\mathrm{m}$ de profundidade.

Tabela 3 - Resultados das provas de carga a compressão no Furo 4.

\begin{tabular}{cccc}
\hline $\begin{array}{c}\text { Profundidade } \\
(\mathrm{m})\end{array}$ & $\begin{array}{c}N_{S P T} \\
(\text { golpes/cm) }\end{array}$ & $\begin{array}{c}L_{i} \\
(\mathrm{~cm})\end{array}$ & $\begin{array}{c}\text { Carga Max. } \\
(\mathrm{kgf})\end{array}$ \\
\hline 2,0 & $6 / 30$ & 26 & 508,0 \\
5,0 & $8 / 31$ & 27 & 656,5 \\
\hline
\end{tabular}

Para a determinação da eficiência, calcula-se a área sob a curva do gráfico obtido pela prova de carga estática, correspondente ao deslocamento resultante de um único golpe do ensaio $\left(s_{m}\right)$ : 


$$
s_{m}=300 / N_{S P T}
$$

A Tabela 4 apresenta os valores do deslocamento para um golpe de martelo nas duas profundidades ensaiadas ( $2 \mathrm{~m}$ e $5 \mathrm{~m})$.

Tabela 4 - Deslocamento correspondente a um golpe do ensaio SPT.

\begin{tabular}{ccc}
\hline $\begin{array}{c}\text { Profundidade } \\
(\mathrm{m})\end{array}$ & $\begin{array}{c}N_{S P T} \\
(\text { golpes } / \mathrm{cm})\end{array}$ & $\begin{array}{c}s_{m} \\
(\mathrm{~mm})\end{array}$ \\
\hline 2,0 & $6 / 30$ & 50,0 \\
5,0 & $8 / 31$ & 38,7 \\
\hline
\end{tabular}

Para um valor mais preciso da eficiência é importante descontar na curva carga $\mathrm{x}$ deslocamento a parcela do encurtamento elástico da haste $\left(\rho_{e}\right)$ e considerar a eficiência por meio do trabalho realizado para penetração do amostrador do solo. Para tanto, temos a seguinte equação de $\rho_{e}$ :

$$
\rho_{e}=\frac{P . L_{h}}{A . E}
$$

Na Equação 32, $P$ é a carga determinada no ensaio à compressão resultante da aplicação de um único golpe para a obtenção do índice $N_{S P T}, L_{h}$ representa o comprimento total de haste, $A$ corresponde à área da seção transversal da haste e $E$ equivale ao módulo de elasticidade do material da haste.

A Tabela 5 a seguir apresenta todos os valores utilizados, e também o resultado do encurtamento elástico encontrado para cada profundidade:

Tabela 5 - Encurtamento elástico da haste nos ensaios relativos a um golpe de martelo.

\begin{tabular}{cccccc}
\hline $\begin{array}{c}\text { Profundidade } \\
(\mathrm{m})\end{array}$ & $P$ & $\begin{array}{c}L_{h} \\
(\mathrm{kN})\end{array}$ & $\begin{array}{c}A \\
(\mathrm{~m})\end{array}$ & $\begin{array}{c}E \\
(\mathrm{kPa})\end{array}$ & $\begin{array}{c}\rho_{e} \\
(\mathrm{~mm})\end{array}$ \\
\hline 2,0 & 4,9 & 3,0 & 0,0003644 & 205000000 & 0,1 \\
5,0 & 6,4 & 6,0 & 0,0003644 & 205000000 & 0,5 \\
\hline
\end{tabular}


Aoki e Cintra (2000) propõem a determinação da eficiência do ensaio SPT por meio do trabalho $W_{p}$ realizado para a penetração do amostrador no solo:

$$
\eta_{s}=W_{p} / E P_{\text {sistema }} \times 100
$$

Porém, neste trabalho foi feita a correção da energia potencial no sistema proposta por Odebrecht et al. (2005), considerando-se na altura de queda do martelo a parcela de penetração do amostrador referente a um golpe do martelo para determinação de $N_{S P T}$.

Odebrecht et al. (2005) assume que a transferência de energia não necessariamente aumenta com o acréscimo do comprimento das hastes. A influência do comprimento da haste pode ser embasada nos seguintes fatores: quanto maior o comprimento utilizado, maior será a perda de energia observada durante propagação da onda ao longo destes segmentos; no entanto para baixa resistência de solos os valores do ganho em energia a partir do peso da haste às vezes pode ser maior do que as perdas de energia resultante reais de propagação da onda. Usando-se comprimentos curtos, estes dois efeitos são pequenos e consequentemente se anulam. Como resultado, os autores não usam o comprimento da haste para cálculo de energia, mas enfatizam a importância de contabilizar a penetração permanente do amostrador para interpretação desta energia $\left(E P_{\text {sistema* }}\right)$ em ensaios SPT.

$$
E P_{\text {sistema* }}=\eta(H+\Delta \rho) \times M_{h} \times g
$$

A Tabela 6 mostra os valores empregados assim como os resultados encontrados de $E P_{\text {sistema }}$ para as profundidades de 2,0 e 5,0 m.

Tabela 6 - Energia do sistema corrigida.

\begin{tabular}{ccccccc}
\hline $\begin{array}{c}\text { Profundidade } \\
(\mathrm{m})\end{array}$ & $\begin{array}{c}N_{S P T} \\
(\mathrm{golpes} / \mathrm{cm})\end{array}$ & $\begin{array}{c}H \\
(\mathrm{~cm})\end{array}$ & $\begin{array}{c}\Delta \rho \\
(\mathrm{cm})\end{array}$ & $\begin{array}{c}M_{h} \\
(\mathrm{~kg})\end{array}$ & $\begin{array}{c}g \\
\left(\mathrm{~m} / \mathrm{s}^{2}\right)\end{array}$ & $\begin{array}{c}E P_{\text {Sistema* }} \\
(\mathrm{J})\end{array}$ \\
\hline 2,0 & $6 / 30$ & 75,0 & 5,0 & 65,0 & 9,8 & 510,1 \\
5,0 & $8 / 31$ & 75,0 & 3,8 & 65,0 & 9,8 & 502,4 \\
\hline
\end{tabular}


Descontando-se o valor do encurtamento elástico $\rho_{e}$ da composição de hastes, o trabalho $W_{p}$ foi obtido considerando a área sob a curva do gráfico obtido pela prova de carga estática correspondente ao deslocamento resultante de um golpe. Corrigindo-se a energia potencial do sistema, temos para a eficiência:

$$
\eta_{s}=W_{p} / E P_{\text {sistema* }} \times 100
$$

A Tabela 7 apresenta os resultados finais de trabalho e energia potencial do sistema, empregados para a determinação da eficiência, assim como seu respectivo valor:

Tabela 7 - Eficiência do equipamento de sondagem empregado.

\begin{tabular}{cccc}
\hline $\begin{array}{c}\text { Profundidade } \\
(\mathrm{m})\end{array}$ & $W_{p}$ & $\begin{array}{c}E P_{\text {sistema* }} \\
(\mathrm{J})\end{array}$ & $\eta_{s}$ \\
\hline 2,0 & $(\mathrm{~J})$ & 510,1 & $(\%)$ \\
5,0 & 225,2 & 502,4 & 44,1 \\
\hline
\end{tabular}

Nota-se que a eficiência do martelo automatizado utilizado na atual pesquisa foi praticamente a mesma nas duas profundidades testadas, fato que faz validar este procedimento de obter eficiência por prova de carga. $\mathrm{O}$ valor obtido ficou abaixo do intervalo típico encontrado na prática brasileira entre $50 \%$ e $75 \%$.

Os valores de eficiência encontrados no presente estudo assemelham-se aos valores determinados também para o martelo automático usado em Neves (2004), que variaram de $40 \%$ a 47\%. Este autor realizou provas de carga estática para determinação de eficiência no mesmo tipo de solo desta pesquisa, areia siltosa. Além disso, Kovacs et al. (1983) também apresentaram diversos resultados onde os valores da eficiência de sondagens a percussão com martelo vazado apontaram uma média de $45 \%$. 


\subsection{Resultados dos ensaios de caracterização granulométrica dos solos nas profundidades ensaiadas $(2,5$ e $10 \mathrm{~m})$}

No Furo 4, foram retiradas amostras para a caracterização granulométrica do solo em laboratório nas profundidades de 2, 5 e $10 \mathrm{~m}$,

Esta caracterização foi necessária visto que um dos objetivos do trabalho foi comparar a caracterização obtida pela razão de atrito no ensaio SPT com o tipo de solo caracterizado em laboratório.

Nas Figuras 29, 30 e 31 são apresentados os resultados da analise granulométrica feita pela empresa ARC Engenharia e Tecnologia, para as três profundidades em que foram realizados ensaios de arrancamento do amostrador nesta pesquisa $(2,5$ e $10 \mathrm{~m})$.

Os resultados das curvas granulométricas são resumidos na Tabela 8 abaixo:

Tabela 8 - Resultados dos ensaios de granulometria.

\begin{tabular}{ccccccccc}
\hline $\begin{array}{c}\text { Profundida } \\
\text { de } \\
(\mathrm{m})\end{array}$ & Argila & Silte & $\begin{array}{c}\text { Areia } \\
\text { fina }\end{array}$ & $\begin{array}{c}\text { Areia } \\
\text { média }\end{array}$ & $\begin{array}{c}\text { Areia } \\
\text { grossa }\end{array}$ & $\begin{array}{c}\text { Pedregul } \\
\text { ho }\end{array}$ & $\begin{array}{c}\text { Classificação do } \\
\text { material }\end{array}$ & $\begin{array}{c}\mathrm{D}_{50} \\
(\mathrm{~mm})\end{array}$ \\
\hline 2,0 & 4,9 & 13,4 & 19,8 & 12,8 & 7,3 & 41,9 & $\begin{array}{c}\text { Pedregulho } \\
\text { arenoso }\end{array}$ & 0,450 \\
5,0 & 23,2 & 27,4 & 39,4 & 9,2 & 0,2 & 0,5 & $\begin{array}{c}\text { Areia } \\
\text { Silto-argilosa }\end{array}$ & 0,058 \\
10,0 & 10,6 & 38,1 & 46,2 & 5,0 & 0,0 & 0,0 & Areia Siltosa & 0,063 \\
\hline
\end{tabular}




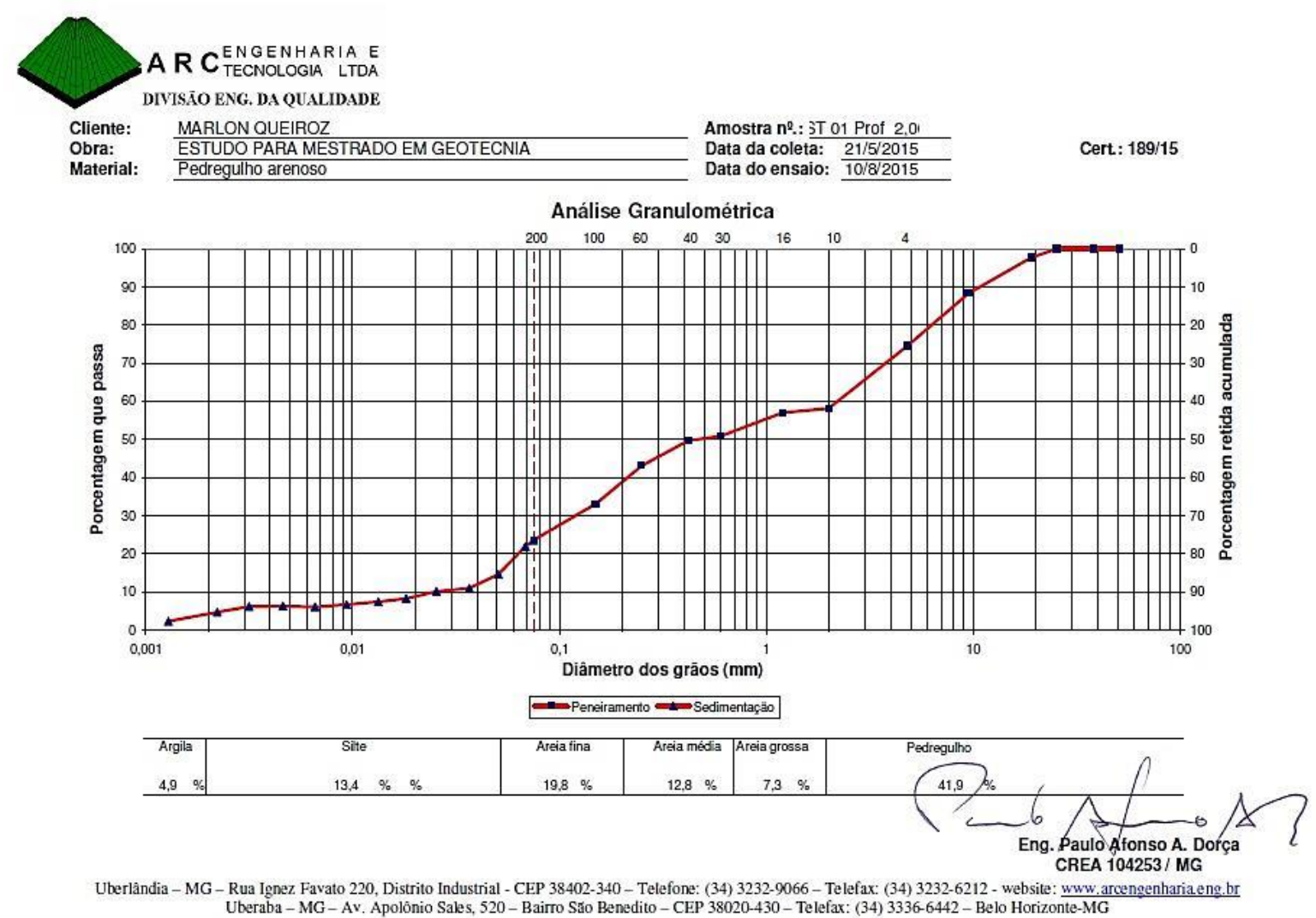

Figura 29 - Curva Granulométrica para amostra obtida a 2,0 m de profundidade.

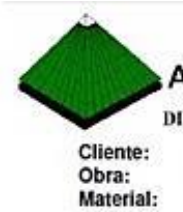

A R C ENGENHARIA E

DNISIOOENG. DAQU.LIDADE

Cliente: $\quad$ MARLON OUEIROZ

Materia

ESTUDO PARA MESTRADO EM GEOTECNIA

Amostra ne: ST 01 Prof 5,06

Data da coleta: $\frac{21 / 5 / 2015}{015}$

Cert: $192 / 15$

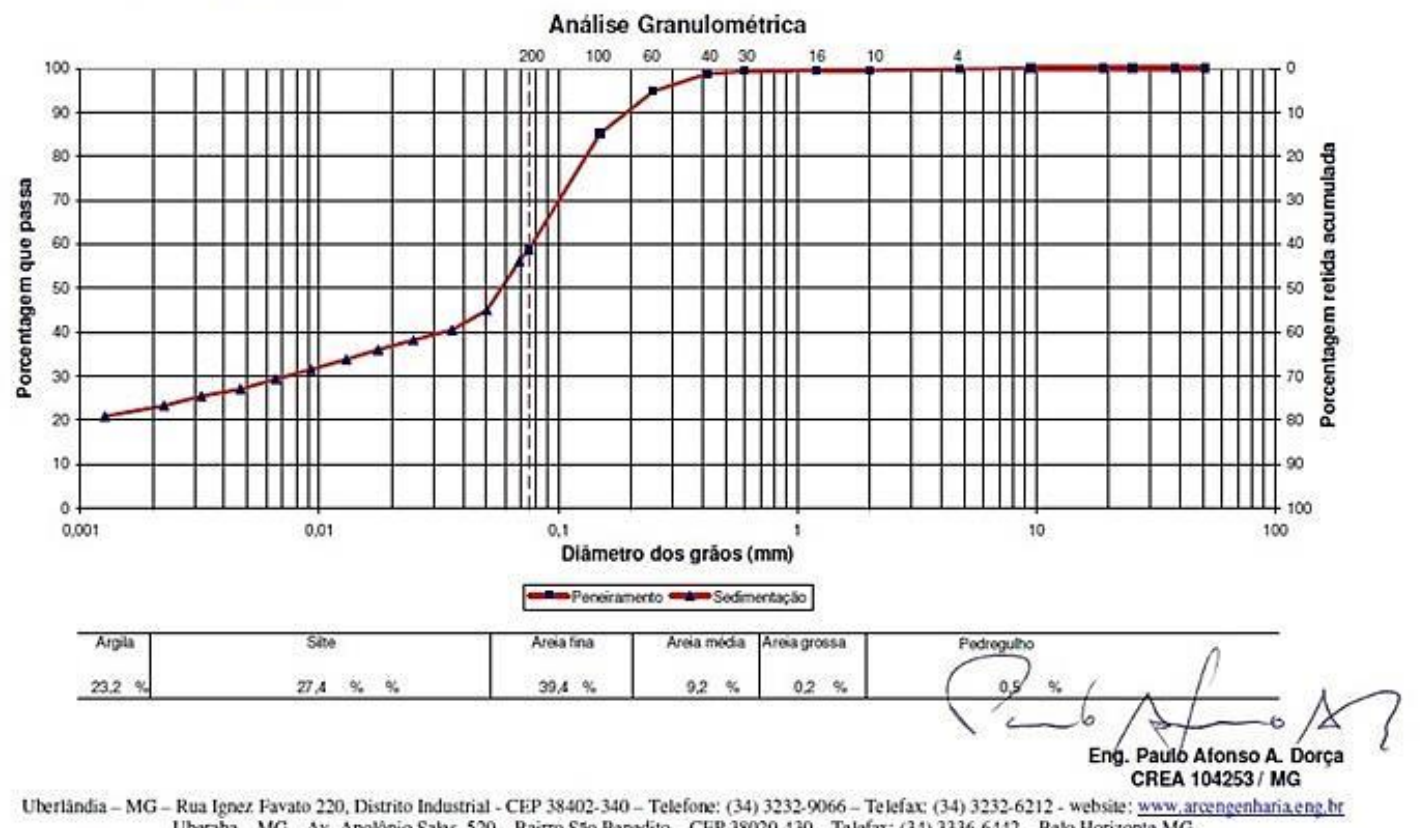

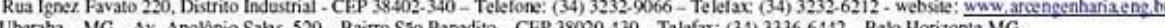

Figura 30 - Curva Granulométrica para amostra obtida a 5,0 m de profundidade. 
A R C ENGENHALIA LIAE

DIVISĀO ENG. DA QUALIDADE

Cliente: MARLONOUEROZ

Obra:

ESTUDO PARA MESTRADO EM GEOTECNIA

areia siltosa

Amostra $\mathbf{n}^{2} .:$ iT 01 Prof 10,0

Data da coleta: $21 / 5 / 2015$

Data do ensaio: $\frac{10 / 8 / 2015}{2}$

Cert: $191 / 15$

Análise Granulométrica

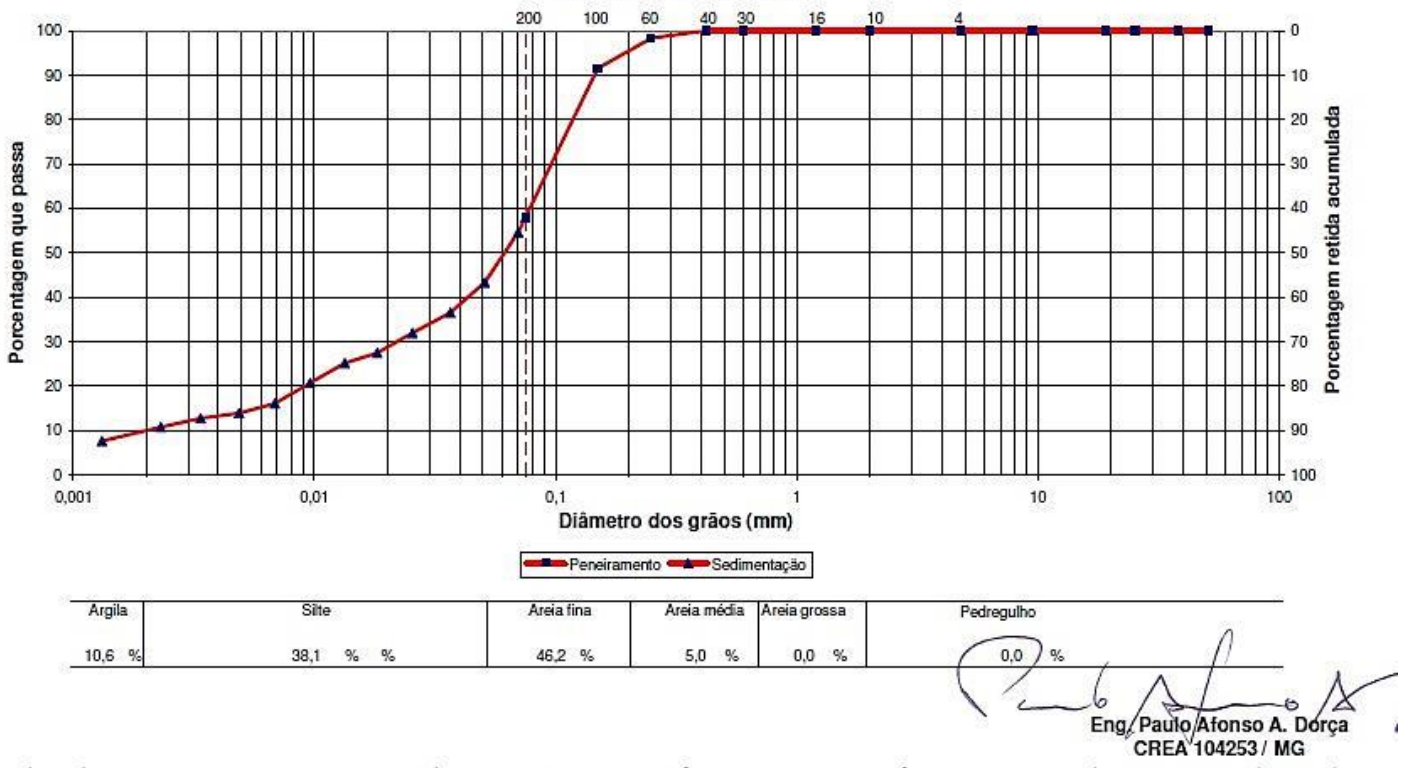

Uberlândia - MG - Rua Ignez Favato 220, Distrito Industrial - CEP 38402-340 - Telefone: (34) 3232-9066 - Telefax: (34) 3232-6212 - website: www. arcengenhariaeng.br Uberaba - MG - Av. Apolônio Sales, 520 - Bairro Sđ̌o Benedito - CEP 38020-430 - Telefax: (34) 3336-6442 - Belo Horizonte-MG

Figura 31 - Curva Granulométrica para amostra obtida a 10,0 m de profundidade.

A Figura 32 apresenta uma comparação entre as três curvas obtidas nos ensaios.

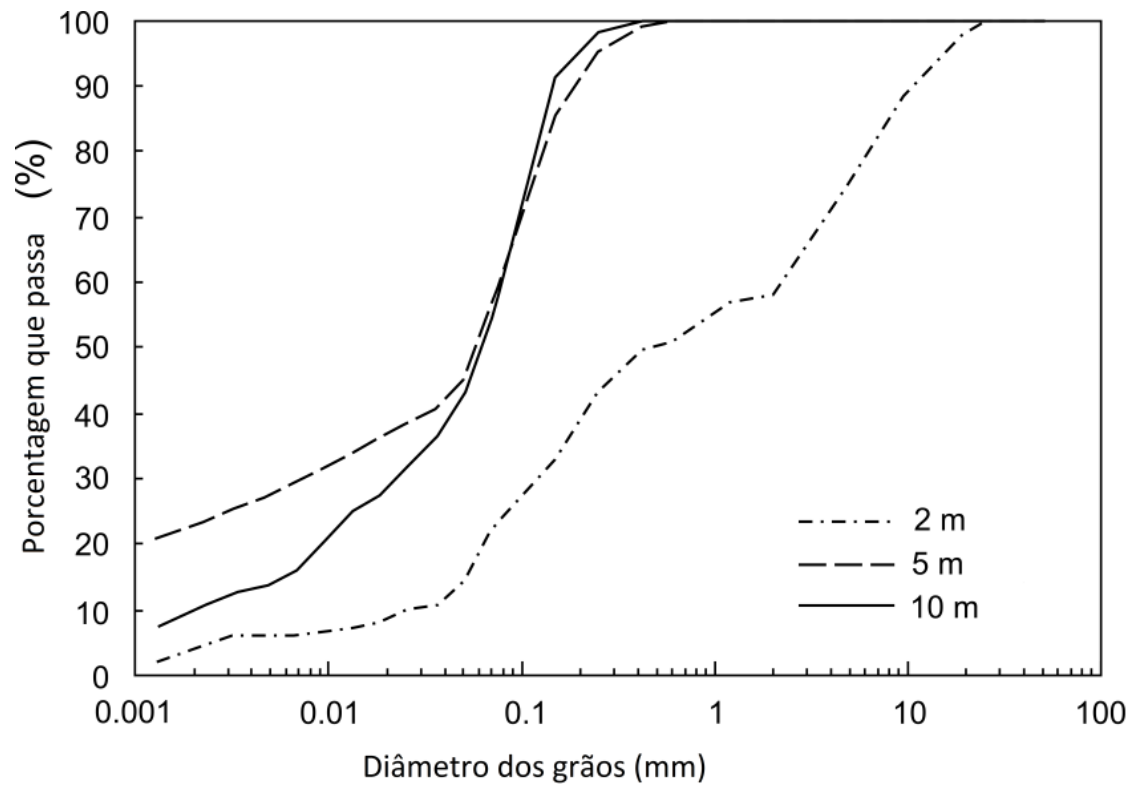

Figura 32 - Curvas Granulométricas obtidas das amostras a 2, 5 e 10m de profundidade. 


\section{ANÁLISE DOS RESULTADOS}

Para todas as profundidades os valores de $R_{u}$ utilizados foram aqueles obtidos através da fórmula proposta por Aoki et al. (2007), conforme Equação 36. Os dados utilizados foram os respectivos resultados de $N_{S P T}$, os valores de $E P_{\text {sistema }}$ determinados para cada profundidade conforme apresentado no capítulo anterior e uma eficiência de $44 \%$.

$$
R_{u}=\left(44 \times E P_{\text {sistema }} \times N_{S P T}\right) / 0,3 \mathrm{~m}
$$

Como descrito na Figura 12, uma vez que $R_{b}$ é calculado $\left(\mathrm{R}_{\mathrm{b}}=\mathrm{R}_{\mathrm{u}}+\mathrm{W}-\mathrm{R}_{\mathrm{se}}\right)$, pode-se então determinar a resistência de ponta $q_{s p t}$ do amostrador padrão no ensaio SPT dividindo $R_{b}$ pela área total na ponta do amostrador:

$$
q_{s p t}=\frac{R b}{(\pi / 4) \times D b^{2}}
$$

A Tabela 9 mostra os valores de encontrados de $R_{u}, q_{s p t,} f_{s-s p t}$ e razão de atrito nas profundidades ensaiadas:

Tabela 9 - Resultados de $R_{\mathrm{u}}$ e $q_{s p t}, f_{s-s p t}$, e razão de atrito.

\begin{tabular}{cccccccccc}
\hline $\begin{array}{c}\text { Prof. } \\
(\mathrm{m})\end{array}$ & Furo & $\begin{array}{c}\mathrm{Li} \\
(\mathrm{m})\end{array}$ & $\begin{array}{c}N s p t \\
(\mathrm{golpes} \\
/ 0.3 \mathrm{~m})\end{array}$ & $\begin{array}{c}R_{\text {se }} \\
(\mathrm{kN})\end{array}$ & $\begin{array}{c}f_{s-s p t} \\
(\mathrm{kPa})\end{array}$ & $\begin{array}{c}R_{u} \\
(\mathrm{kN})\end{array}$ & $\begin{array}{c}W \\
(\mathrm{kN})\end{array}$ & $\begin{array}{c}q_{s p t} \\
(\mathrm{MPa})\end{array}$ & $\begin{array}{c}\text { Razão de } \\
\text { atrito } \\
f_{s-s p t} / q_{s p t} \\
(\%)\end{array}$ \\
\hline \multirow{2}{*}{2.0} & 1 & 0.25 & 6 & 0.72 & 10.0 & 4.49 & 0.17 & 3.5 & 0.29 \\
& 2 & 0.36 & 10 & 0.95 & 13.2 & 7.30 & 0.17 & 5.7 & 0.23 \\
& 3 & 0.38 & 17 & 0.61 & 8.5 & 12.21 & 0.17 & 10.3 & 0.08 \\
\hline & 1 & 0.25 & 7 & 2.58 & 35.9 & 5.19 & 0.27 & 2.5 & 1.42 \\
& 2 & 0.21 & 7 & 2.42 & 33.7 & 5.19 & 0.27 & 2.7 & 1.26 \\
& 3 & 0.21 & 7 & 2.81 & 39.1 & 5.19 & 0.27 & 2.3 & 1.68 \\
\hline & 1 & 0.21 & 14 & 2.18 & 30.4 & 10.10 & 0.44 & 7.3 & 0.42 \\
& 2 & 0.21 & 15 & 2.56 & 35.7 & 10.80 & 0.44 & 7.6 & 0.47 \\
& 3 & 0.21 & 22 & 2.60 & 36.3 & 15.71 & 0.44 & 11.9 & 0.31 \\
\hline
\end{tabular}




\subsection{Comparação da resistência de ponta do ensaio SPT, $q_{s p t}$, com valores de $N_{s p t}$}

A Figura 33 compara os valores de $q_{s p t}$ obtidos com os respectivos valores de $N_{S P T}$, para os solos encontrados a 2,0,5,0 e 10,0 m de profundidade.

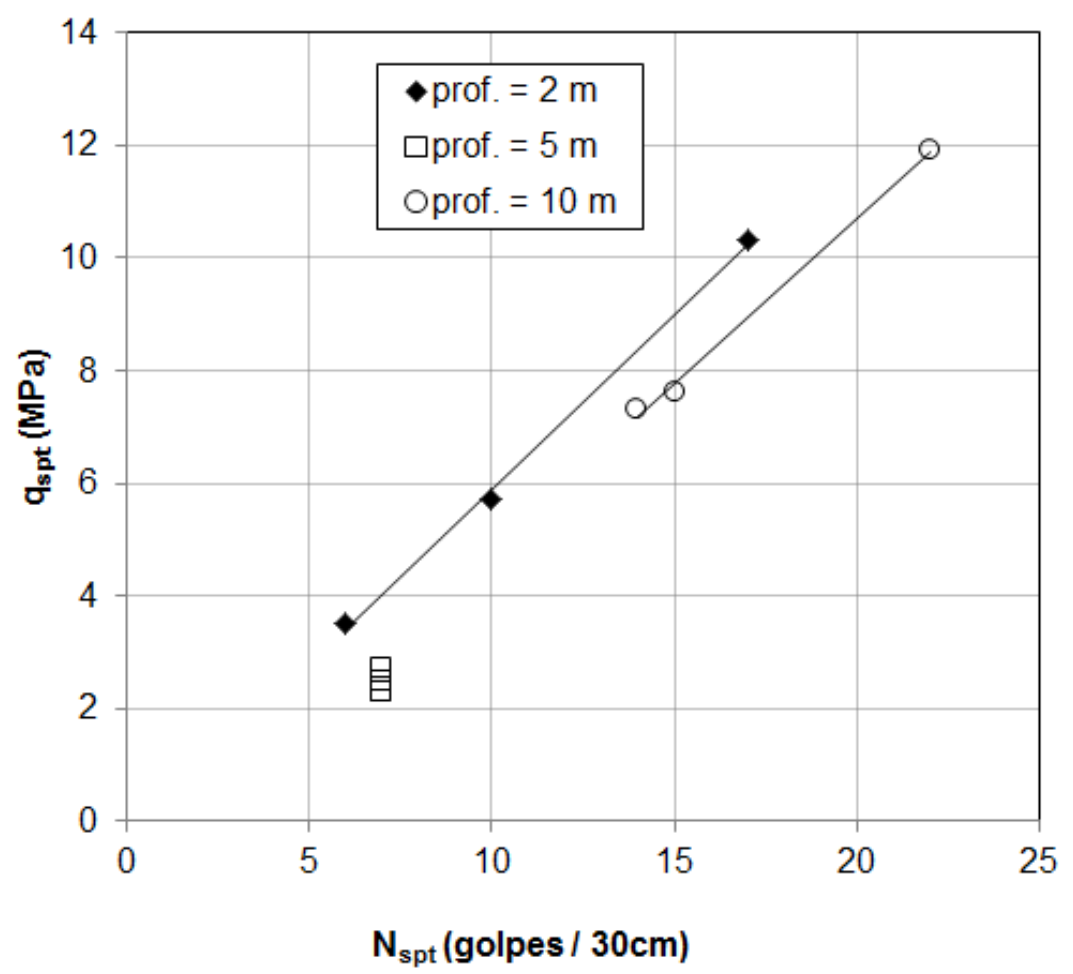

Figura 33 - Resultados de $q_{s p t}$ x $N_{s p t}$ para as profundidades de $2,0 \mathrm{~m}, 5,0 \mathrm{~m}$ e $10 \mathrm{~m}$.

A relação entre $q_{s p t}$ e os respectivos valores de $N_{s p t}$ mostrada na Figura 33 para cada tipo de solo mostra-se linear. Apenas na profundidade de $5 \mathrm{~m}$, em que o $N_{s p t}$ medido foi igual nos 3 furos de ensaio, os valores de $q_{s p t}$ foram praticamente os mesmos. Esta figura retrata para as três camadas de solo avaliadas que quanto maior o valor de $N_{s p t}$, maior será o valor de $q_{S P T}$.

Além disso, a Figura 33 mostra que a razão entre $q_{s p t}$ e $N_{s p t}$ é única para o mesmo tipo de solo desde que o valor da eficiência no ensaio seja o mesmo. Portanto, os resultados acimas mostram que a relação entre a resistência de ponta do ensaio SPT e o valor de $N_{S P T}$ varia com o tipo de solo, do mesmo modo que a relação entre a resistência de ponta do ensaio de cone $\left(q_{c}\right)$ e o $N_{\text {spt., }}$, como mostra a Tabela 10. 
Tabela 10 - Resultados da razão $q_{s p t} / N_{s p t .}$

\begin{tabular}{cccccc}
\hline $\begin{array}{c}\text { Profundidade } \\
(\mathrm{m})\end{array}$ & Solo & Furo & $\begin{array}{c}N_{s p t} \\
\text { (golpes/ } \\
0.3 \mathrm{~m})\end{array}$ & $\begin{array}{c}q_{s p t} \\
(\mathrm{MPa})\end{array}$ & $\begin{array}{c}q_{s p t} / N_{s p t} \\
\mathrm{MPa} / \\
(\text { golpes } / 0.3 \mathrm{~m})\end{array}$ \\
\hline \multirow{2}{*}{2.0} & Pedregulho & 1 & 6 & 3.5 & 0.58 \\
& arenoso & 2 & 10 & 5.7 & 0.57 \\
& 3 & 17 & 10.3 & 0.61 \\
\hline \multirow{2}{*}{5.0} & Areia silto- & 1 & 7 & 2.5 & 0.36 \\
& argilosa & 2 & 7 & 2.7 & 0.38 \\
& & 3 & 7 & 2.3 & 0.33 \\
\hline \multirow{2}{*}{10.0} & Areia & 1 & 14 & 7.3 & 0.52 \\
& siltosa & 2 & 15 & 7.6 & 0.51 \\
& & 3 & 22 & 11.9 & 0.54 \\
\hline
\end{tabular}

\subsection{Comparação das resistências de ponta do ensaio de cone $q_{c}$ e do ensaio SPT $\boldsymbol{q}_{s p t}$}

Um dos objetivos deste trabalho foi verificar a possibilidade de equivalência entre resistência de ponta do ensaio SPT $\left(q_{s p t}\right)$ e o valor de $q_{c}$ do ensaio de cone, visto que uma correlação direta entre $q_{c}$ e $q_{s p t}$ parece ser mais adequada do que as típicas correlações entre $q_{c}$ e $N_{S P T}$ usadas normalmente para a transformação de dados de ensaio SPT em dados de ensaio de cone.

Nesta pesquisa são comparadas as correlações obtidas experimentalmente entre $q_{S P T}$ e o valor de $N_{S P T}$ com a relação de resultados apresentados em outras pesquisas entre de $q_{c}$ do ensaio de cone o valor de $N_{S P T}$. Na literatura diversos autores apresentam correlações entre $q_{c}$ e $N_{S P T}$. Danziger (1982) apresenta alguns resultados na Tabela 11. No entanto, cabe ressaltar que os valores destas relações propostas na literatura são variados, já que a foram obtidas por meio de ensaios SPT realizados com diferentes eficiências. Esta relação seria única para o mesmo tipo de solo e mesma eficiência para a obtenção de $N_{S P T}$.

Comparando-se os resultados da razão $q_{c} / N_{S P T}$ (Tabela 11) com os resultados de $q_{s p t} / N_{S P T}$ (Tabela 10) nota-se que para o mesmo tipo de solo as razões são da mesma ordem de grandeza. Isto mostra que as resistências de ponta dos dois ensaios são similares apesar da geometria da ponta do amostrador do ensaio SPT e do cone serem diferentes (Figura 34). No mais, tanto a razão $q_{c} / N_{S P T}$ quanto a razão $q_{s p t} / N_{S P T}$ aumenta o tamanho do grão do solo. 
Tabela 11 - Valores de qc/ $\mathrm{N}_{\text {SPT }}$ proposto por Schmertmann (1970 apud Danziger 1982).

Tipo de solo

$$
\mathrm{q}_{\mathrm{c}} / \mathrm{N}_{\mathrm{SPT}}
$$

$\mathrm{Mpa} /\left(\mathrm{n}^{\circ}\right.$ golpes $\left./ 30 \mathrm{~cm}\right)$

Siltes, siltes arenosos e misturas

pouco coesivas de siltes e areia

Areias puras, finas e médias, e areias pouca siltosas

Areias grossas e pouco pedregulhosas

Areias pedregulhosas e pedregulhos

0,60
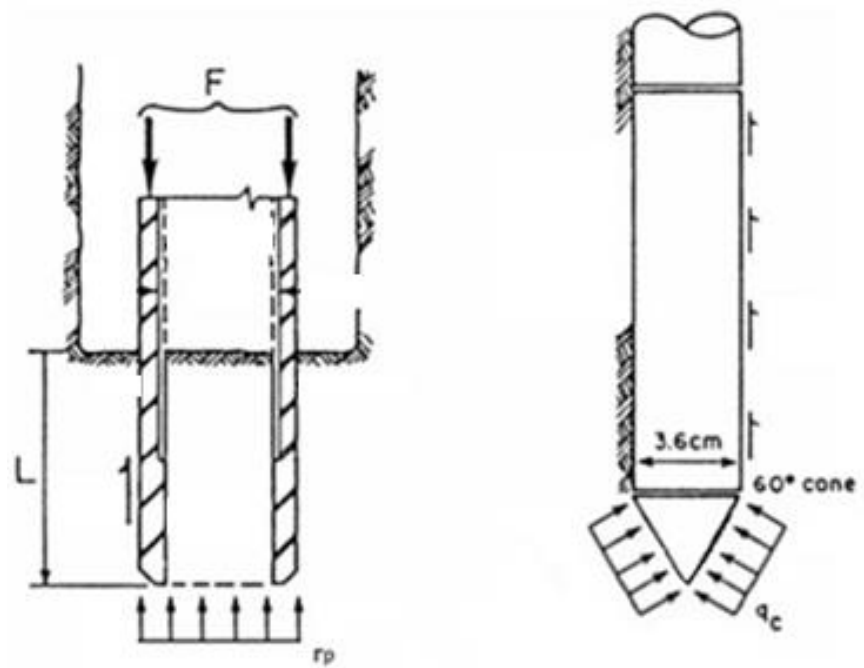

Figura 34 - Comparação entre as componentes de resistência à penetração do ensaio SPT e CPT (modificado de Schmertmann (1979)).

Nota-se que os valores encontrados de $q_{S P T} / N_{S P T}$ variam com o tamanho do grão, como para os valores sugeridos de $q_{c} / N_{S P T}$ por Schmertmann (1970). O solo a $5 \mathrm{~m}$ de profundidade que apresentou uma parcela maior de argila em relação às outras profundidades proporcionou menor valor de $q_{S P T} / N_{S P T}$.

Robertson et al. (1983) apresenta valores da relação entre $q_{c} / N_{S P T}$ obtida por vários autores (Figura 35), e mostra que esta relação aumenta com o tamanho médio do grão $\left(D_{50}\right)$. No presente trabalho também encontramos a mesma tendência, como mostra a Figura 36. 
$\mathrm{Na}$ Figura 36b apresenta-se um comparação de $q_{S P T} / N_{S P T} \operatorname{com}$ o $\mathrm{D}_{20}$, já que na literatura algumas pesquisas (Baez et al. 2000 e Jefferies and Davies 1983) citam que a relação $q_{c} / N_{S P T}$ decresce com o aumento da porcentagem de finos. Portanto, do mesmo modo a relação $q_{s p t} / N_{S P T}$ também decresce com a porcentagem de finos.
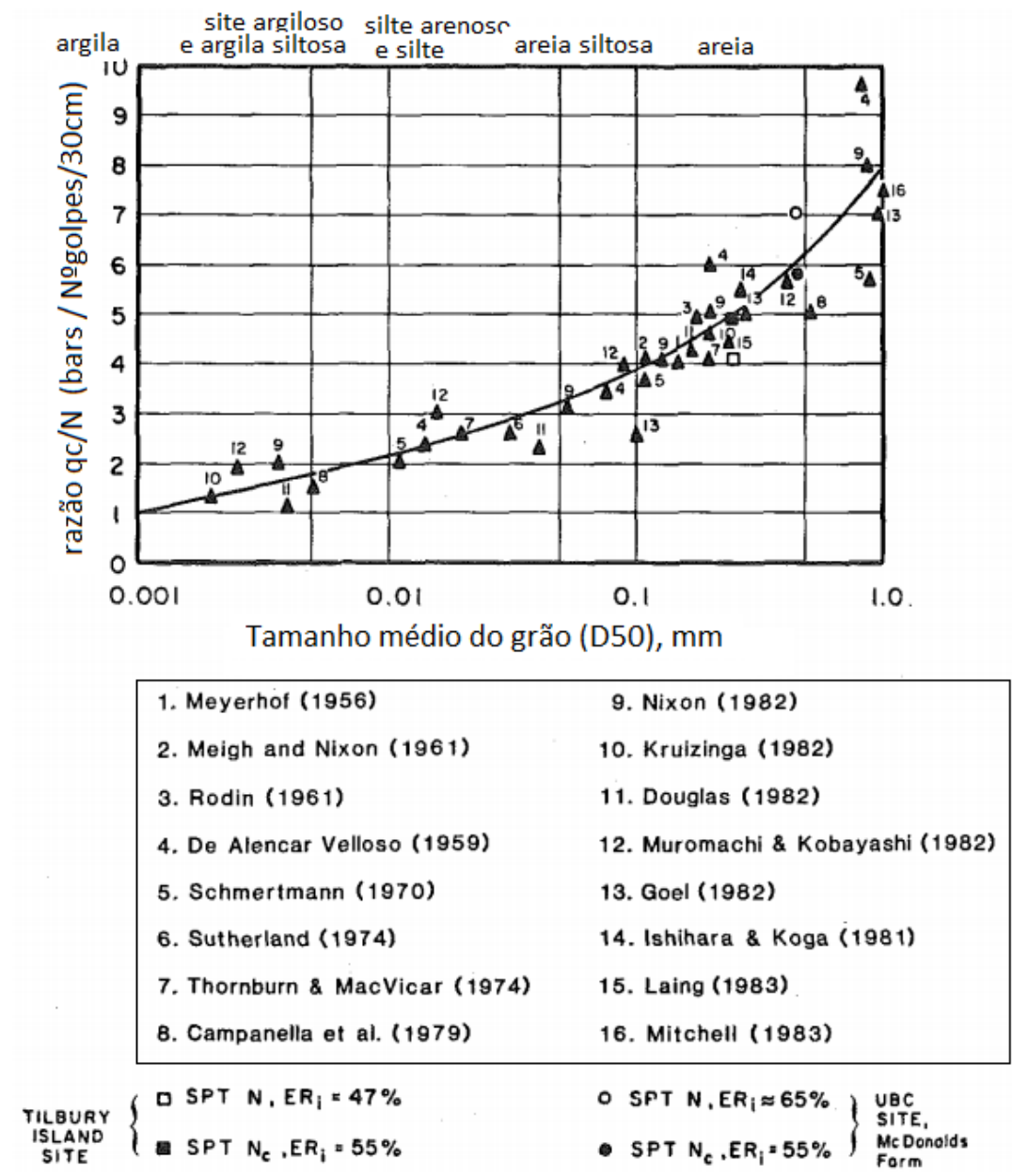

Figura 35 - Valores da razão $q_{c} / N_{S P T}$ x D50 (Robertson et. al. 1983).
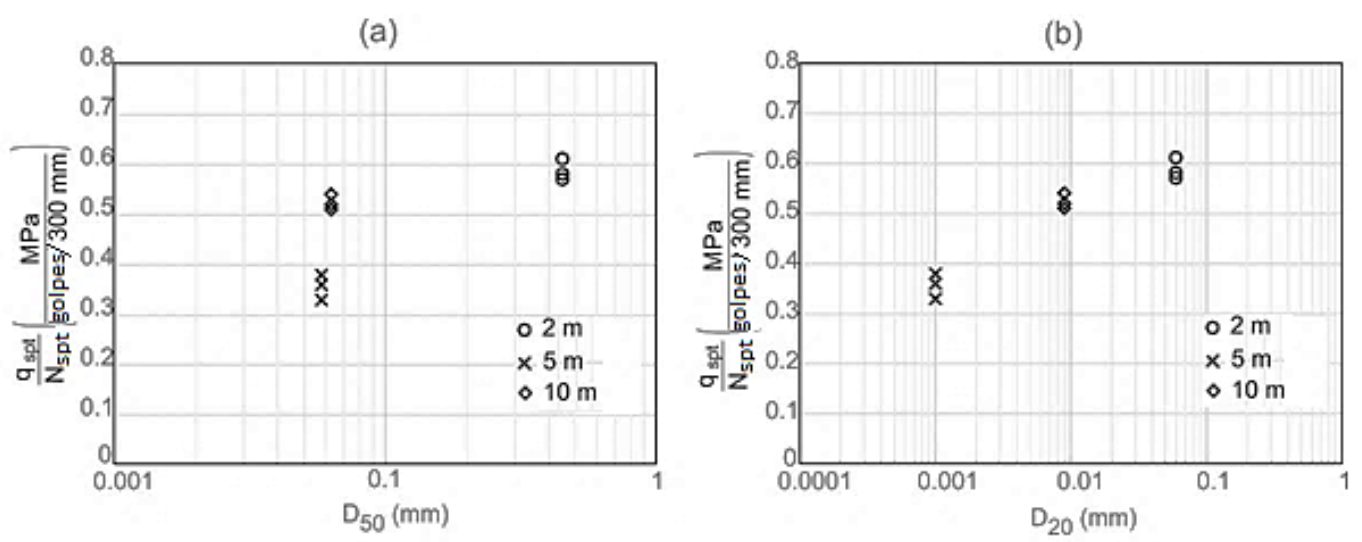

Figura 36 - Valores da razão $q_{s p t} / N_{S P T}$ x D50 e $q_{s p t} / N_{S P T}$ x D20 obtidos nesta pesquisa para os solos a 2.5 e $10 \mathrm{~m}$ de profundidade. 


\subsubsection{Razão de atrito do Ensaio $\operatorname{SPT}\left(\boldsymbol{f}_{\text {s-spt }} / \boldsymbol{q}_{\text {spt }}\right)$}

No ensaio de cone CPT (Lunne et al.,1997), a razão entre o atrito lateral externo com a resistência de ponta do solo é denominado como razão de atrito $R_{f}$, e é utilizado para a classificação do solo.

Do mesmo modo, nesta pesquisa foi estimada a razão de atrito obtida em ensaio SPT, já que foram medidos valores de $f_{s-s p t}$ (pelos ensaios de arrancamento) e estimados valores de $q_{s p t}$, como mostra a Tabela 12 .

Tabela 12 - Resultados de razão de atrito.

\begin{tabular}{ccccc}
\hline $\begin{array}{c}\text { Prof. } \\
(\mathrm{m})\end{array}$ & Furo & $f_{s-s p t}(\mathrm{kPa})$ & $\begin{array}{c}q_{s p t} \\
(\mathrm{MPa})\end{array}$ & $\begin{array}{c}\text { Razão de } \\
\text { atrito } \\
f_{s-s p t} / q_{s p t} \\
(\%)\end{array}$ \\
\hline \multirow{2}{*}{2.0} & 1 & 10.0 & 3.5 & 0.29 \\
& 2 & 13.2 & 5.7 & 0.23 \\
& 3 & 8.5 & 10.3 & 0.08 \\
\hline \multirow{3}{*}{5.0} & 1 & 35.9 & 2.5 & 1.42 \\
& 2 & 33.7 & 2.7 & 1.26 \\
\hline \multirow{2}{*}{10.0} & 3 & 39.1 & 2.3 & 1.68 \\
& 1 & 30.4 & 7.3 & 0.42 \\
& 2 & 35.7 & 7.6 & 0.47 \\
\hline
\end{tabular}

Sabendo-se que os valores de $q_{S P T}$ e $q_{c}$ correspondem a resistência de ponta dos ensaios SPT e CPT respectivamente, os valores de razão de atrito da Tabela 12 foram interpretados empregando-se o ábaco de classificação de Robertson et al. (1986), como mostra a Figura 37.

Os resultados obtidos pelo ábaco da Figura 37 e os obtidos experimentalmente pelo ensaio de granulometria, são comparados na Tabela 13 para cada profundidade: 


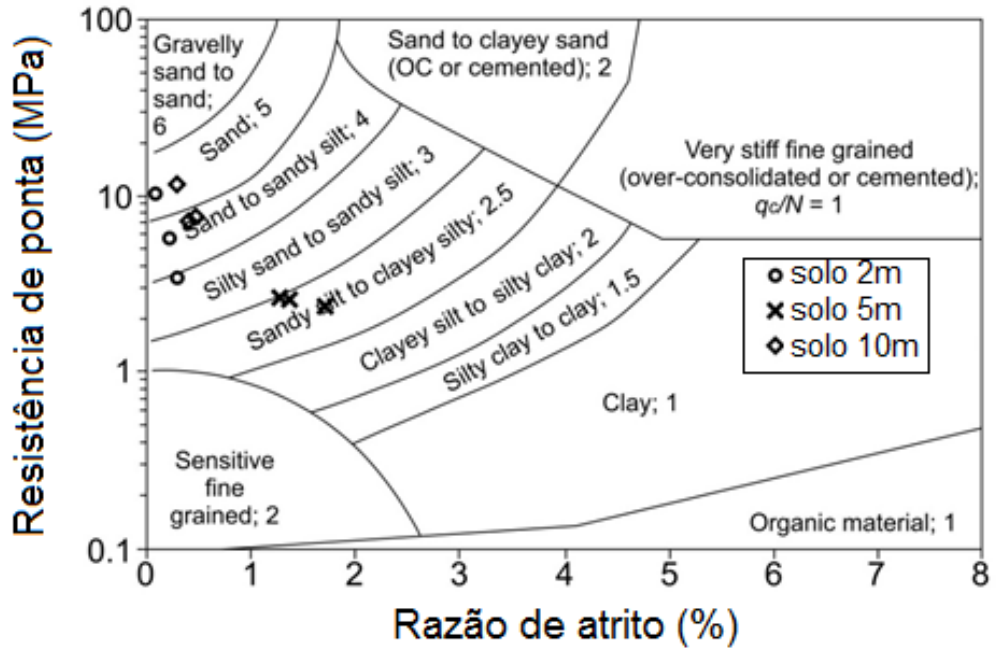

Figura 37 - Resultados de $q_{S P T}$ x $R_{f}$ plotados no ábaco de classificação de solo por Robertson et al. (1986).

Tabela 13-Classificação pelo ensaio de granulometria e através do ábaco de Robertson et al.(1986)

\begin{tabular}{ccc}
\hline $\begin{array}{c}\text { Profundidade } \\
(\mathrm{m})\end{array}$ & $\begin{array}{c}\text { Classificação pelo ensaio de } \\
\text { granulometria }\end{array}$ & $\begin{array}{c}\text { Classificação do material pelo } \\
\text { ábaco de Robertson et al } \\
(1986)\end{array}$ \\
\hline 2,0 & Pedregulho arenoso & $\begin{array}{c}\text { Areia, silte arenoso, areia } \\
\text { siltosa }\end{array}$ \\
5,0 & Areia silto-argilosa & Silte arenoso e Silte argiloso \\
10,0 & Areia siltosa & Areia e Silte arenoso \\
\hline
\end{tabular}

Nota-se que os resultados plotados no ábaco de Robertson et al. (1986) são similares àqueles obtidos pelos ensaios de granulometria. Sendo assim, pode-se concluir que, uma vez determinando a razão de atrito $R_{f}$ e resistência de ponta $q_{S P T}$ do ensaio SPT é possível avaliar o tipo de solo pelo ábaco de $q_{c}$ e $R_{f}$ do ensaio de cone sugerido por Robertson et al. (1986).

Vale ressaltar a importância desta classificação, visto que a classificação táctil visual feita para as sondagens SP-01 e SP-02 desta pesquisa não coincide com a análise granulométrica feita em laboratório. Já a classificação pela razão de atrito obtida pelo ensaio SPT está mais próxima dos ensaios de laboratório. 


\subsection{Análise da relação entre atrito interno e externo no amostrador " $a$ " proposta em Aoki (2012)}

Aoki (2012) apresenta a relação " $a$ " que é definida como a razão entre a resistência de atrito lateral interna $r_{L i}$ e a resistência de atrito lateral externa $r_{L e}$ no amostrador padrão.

\subsubsection{Valores de a}

Nesta pesquisa, os valores de $r_{L e}$ são iguais aos valores de $f_{s-s p t}$. O valor de $r_{L i}$ é igual ao valor de $\tau_{i}$ mostrado no equilíbrio de forças na Figura $12 \mathrm{~b}$, e, como mostra esta figura, pode ser calculado por:

$$
r_{L i}=\frac{q_{s p t} D_{i}}{4 L_{i}}
$$

A razão " $a$ " entre o atrito interno e atrito externo, conforme apresentado abaixo, pode ser determinada por:

$$
a=\frac{r_{L i}}{r_{L e}}
$$

Os valores de $a$ são mostrados na Tabela 14. Nota-se que estes valores foram menores para o solo com maior porcentagem de argila (a $5 \mathrm{~m}$ de profundidade).

Como $r_{L i}$ é equivalente à resistência de ponta do amostrador, e a 2 metros o solo predominante é o pedregulho, a resistência de ponta foi elevada, aumentando consideravelmente o valor de $a$. 
Tabela 14 - Valores de " $a$ ".

\begin{tabular}{cccccc}
\hline $\begin{array}{c}\text { Prof. } \\
(\mathrm{m})\end{array}$ & Furo & $\begin{array}{c}L i \\
(\mathrm{~m})\end{array}$ & $\begin{array}{c}f_{s-s p t} \\
(\mathrm{kPa})\end{array}$ & $\begin{array}{c}r_{L i} \\
(\mathrm{kPa})\end{array}$ & $a\left(\mathrm{r}_{\mathrm{Li}} / \mathrm{f}_{\mathrm{s}-\mathrm{spt}}\right)$ \\
\hline \multirow{3}{*}{2.0} & 1 & 0.25 & 10.0 & 122 & 12,2 \\
& 2 & 0.36 & 13.2 & 138 & 10,5 \\
& 3 & 0.38 & 8.5 & 236 & 27,8 \\
\hline & 1 & 0.25 & 35.9 & 87 & 2,4 \\
5.0 & 2 & 0.21 & 33.7 & 112 & 3,3 \\
& 3 & 0.21 & 39.1 & 96 & 2,4 \\
\hline \multirow{3}{*}{10.0} & 1 & 0.21 & 30.4 & 303 & 10,0 \\
& 2 & 0.21 & 35.7 & 316 & 8,8 \\
& 3 & 0.21 & 36.3 & 494 & 13,6 \\
\hline
\end{tabular}

\subsubsection{Analise da relação entre a $x N_{S P T}$}

Como mostra a Figura 38 o valor de " $a$ " parece tender a crescer com o valor de $N_{s p t}$. No entanto, pelos resultados desta figura não ficou clara uma relação entre estes dois parâmetros.

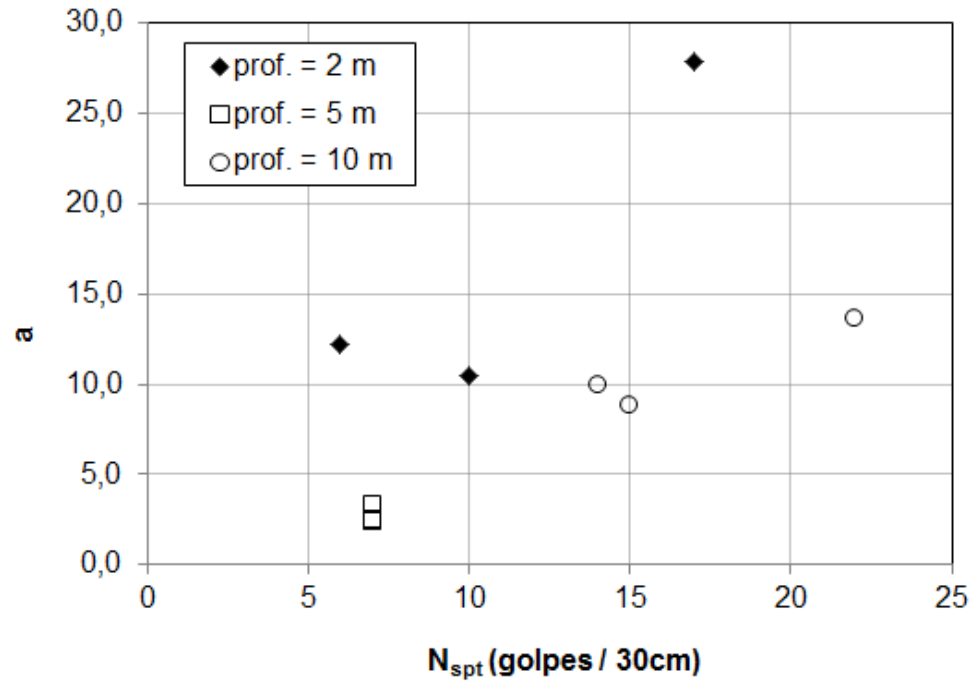

Figura 38 - Valores de “ $a$ ” $\mathrm{x}$ valores de $\mathrm{N}_{S P T}$. 


\subsubsection{Analise da relação entre a $x N_{S P T} / \sigma v$}

Sabendo que o valor de $a$ depende do atrito solo-parede do amostrador, uma comparação foi feita desconsiderando-se o efeito do confinamento do solo para índice $N_{S P T}$. Para tanto, foram estimados valores de tensão efetiva vertical nas profundidades de ensaio, apresentados na Tabela 15. A partir dos resultados encontrados, elaborou-se o seguinte gráfico de $a \times N_{S P T} / \sigma_{v}$ mostrado na Figura 39, no qual para os solos estudados é mostrada uma relação linear crescente entre a razão " $a$ " e o valor de $N_{S P T}$ dividido pela tensão efetiva vertical na profundidade do ensaio.

Tabela 15 - Valores de $N_{S P T} / \sigma_{v}$ para todas as profundidades.

\begin{tabular}{ccccc}
\hline Profundidade $(\mathrm{m})$ & Furo & $N_{S P T} / 30$ & $\sigma_{\mathrm{v}}$ & $N_{S P T} / \sigma \mathrm{v}$ \\
\hline \multirow{2}{*}{2,0} & 1 & 6 & 34,0 & 0,17 \\
& 2 & 10 & 34,0 & 0,29 \\
& 3 & 17 & 34,0 & 0,50 \\
5,0 & 1 & 7 & 85,0 & 0,08 \\
& 2 & 7 & 85,0 & 0,08 \\
& 3 & 7 & 85,0 & 0,08 \\
& 1 & 14 & 140,0 & 0,10 \\
10,0 & 2 & 15 & 140,0 & 0,11 \\
& 3 & 22 & 140,0 & 0,16 \\
\hline
\end{tabular}

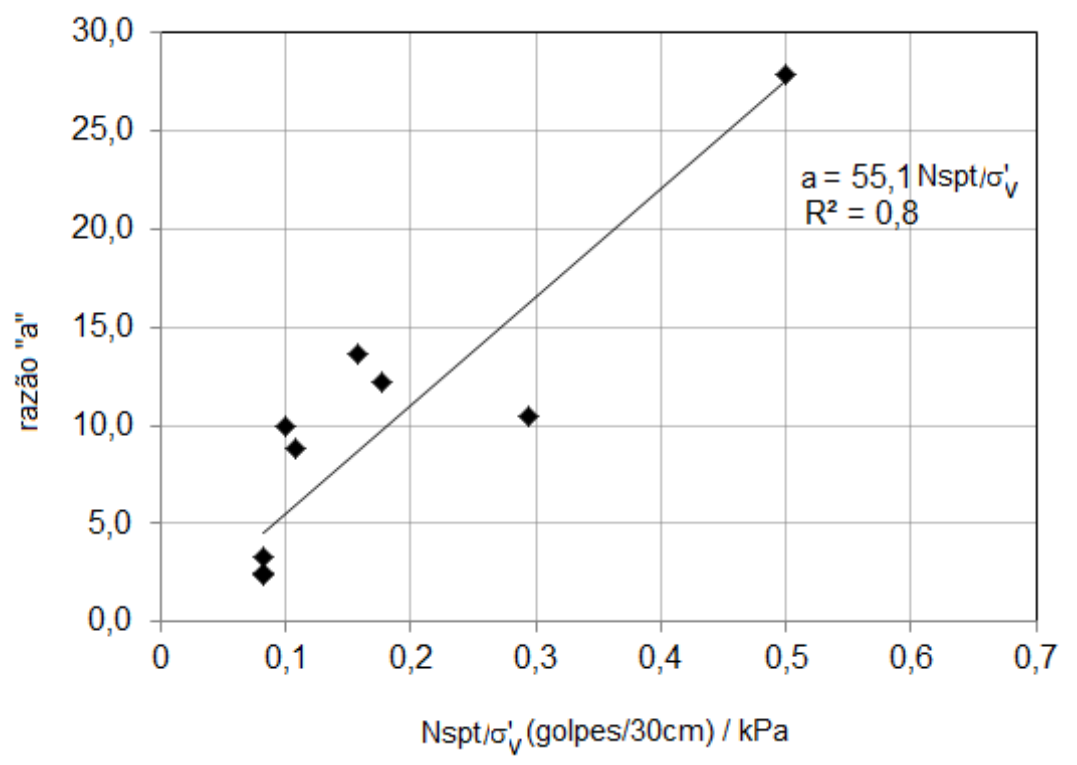

Figura $39-a \times \mathrm{N}_{\mathrm{SPT}} / \sigma_{\mathrm{v}}$ para todas as profundidades. 


\section{CONCLUSÃO}

Neste trabalho foi investigada a possibilidade de melhorar o ensaio SPT, adicionando-se alguns procedimentos simples e de fácil execução, com o objetivo de obter parâmetros adicionais ao valor de $N_{S P T}$ para o dimensionamento de fundações. Os novos parâmetros obtidos pelo ensaio SPT foram: (i) resistência de ponta do ensaio SPT, que é equivalente ao parâmetro $q_{c}$ do ensaio de cone, (ii) resistência por atrito lateral do ensaio SPT, e (iii) razão de atrito, que é uma parâmetro usado para a classificação do solo quanto ao seu comportamento.

As principais conclusões deste estudo são as seguintes:

1) O ensaio SPT complementado com ensaios de arrancamento no amostrador, e com medida da eficiência do equipamento (obtida por instrumentação apropriada ou por prova de carga a compressão) pode fornecer resultados de resistência de ponta e razão de atrito do ensaio SPT similarmente ao ensaio de cone.

2) Para um mesmo solo, sob as mesmas condições e mesma eficiência de equipamento, existe uma relação única entre resistência de ponta do ensaio SPT com o valor de $N_{s p t}$.

3) O valor da razão entre a resistência de ponta $\left(q_{s p t}\right)$ do ensaio SPT e o valor $N_{s p t}$ aumenta com o tamanho do grão, como igualmente ocorre para a relação entre $q_{c}$ do ensaio de cone e $N_{s p t}$. Estes resultados indicam que uma correlação direta entre os valores de resistência de ponta do ensaio SPT e do ensaio de cone parece ser mais adequada do que as correlações comumente utilizadas entre a resistência de ponta do ensaio do cone e o valor de $\mathrm{N}_{\mathrm{SPT}}$.

4) Usando-se a razão de atrito do ensaio SPT foi possível classificar o tipo de solo de acordo com o ábaco sugerido por Robertson et al. (1986). Esta classificação coincidiu com os ensaios granulométricos. 
5) A razão " $a$ ", que é a razão entre a resistência de atrito lateral interna $r_{L i}$ com a resistência de atrito lateral externa $r_{L e}$ no amostrador padrão, foi investigada nesta pesquisa. Para os tipos de solo investigados (pedregulho arenoso, areia silto-argilosa e areia siltosa), os resultados mostraram que existe uma relação linear crescente entre a razão " $a$ " e o valor de $N_{S P T}$ dividido pela tensão efetiva vertical na profundidade de ensaio. 


\section{REFERÊNCIAS BIBLIOGRÁFICAS}

ASSOCIAÇÃO BRASILEIRA DE NORMAS TÉCNICAS - ABNT - NBR 6484; Execução de sondagens de simples reconhecimento dos solos. Rio de Janeiro: ABNT, 2001.

AOKI, N., CINTRA. J. C. A. The application of energy conservation Hamilton's principle to the determination of energy efficiency in SPT tests. In: INTERNATIONAL CONFERENCE ON THE APPLICATION OF STRESS WAVE THEORY TO PILES, São Paulo, v. 1, P457-460, 2000.

AOKI, N.; ESQUIVEL, E. R.; NEVES, L. F. S.; CINTRA, J. C. A. The impact efficiency obtained from static load test performed on the SPT sampler. Soil and Foundation, v. 47, n. 6, p. 1045-1052, Dec. 2007.

AOKI, N. Princípio de Hamilton aplicado ao ensaio SPT. Palestra proferida no Seminário de Fundações com Solicitações Dinâmicas, Escola de Engenharia da Universidade Federal Fluminense, Niterói, 2012.

AOKI, N.; VELLOSO, D. A. An approximate method to estimate the bearing capacity of piles. In.: PANAMERICAN CONFERENCE ON SOIL MECHANICS AND FOUNDATION ENGINEERING, 5., Buenos Aires, 1975. Anais. Buenos Aires: ISSMFE, V.1, p. 367-376, 1975.

BAEZ, J.I.; MARIN, G. R.; YOUD, T. L. Comparison of SPT-CPT liquefaction evaluations and CPT interpretations, in Innovations and applications in geotechnical site characterization. Geo-Denver 2000, ASCE, GSP No. 97, 2000.

BELINCANTA, A. Energia dinâmica no SPT: resultados de uma investigação teóricoexperimental. 217 f. Dissertação (Mestrado) - Escola Politécnica, Universidade de São Paulo, São Paulo, 1985.

BELINCANTA, A. Avaliação de fatores intervenientes no índice de resistência à penetração do SPT. 141 p. Tese (Doutorado) - Escola de Engenharia de São Carlos, Universidade de São Paulo, São Carlos, 1998.

BELINCANTA, A; FERRAZ, R. L. Fundamentos e métodos de medidas de energia dinâmica no SPT. Acta Scientiarum, UEM. Maringá (PR), v. 22, n. 5. p. 1574-1482, 2000. 
BELINCANTA, A; PEIXOTO, A. S. P; MiguEL, M. G. Sondagem de simples reconhecimento com SPT e torque. Editora da Universidade Estaudal de Maringá (Eduem), Coleção Fundamentum, n. 63, 64p, 2010.

CAVALCANTE, E. H. Investigação teórico-experimental sobre SPT. 410p. v.1. Tese (Doutorado em Ciências em Engenharia Civil)- Universidade Federal do Rio de Janeiro, COPPE/UFRJ, Rio de Janeiro/RJ, 2002.

CINTRA. J. C. A; AOKI N; TSUHA C. H. C.; GIACHETI H.L. Fundações ensaios estáticos e dinâmicos. São Paulo: Oficina de textos, 2013.

DANZIGER, B. R. Estudo de correlações entre os ensaios de penetração estática e dinâmica e suas aplicações ao projeto de fundações profundas. Tese de M. Sc., COPPE/UFRJ, Rio de Janeiro, 1982.

JEFFERIES, M. G.; DAVIES, M. P. Use of CPTU to estimate equivalent SPT N60. Geotech.Testing, 1993.

KOVACS, W. D.; SALAMONE, L. A. "SPT Hammer Energy Measurement”, Journal of the Soil Mechanics and Foundations Division - ASCE - vol.108, nGT4, pp. 599-620, 1982.

KOVACS, W. D.; SALAMONE, L. A.; YOKEL, F. Y. "Comparison of energy measurements in the Standard Penetration Test using the cathead and rope method", Final Report prepared for the U.S. Nuclear Regulatory Comission. 1983.

LUKIANTCHUKI, J. A. Interpretação de resultados do ensaio SPT com base em instrumentação dinâmica. Tese (Doutorado) - Escola de Engenharia de São Carlos, Universidade de São Paulo, São Carlos, 2012.

LUKIANTCHUKI, J. A; ESQUIVEL, E. R; BERNARDES, G. P. Interpretation of force and acceleration signals during hammer impact in SPT test. In: Proc., 14th PANAMERICAN CONFERENCE ON SOIL MECHANICS AND GEOTECHNICAL ENGINEERING, Toronto/Canda, 2011.

LUNNE, T.; ROBERTSON, P. K.; POWELL, J. J. M. Cone penetration testing in geotechnical practice. Blackie Academic \& Professional, 312 p, 1997.

Manual de execução de fundações e geotecnia: práticas recomendadas / ABEF Associação Brasileira de Empresas de Engenharia de Fundações e Geotecnia - São Paulo: Pini, 2012. 
NEVES, S. L. F. Metodologia para a determinação da eficiência no ensaio SPT através de prova de carga estática sobre o amostrador padrão. Dissertação (Mestrado em Geotecnia) - Escola de Engenharia de São Carlos, Universidade de São Paulo, São Carlos/SP. 111 pp, 2004.

ODEBRECHT, E. Medidas de energia no ensaio SPT. Tese de Doutorado Universidade Federal do Rio Grande do Sul. Porto Alegre - RS. 250 p, 2003.

ODEBRECHT, E.; ROCHA, M. M.; SCHNAID. F.; BERNARDES, G. P. Energy efficiency for standard penetration test. ASCE. Vol. 131:10. 2005.

ROBERTSON, P. K. Soil classification using the cone penetration test. Canadian Geotechnical Journal. 1990.

ROBERTSON, P. K., CAMPANELLA, R. G., GILLESPIE, D., AND GREIG, J. Use of piezometer cone data. Proc., ASCE Specialty Conf. In Situ'86: Use of In Situ Tests in Geotechnical Engineering, New York, 1263-1280. 1986

ROBERTSON, P. K., CAMPANELLA, R. G., and Wightman, A. SPT-CPT correlations, Journal of Geotechnical Engineering, Vol. 109, No. 11, pp. 1449-1459, 1983.

SCHMERTMANN, J. H. "Statics of SPT", Journal of the Soil Mechanics and Foundation Division - ASCE - vol.105, nGT5, pp. 665-670, 1979.

SCHMERTMANN, J. H.; PALACIOS, A. "Energy Dynamics of SPT", Journal of the Soil Mechanics and Foundation Division - ASCE - vol.105, nGT8, pp. 909-926, 1979.

SCHNAID, F. Ensaio de campo e suas aplicações à Engenharia de fundações. São Paulo: Oficina de textos, 2000. 